\title{
Preconceptual Design Studies and Cost Data of Depleted Uranium Hexafluoride Conversion Plants
}

\author{
E. Jones \\ (Technical Coordinator)
}

July 26, 1999

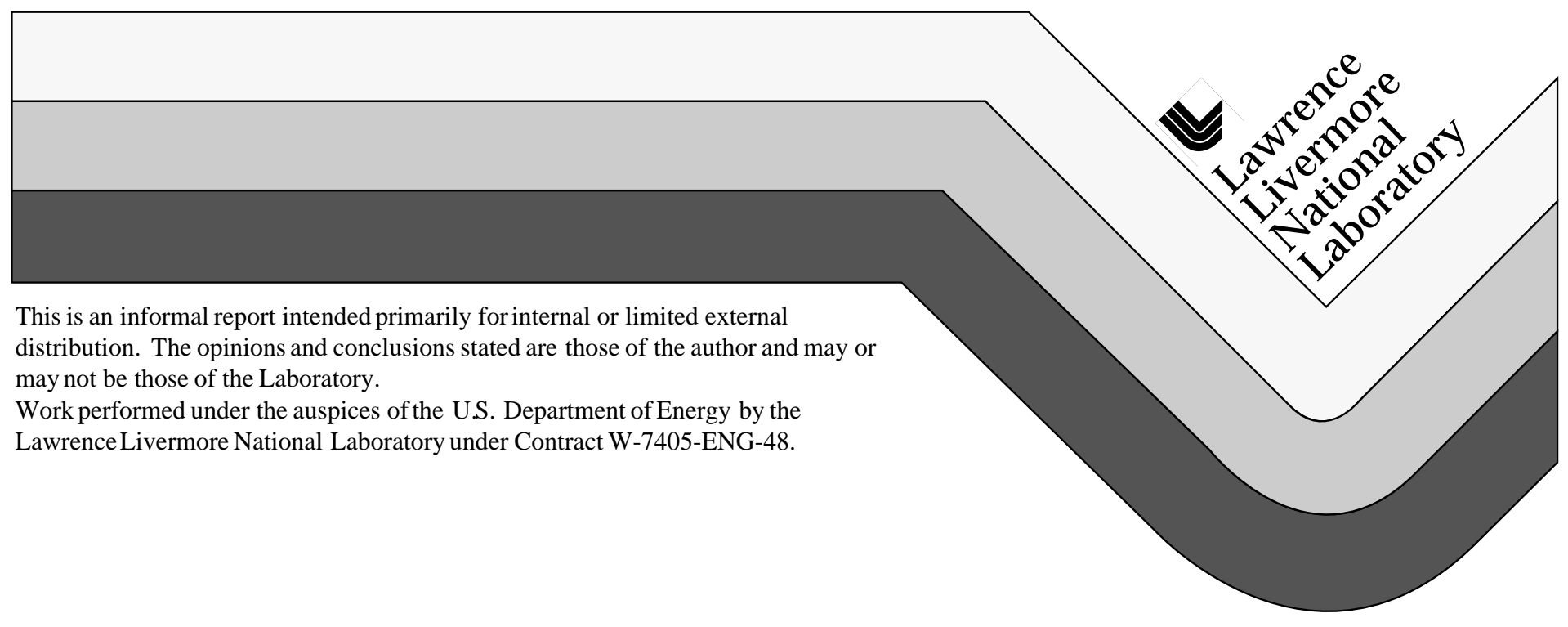




\section{DISCLAIMER}

This document was prepared as an account of work sponsored by an agency of the United States Government. Neither the United States Government nor the University of California nor any of their employees, makes any warranty, express or implied, or assumes any legal liability or responsibility for the accuracy, completeness, or usefulness of any information, apparatus, product, or process disclosed, or represents that its use would not infringe privately owned rights. Reference herein to any specific commercial product, process, or service by trade name, trademark, manufacturer, or otherwise, does not necessarily constitute or imply its endorsement, recommendation, or favoring by the United States Government or the University of California. The views and opinions of authors expressed herein do not necessarily state or reflect those of the United States Government or the University of California, and shall not be used for advertising or product endorsement purposes.

This report has been reproduced directly from the best available copy.

Available to DOE and DOE contractors from the Office of Scientific and Technical Information P.O. Box 62, Oak Ridge, TN 37831

Prices available from (423) 576-8401

Available to the public from the National Technical Information Service

U.S. Department of Commerce 5285 Port Royal Rd. Springfield, VA 22161 


\section{Preconceptual Design Studies and Cost Data of Depleted Uranium Hexafluoride Conversion Plants}

Prepared by

Lawrence Livermore National Laboratory

Bechtel National, Inc.

Prepared for

Office of Nuclear Energy, Science and Technology

U.S. Department of Energy 



\section{Preconceptual Design Studies and Cost Data of Depleted Uranium Hexafluoride Conversion Plants}

Manuscript date: July 26, 1999

Prepared by

Lawrence Livermore National Laboratory

Bechtel National, Inc.

Lawrence Livermore National Laboratory

7000 East Avenue

Livermore, CA 94550

Prepared for

Office of Nuclear Energy, Science and Technology

U.S. Department of Energy 


\section{Table of Contents}

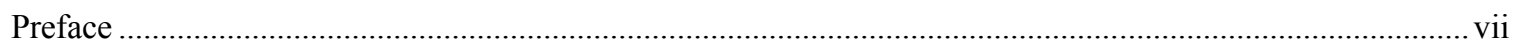

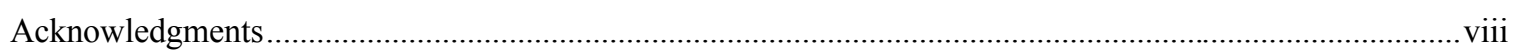

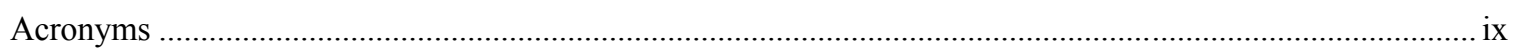

1. Background to Preconceptual Design Studies of Conversion Plant Options ......................................1-1

2. Overview of Preconceptual Design Study Project .....................................................................2-1

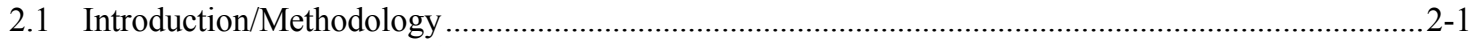

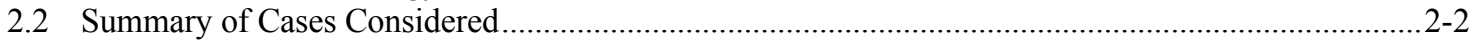

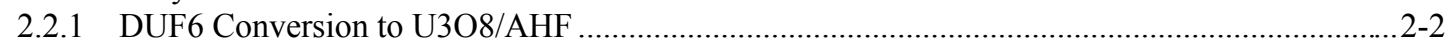

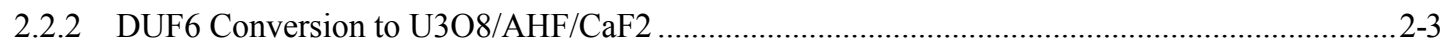

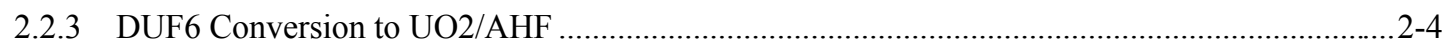

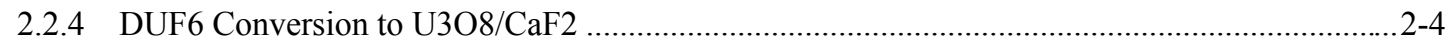

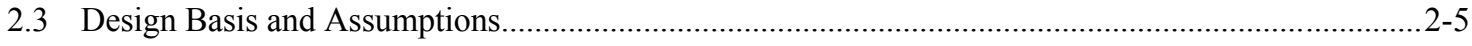



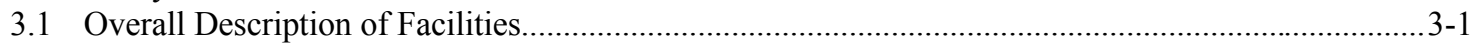

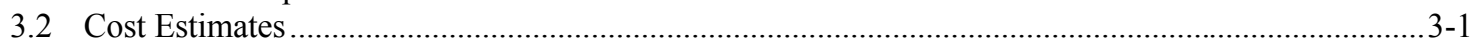

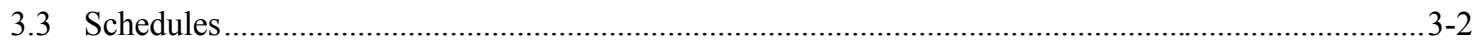

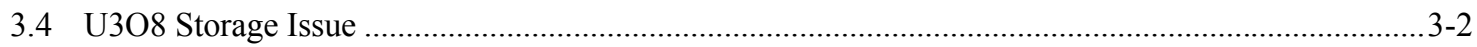

4. Base Case: DUF6 Conversion to U3O8/AHF ............................................................................

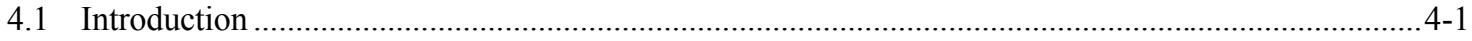

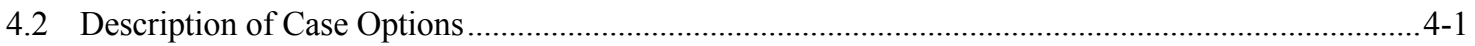

4.3 Summary of Results .........................................................................................................

4.3.1 Government Owned and Government Operated with 25 Year Operations (GOCO/25) ............4-2

4.3.2 Government Owned and Government Operated with 15 Year Operations (GOCO/15) ............4-2

4.3.3 Privately Owned and Privately Operated with 25 Year Operations (POPO/25) ....................... 4-3

4.3.4 Privately Owned and Privately Operated with 15 Year Operations (POPO/15).......................4-3

4.4 Conversion Process Description ......................................................................................... $4-4$

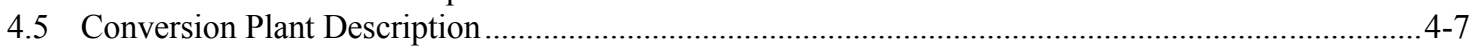



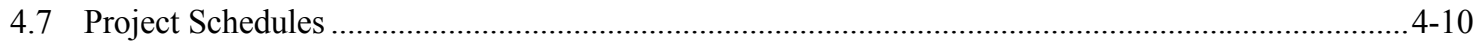



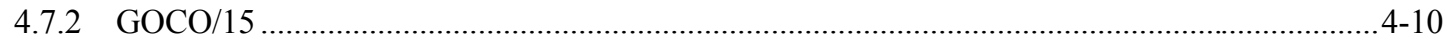

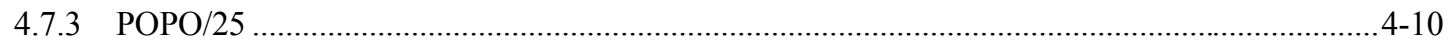

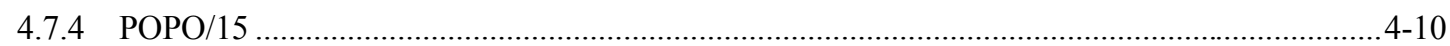

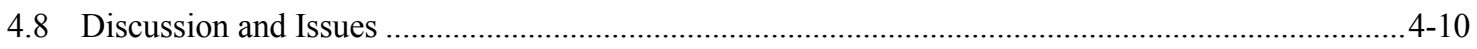









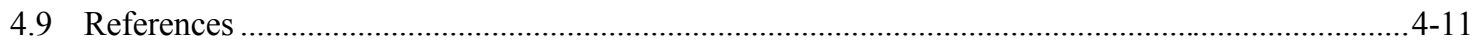

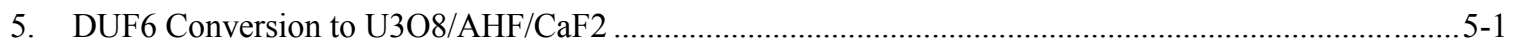

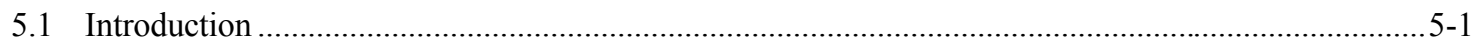

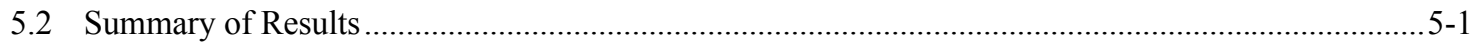

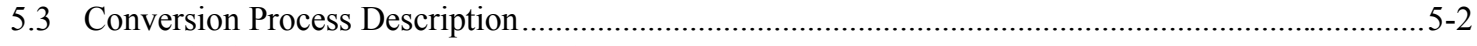

5.3.1 Anhydrous HF Production Mode ..................................................................................

5.3.2 Calcium Fluoride Production Mode ................................................................................. 5-3

5.3.3 Major Feeds and Products, and Process Equipment ................................................................ 5-4

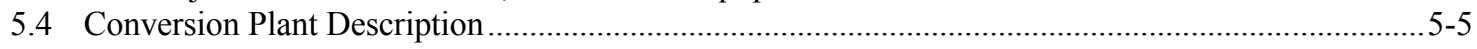

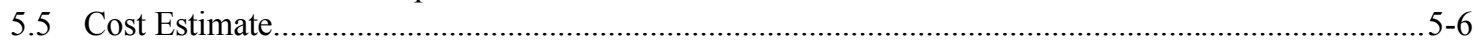

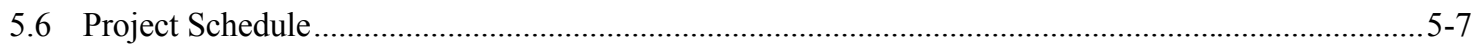






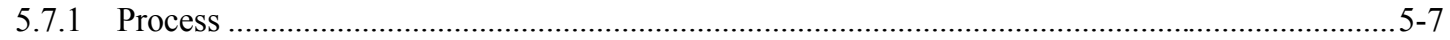

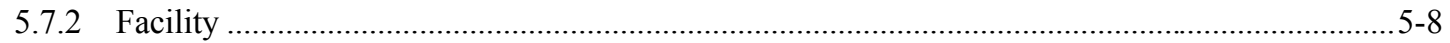

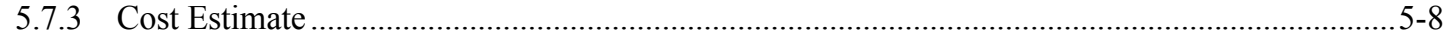



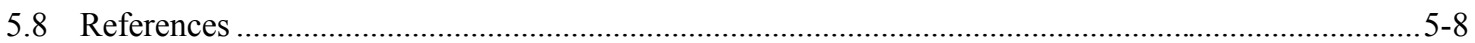

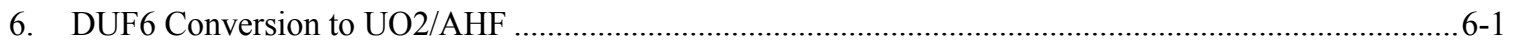

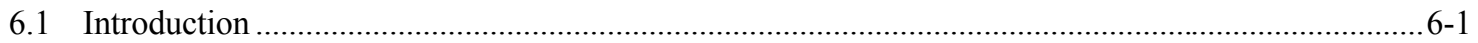

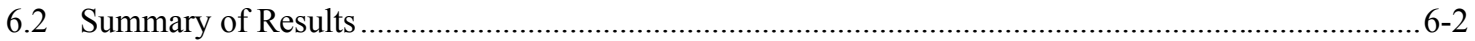

6.3 Conversion Process Description ........................................................................................... 6-2

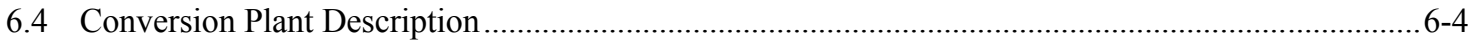

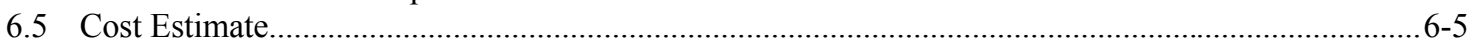

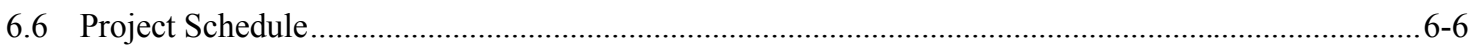

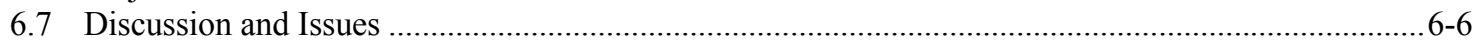



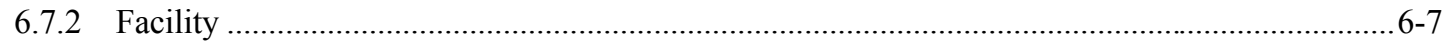





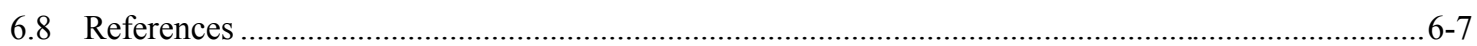

7. Preliminary Case Study: DUF6 Conversion to U3O8/CaF2 ….................................................... $7-1$

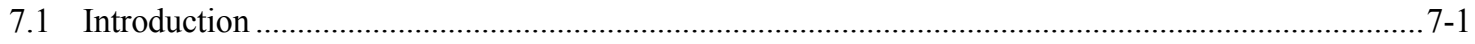



7.3 Conversion Process Description ........................................................................................... 7-2

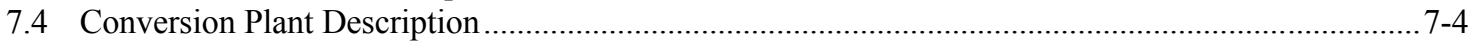

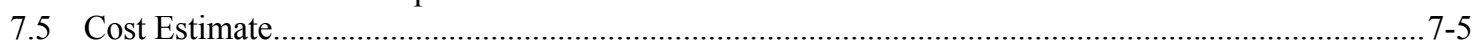

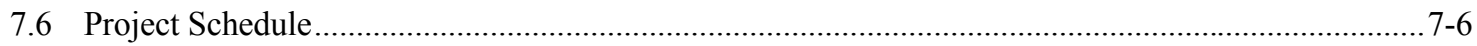





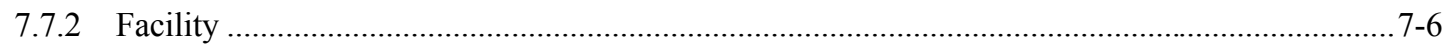

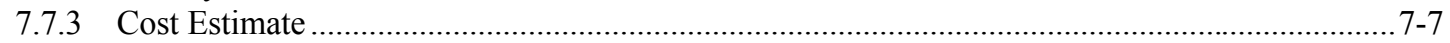

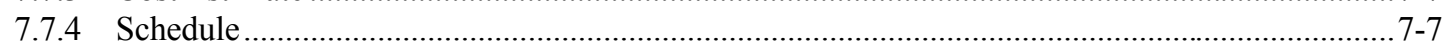

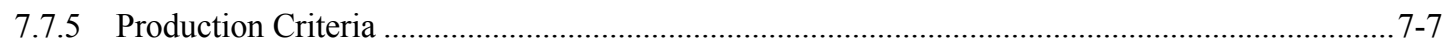



Appendix: Preconceptual Cost Estimate Bases and Details ..................................................................... A-1 


\section{List of Figures}



Figure 2.2 Process Block Flow Diagram Conversion to U3O 8 and AHF ..................................................2-8

Figure 2.3 Cost Estimate Factors for POPO vs GOCO .................................................................................. 2-9

Figure 3.1 Conversion Facility and Storage Site Plan DUF6 Conversion to U3O8 and AHF .......................3-4

Figure 3.2 Process Building General Arrangement Conversion to U3O8 and AHF .....................................3-5

Figure 3.3 Funding Profiles GOCO vs POPO - 15 Years U3O8/AHF (w/10 year loan payback time

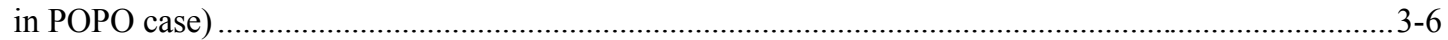

Figure 3.4 Funding profiles GOCO vs. POPO - U3O8/AHF 15 Operating Years (w/5 year loan

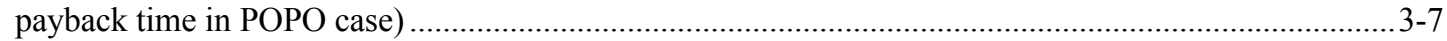

Figure 3.5 U3O8/AHF Plant, 25 Year Government Owned and Contractor Operated Preliminary

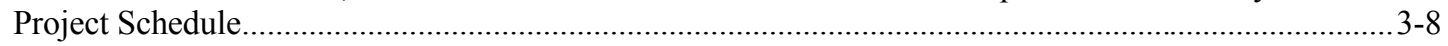

Figure 4.1a Process Block Flow Diagram Conversion to U3O8 and AHF (25 yr) ....................................4-12

Figure 4.1b Process Block Flow Diagram Conversion to U3O8 and AHF (15 yr).................................... $4-13$

Figure 4.2a Facility Site Plan Conversion to U3O8 and AHF (25 yr) ..................................................... 4-14

Figure 4.2b Facility Site Plan Conversion to U3O8 and AHF (15 yr).................................................... 4-15

Figure 4.3a Process Building General Arrangement Conversion to U3O8 and AHF (25 yr)......................4-16

Figure 4.3b Process Building General Arrangement Conversion to U3O8 and AHF (15 yr) .....................4-17

Figure 4.4a U3O8 Storage Building Plan Conversion to U3O8 and AHF (25 yr) ..................................... 4-18

Figure 4.4b U3O8 Storage Building Plan Conversion to U3O8 and AHF (15 yr).....................................4-19

Figure 4.5 U3O8/AHF Plant, 25 Year Government Owned and Contractor Operated Preliminary

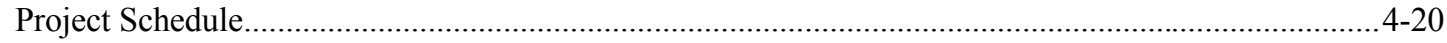

Figure 4.6 U3O8/AHF Plant, 15 Year Government Owned and Contractor Operated Preliminary

Project Schedule.................................................................................................................... 4-21

Figure 4.7 U3O8/AHF Plant, 25 Year Privately Owned and Operated Preliminary Project Schedule ........ 4-22

Figure 4.8 U3O8/AHF Plant, 15 Year Privately Owned and Operated Preliminary Project Schedule .........4-23

Figure 5.1 Process Block Flow Diagram - AHF Production Conversion to U3O8, AHF and CaF2 …........5-9

Figure 5.2 Process Block Flow Diagram - CaF2 Production Conversion to U3O8, AHF and CaF2 ….......5-10

Figure 5.3 Facility Site Plan Conversion to U3O8, AHF and CaF2 ........................................................5-11

Figure 5.4 Process Building General Arrangement Conversion to U3O8, AHF and CAF2 ........................5-12

Figure 5.5 U3O8 Storage Building Plan Conversion to U3O8, AHF and CaF2 ……..................................5-13

Figure 5.6 CaF2 Storage Building Plan Conversion to U3O8, AHF and CaF2 …….................................5-14

Figure 5.7 U3O8/AHF/CaF2 Plant, 25 Year Privately Owned and Operated Preliminary Project

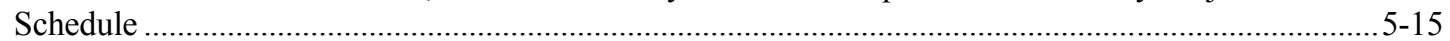

Figure 6.1 Process Block Flow Diagram Conversion to UO2 and AHF .......................................................6-8

Figure 6.2 Facility Site Plan Conversion to UO2 and AHF .......................................................................... 6-9

Figure 6.3 Process Building General Arrangement Conversion to UO2 and AHF .....................................6-10

Figure 6.4 UO2 Storage Building Plan Conversion to UO2 and AHF ........................................................ 6-11

Figure 6.5 UO2/AHF Plant, 25 Year Privately Owned and Operated Preliminary Project Schedule ...........6-12

Figure 7.1 Process Block Flow Diagram Conversion to U3O8 and CaF2 ……......................................... 7-9

Figure 7.2 Site Plan Conversion to U3O8 and CaF2 ……..................................................................

Figure 7.3 Process Building General Arrangement Conversion to U3O8 and $\mathrm{CaF} 2$.................................. 7-11

Figure 7.4 U3O8 Storage Building Plan Conversion to U3O8 and CaF2 ……......................................... 7-12

Figure 7.5 CaF2 Storage Building Plan Conversion to U3O8 and CaF2 ................................................. 7-13

Figure 7.6 U3O8/CaF2 Plant, 25 Year Government Owned and Contractor Operated Preliminary

Project Schedule..

$.7-14$ 


\section{List of Tables}

Table 3.1 Preconceptual Facility Design Summary .................................................................................. 3-9

Table 3.2 Comparison of DUF6 Integrated Plant Cost Estimates.................................................................. 3-10

Table 4.1 Typical Production Data -25 and 15 Years................................................................................4-24

Table 4.2 Comparison of DUF6 Plant Cost Estimates (in million FY2000 dollars).....................................4-25

Table 4.3 Typical Manpower Loading of a GOCO and POPO Facility ...................................................4-26

Table 4.4a U3O8/AHF Project Capital Cost Estimate Government Owned and Contractor Operated

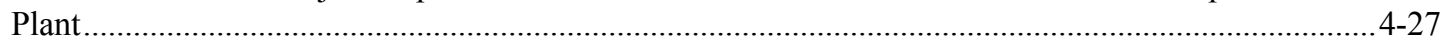

Table 4.4b U3O8/AHF Project Capital Cost Estimate Privately Owned and Privately Operated Plant ......4-27

Table 4.5a Operation and Maintenance Cost Estimate Government Owned and Contractor Operated



Table 4.5b Operation and Maintenance Cost Estimate Privately Owned and Privately Operated Plant......4-29

Table 4.6 Expenditure Cost Funding Profile (GOCO 15 Year Operation) (in million FY2000

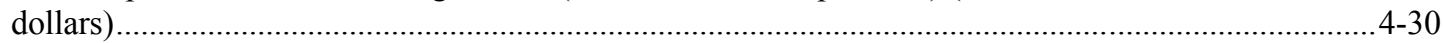

Table 4.7 Expenditure Cost Funding Profile (GOCO 25 Year Operation) (in million FY2000 dollars)

Table 4.8 Expenditure Funding Profile (POPO 15 Year Operation) 10-year payback (in million FY2000 dollars)

Table 4.9 Expenditure Funding Profile U3O8/AHF (POPO 25 Year Operation) 10-year payback (in million FY2000 dollars)

Table 4.10 Expenditure Funding Profile U3O8/AHF (POPO 15 Year Operation) 5-year payback (in million FY2000 dollars)

Table 4.11 Expenditure Funding Profile U3O8/AHF (POPO 25 Year Operation) 5-year payback (in million FY2000 dollars)

Table 5.1 Plant Operation Manpower Estimates for U3O8/AHF/CaF2 Conversion Facility 25 Years Privately Operated

Table 5.2 U3O8/AHF/CaF2 Project Capital Cost Estimate

Table 5.3 Operation and Maintenance Cost Estimate U3O8 / AHF / CaF2

Table 5.5 Expenditure Funding Profile U3O8/AHF/CaF2 25 Years POPO 10-year payback AHF Production Mode (in million FY2000 dollars) .......................................................................... 5-18

Table 5.6 Expenditure Funding Profile U3O8/AHF/CaF2 25 Years POPO 10-year payback CaF2 Production Mode (in million FY2000 dollars) ……….................................................................... 5-21

Table 6.1 Plant Manpower Estimates for UO2/AHF Conversion Facility 25 Years Privately Owned and Privately Operated

Table 6.2 UO2/AHF Project Capital Cost Estimate

Table 6.3 UO2 and AHF Operation and Maintenance Cost Estimate

Table 6.4 Expenditure Funding Profile UO2/AHF 25 Years POPO 10-year payback (in million FY2000 dollars)

Table 7.1 Plant Operation Manpower Estimates for U3O8/CaF2 Conversion Facility 25 Years Government Owned and Contractor Operated .....

Table 7.2 U3O8/CaF2 Project Capital Cost Estimate.

Table 7.3 U3O8/CaF2 Operation and Maintenance Cost Estimate

Table 7.4 Expenditure Funding Profile U3O8/CaF2 25 Years GOCO (in million FY2000 dollars) 


\section{Preface}

One of the more important legacies left with the Department of Energy (DOE) after the privatization of the United States Enrichment Corporation is the large inventory of depleted uranium hexafluoride (DUF6). The DOE Office of Nuclear Energy, Science and Technology (NE) is responsible for the longterm management of some 700,000 metric tons of DUF6 stored at the sites of the two gaseous diffusion plants located at Paducah, Kentucky and Portsmouth, Ohio, and at the East Tennessee Technology Park in Oak Ridge, Tennessee. The DUF6 management program resides in NE's Office of Depleted Uranium Hexafluoride Management.

The current DUF6 program has largely focused on the ongoing maintenance of the cylinders containing DUF6. However, the long-term management and eventual disposition of DUF6 is the subject of a Programmatic Environmental Impact Statement (PEIS) and Public Law 105-204. The first step for future use or disposition is to convert the material, which requires construction and long-term operation of one or more conversion plants. To help inform the DUF6 program's planning activities, it was necessary to perform design and cost studies of likely DUF6 conversion plants at the preconceptual level, beyond the PEIS considerations but not as detailed as required for conceptual designs of actual plants.

This report contains the final results from such a preconceptual design study project. In this fast track, three month effort, Lawrence Livermore National Laboratory and Bechtel National Incorporated developed and evaluated seven different preconceptual design cases for a single plant. The preconceptual design, schedules, costs, and issues associated with specific DUF6 conversion approaches, operating periods, and ownership options were evaluated based on criteria established by DOE. The single-plant conversion options studied were similar to the dry-conversion process alternatives from the PEIS. For each of the seven cases considered, this report contains information on the conversion process, preconceptual plant description, rough capital and operating costs, and preliminary project schedule. 


\section{Acknowledgments}

This work was sponsored by the U.S Department of Energy (DOE), Office of Nuclear Energy, Science and Technology (NE), and directed by NE's Office of Depleted Uranium Hexafluoride Management, with John W. Warren as the DOE/NE program manager.

The work was performed by the Fission Energy and Systems Safety Program at Lawrence Livermore National Laboratory (LLNL), and by Bechtel National Incorporated (Bechtel) as a subcontractor to LLNL. The preconceptual designs, cost estimates, and preliminary schedules were based on case options and criteria established by DOE/NE. Significant contributors, co-authors, or reviewers to this fast track, three month study included (in alphabetical order):

Ted Breitmayer, Bechtel

Raymond Chiu, Bechtel

Ed Jones, LLNL

Daniel Kelleher, Bechtel

George Larson, LLNL

Dan Loftus, Bechtel

Brian Marais, Bechtel

Chan Pang, Bechtel

Max Pong, Bechtel

Jeffrey Stewart, LLNL

Danilo Tiojanco, Bechtel

Ken Young, LLNL

Sam Young, Bechtel 


\section{Acronyms}

\begin{tabular}{|l|l|}
\hline AHF & Anhydrous hydrogen fluoride \\
\hline CAF2 & Calcium fluoride \\
\hline D\&D & Decontamination and Decommissioning \\
\hline DOE & Department of Energy \\
\hline DUF6/UF6 & Depleted Uranium Hexafluoride \\
\hline EIS & Environmental Impact Statement \\
\hline GDP & Gaseous diffusion plant \\
\hline GOCO & Government Owned and Contractor Operated facility \\
\hline HF & Hydrogen fluoride \\
\hline MT & Metric Tons \\
\hline NEPA & National Environmental Policy Act \\
\hline NRC & Nuclear Regulatory Commission \\
\hline O\&M & Operations and Maintenance \\
\hline PEIS & Programmatic Environmental Impact Statement \\
\hline POPO & Privately owned and privately operated facility \\
\hline SSC & Structures, systems, and components \\
\hline UO2 & Uranium dioxide \\
\hline U3O8 & Uranium oxide \\
\hline USEC & United States Enrichment Corporation \\
\hline
\end{tabular}




\section{Background to Preconceptual Design Studies of Conversion Plant Options}

One of the more important legacies left with the Department of Energy (DOE) after the privatization of the United States Enrichment Corporation (USEC) is the large inventory of depleted uranium hexafluoride (DUF6). Some 700,000 metric tons (MT) of DUF6 are stored at the sites of the two gaseous diffusion plants located at Paducah, Kentucky and Portsmouth, Ohio, and at the East Tennessee Technology Park in Oak Ridge, Tennessee.

The current DUF6 management program has largely focused on the ongoing maintenance of the cylinders containing DUF6. The question, however, of the long-term management and eventual disposition of DUF6 is the subject of a Programmatic Environmental Impact Statement (PEIS) and considerable debate in Congress. Congress stated its intentions with regard to DUF6 in Public Law 105-204. This law directed the Secretary of Energy to prepare a plan to ensure that all funds accrued on the books of USEC for the disposition of DUF6 will be used for the construction and operation of plants to treat and recycle the DUF6 consistent with the National Environmental Policy Act (NEPA).

"Treat and recycle," in this context, refers to the chemical processing of DUF6 to remove the fluorine and create products that would present both a lower long-term storage hazard and provide material that would be suitable for use or disposal. Importantly, this would also allow the private and government sectors to explore the reuse of some of the end products resulting from the conversion of DUF6.

The first step for future use or disposition is to convert the material. To do so, construction and long-term operation of one or more conversion plants is essential. Traditionally, a project like this might be the subject of a multi-year Federal government-managed project to build one or two plants. However, such projects require a significant outlay of Federal funds early on and require many years to complete. In comparison, the private sector is well-equipped to pursue plant projects expeditiously and economically, as needed for the DUF6 program.

Thus, to help inform the program's planning activities, it is essential to perform design and cost studies, at least at the preconceptual level, of likely DUF6 conversion plants, whether they are government owned and contractor operated or privately owned and operated. This requires evaluations of conversion capability specifics and costs beyond the PEIS considerations, but not as detailed as required for conceptual designs of actual plants. This report contains results from such a preconceptual design study project. 



\section{Overview of Preconceptual Design Study Project}

\subsection{Introduction/Methodology}

The PEIS (Programmatic Environmental Impact Statement for Alternative Strategies for the Long-Term Management and Use of Depleted Uranium Hexafluoride) considers alternatives for the long-term management of the DUF6 stockpile. Engineering analyses and cost analyses for each of the alternatives were also prepared to support the PEIS. The projected costs of the alternatives were developed in the Cost Analysis Report for the Long-Term Management of Depleted Uranium Hexafluoride (Cost Analysis Report). The engineering and cost analyses used generic basis assumptions to be applied to the evaluation of all alternatives. In this sense, these previous studies were 'parametric' and did not address site-specific and technology-specific issues. For instance, the cost analysis was intended to identify the relative differences in costs for purposes of making comparisons and do not provide absolute costs for developing project budgets or procurement documents. Furthermore, the estimates in the Cost Analysis Report do not represent costs "to" any particular entity, either public or private.

This project seeks to improve the situation by evaluating the preconceptual design, costs, schedule, and issues associated with specific DUF6 conversion technologies. The scope of the preconceptual design study, see Figure 2.1, is focused on the conversion module of the DUF6 management strategy. It is a single plant study, with different conversion options considered. The other elements of an integrated management strategy are not included in this study, such as management of the DUF6 storage containers, transportation to and from the conversion plant, nor use, long-term storage, or disposition options. However, potential expanded interim storage of conversion product at the conversion plant is part of the study scope.

The single-plant conversion options studied were based on the conversion alternatives from the PEIS. DOE selected the cases of most interest to them, see Section 2.2. The studies focused on the preconceptual life-cycle costs, schedule, and other issues pertinent to the early construction of conversion facilities. The DOE plan is based on an aggressive schedule to begin construction of conversion facilities in 2002, and relies on significant private sector involvement to be successful.

The conversion and operation of the conversion plant is based on one of two basic scenarios: the plant will be government-owned and contractor operated in conformance with DOE standards (GOCO), or the plant will be under private ownership and operation with DOE regulations (POPO). In addition, case options were developed for both 25-year and 15-year operations. The 25-year operation is consistent with the PEIS considerations. The 15 -year operation was chosen as a potential alternative for earlier recovery of capital, siting, financing, and return on investment to the private sector.

More detailed information on the design bases and assumptions employed in this study are contained in Section 2.3 and Sections 4 through 7.

This was a fast track study: seven conversion options were analyzed in a period of three calendar months. As such, the studies utilized already available information from a variety of sources like reports and literature, personal communications and quotes, estimates for similar equipment, current estimating manuals, and in-house databases.

This report is organized in the following manner. Sections 2 and 3 provide summary information and results, respectively, based on all the case studies performed. Sections 4-7 each corresponds to the preconceptual study for one of the four major conversion cases. Each of these sections is written to be a 
stand-alone report, in case parties are only interested in specific conversion plants. This results, however, in some redundancy of information among the major sections of the report.

\subsection{Summary of Cases Considered}

In order to examine the costs and issues involved in a 2002 time frame for construction start, DOE selected four plant conversion cases:

- A conversion plant using a dry process to convert DUF6 to uranium oxide (U3O8) and anhydrous hydrogen fluoride (AHF) as final products.

- A conversion plant using a dry process to convert DUF6 to uranium oxide (U3O8) and anhydrous hydrogen fluoride (AHF) and calcium fluoride $(\mathrm{CaF} 2)$ as final products.

- A conversion plant using a dry process to convert DUF6 to uranium dioxide (UO2) aggregate and anhydrous hydrogen fluoride (AHF) as final products.

- A conversion plant using a dry process to convert DUF6 to uranium oxide (U3O8) and calcium fluoride $(\mathrm{CaF} 2)$ as final products.

The last case, $\mathrm{U} 3 \mathrm{O} 8 / \mathrm{CaF} 2$, was used for a preliminary preconceptual study which helped to establish a protocol for the other studies. The U3O8/AHF became the base study, with the most options considered, for this project.

A process block flow diagram of the base case conversion is provided in Figure 2.2 to illustrate the elements incorporated in the conversion facility considerations.

All cases entailed a preconceptual plant design, rough cost estimate, and preliminary project schedule. The conversion plant includes capabilities for DUF6 cylinder preparation, conversion of DUF6 to uranium oxide and fluorine byproducts, empty cylinder treatment for disposal, and interim storage for oxide and byproducts.

\subsubsection{DUF6 Conversion to U3O8/AHF}

This base case study is a conversion plant using a dry process to convert DUF6 to uranium oxide (U3O8) and anhydrous hydrogen fluoride (AHF) as final products. The construction and operation of the U3O8/AHF conversion plant depends on one of two basic scenarios: GOCO or POPO. In addition, case options were developed for both 25-year operations and 15-year operations, which gives a total of four options.

Depleted uranium hexafluoride (DUF6) is processed to produce U3O8 and AHF. For 25-year operation, the average throughput is 5.1 cylinders per day $(5,670 \mathrm{lb} / \mathrm{hr}$ UF6). For 15 -year operation the average throughput is 8.5 cylinders per day $(9,450 \mathrm{lb} / \mathrm{hr}$ UF6). These figures are based on $80 \%$ plant availability (7,000 hours/yr or 292 days/yr).

The DUF6 gas is converted to U3O8 in a series of two reaction chambers, where it is mixed with an $\mathrm{HF} /$ water vapor mixture in the first reaction chamber and with steam in the second reaction chamber. The chemical reactions are:

$\mathrm{UF} 6+2 \mathrm{H}_{2} \mathrm{O}--->\mathrm{UO}_{2} \mathrm{~F}_{2}+4 \mathrm{HF}$ 
$3 \mathrm{UO}_{2} \mathrm{~F}_{2}+3 \mathrm{H}_{2} \mathrm{O}--->\mathrm{U} 3 \mathrm{O} 8+6 \mathrm{HF}+0.5 \mathrm{O}_{2}$

For 25-year operation, four reaction lines are provided to meet the required throughput. (Six lines are provided in the 15-year scenario). The U3O8 product is cooled, compacted to increase its bulk density, and packaged in metal bins. The filled bins are transferred to the U3O8 Storage Building.

Reaction chamber off-gas containing HF, steam and oxygen is filtered to remove uranium particulates. The off-gas then flows to one of two HF distillation systems, which concentrates the mixture to produce anhydrous HF in the overhead product. The AHF is collected, sampled, and pumped to large storage tanks in the HF Storage Building, where the AHF is loaded into railcars or tank trucks for delivery to customers. The AHF is expected to contain less than 1 ppm uranium.

\subsubsection{DUF6 Conversion to U3O8/AHF/CaF2}

This plant construction is based on a conversion plant using a dry process to convert DUF6 to uranium oxide (U3O8), anhydrous hydrogen fluoride (AHF) and calcium fluoride (CaF2) as final products. The plant has two operating modes: $100 \%$ production of AHF only or $100 \%$ production of only CaF 2 . The construction and operation of the conversion plant is based on private ownership and operation with DOE regulations and operating for 25 years.

Depleted uranium hexafluoride (DUF6) is processed to produce U3O8, AHF and CaF2. The average throughput is 5 cylinders per day $(5,670 \mathrm{lb} / \mathrm{hr}$ DUF6) based on $80 \%$ plant availability $(7,000$ hours/yr or 292 days/yr).

The plant is designed to produce AHF or CaF2, but not both simultaneously. Production would be shut down during the transition between the AHF and $\mathrm{CaF} 2$ production modes. The desired mix of $\mathrm{AHF}$ and $\mathrm{CaF} 2$ product is obtained by campaigning operations. Much of the equipment is common and would be used during both production modes.

The AHF production mode is as in Section 2.2.1 above.

For the calcium fluoride production mode, the DUF6 gas is converted to U3O8 in a series of two reaction chambers, where it is mixed with steam and nitrogen in the first chamber and steam and hydrogen in the second chamber. The chemical reactions are:

$\mathrm{UF} 6+2 \mathrm{H}_{2} \mathrm{O}--->\mathrm{UO}_{2} \mathrm{~F}_{2}+4 \mathrm{HF}$

$3 \mathrm{UO}_{2} \mathrm{~F}_{2}+3 \mathrm{H}_{2} \mathrm{O}--->\mathrm{U} 3 \mathrm{O} 8+6 \mathrm{HF}+0.5 \mathrm{O}_{2}$

$\mathrm{H}_{2}+0.5 \mathrm{O}_{2}--->\mathrm{H}_{2} \mathrm{O}$

The U3O8 product is cooled, compacted to increase its bulk density, packaged in metal bins, and transferred to the U3O8 Storage Building. Reaction chamber off-gas containing HF, excess steam, and nitrogen is filtered to remove uranium particulates. The reaction chambers, filters and U3O8 handling equipment are the same ones used in the AHF production mode.

After filtration, the reaction off-gas flows to the HF absorption columns, where the HF and steam are contacted with a liquid solution and condensed. The aqueous HF solution that is produced from absorption is transferred to neutralization tanks and neutralized with slaked lime according to the reaction:

$2 \mathrm{HF}+\mathrm{Ca}(\mathrm{OH})_{2}--->\mathrm{CaF} 2+2 \mathrm{H}_{2} \mathrm{O}$ 
The resulting CaF2 precipitate is separated by filtering, washed with water, dried and loaded into bins. The $\mathrm{CaF} 2$ is expected to contain less than $1 \mathrm{ppm}$ uranium.

\subsubsection{DUF6 Conversion to UO2/AHF}

This case study examines the cost and issues for plant construction based on a conversion plant using a dry process to convert DUF6 to uranium dioxide aggregate and anhydrous hydrogen fluoride (AHF) as final products. The UO2 aggregate can be used to make dense concrete for shielding applications. The construction and operation of the conversion plant is based on private ownership with DOE regulations and operating for 25 years.

Depleted uranium hexafluoride (DUF6) is processed to produce UO2 aggregate and AHF. The average throughput is 5 cylinders per day $(5,670 \mathrm{lb} / \mathrm{hr}$ DUF6) based on $80 \%$ plant availability $(7,000$ hours/yr or 292 days/yr).

The DUF6 gas is converted to UO2 in a series of two reaction chambers, where it is mixed with an $\mathrm{HF} /$ water vapor mixture in the first reaction chamber and with steam, nitrogen and hydrogen in the second reaction chamber. The chemical reactions are:

$\mathrm{UF} 6+2 \mathrm{H}_{2} \mathrm{O}--->\mathrm{UO}_{2} \mathrm{~F}_{2}+4 \mathrm{HF}$

$\mathrm{UO}_{2} \mathrm{~F}_{2}+\mathrm{H}_{2}--->\mathrm{UO} 2+2 \mathrm{HF}$

Four reaction lines are provided to meet the required throughput. The UO2 product is cooled and conveyed to indoor silos for interim storage.

The UO2 is mixed with additives, milled and pressed into pellets. The pellets are sintered to form dense ceramic pellets and packaged in boxes. The filled boxes are transferred to the UO2 storage building.

Reaction chamber off-gas containing HF, steam, nitrogen and hydrogen is filtered to remove uranium particulates. The off-gas then flows to an HF distillation system, which concentrates the mixture to produce anhydrous HF in the overhead product. The AHF is collected, sampled, and pumped to large storage tanks in the HF Storage Building, where the AHF is loaded into railcars or tank trucks for delivery to customers. The AHF is expected to contain less than $1 \mathrm{ppm}$ uranium.

\subsubsection{DUF6 Conversion to U3O8/CaF2}

For this preconceptual design project, the preliminary case study was based on a conversion plant using a dry process to convert DUF6 to uranium oxide (U3O8) and calcium fluoride $(\mathrm{CaF} 2)$ as final products. The process selected to study involves least process equipment and byproduct streams. The construction and operation of the conversion plant is based on a government owned and contractor operated facility in conformance with DOE standards and operating for 25 years.

Depleted uranium hexafluoride (DUF6) is processed to produce uranium oxide (U3O8) and calcium fluoride $(\mathrm{CaF} 2)$. The average throughput is 5 cylinders per day $(5,670 \mathrm{lb} / \mathrm{hr}$ DUF6) based on $80 \%$ plant availability (7,000 hours/yr or 292 days/yr).

The DUF6 gas is mixed with steam, nitrogen and hydrogen and converted to U3O8 in a series of two reaction chambers. The chemical reactions are:

$\mathrm{UF} 6+2 \mathrm{H}_{2} \mathrm{O}--->\mathrm{UO}_{2} \mathrm{~F}_{2}+4 \mathrm{HF}$ 
$3 \mathrm{UO}_{2} \mathrm{~F}_{2}+3 \mathrm{H}_{2} \mathrm{O}--->\mathrm{U} 3 \mathrm{O} 8+6 \mathrm{HF}+0.5 \mathrm{O}_{2}$

$\mathrm{H}_{2}+0.5 \mathrm{O}_{2}--->\mathrm{H}_{2} \mathrm{O}$

Four reaction lines are provided to meet the required throughput. The U3O8 product is cooled, compacted with a rotary compactor to increase its bulk density, and packaged in metal bins. The filled bins are transferred to the U3O8 Storage Building.

Reaction chamber off-gas containing HF, excess steam, and nitrogen is filtered to remove uranium particulates. The off-gas flows to the HF absorption columns, where the HF and steam are condensed and an aqueous HF solution is produced. The HF solution is neutralized with slaked lime according to the reaction:

$2 \mathrm{HF}+\mathrm{Ca}(\mathrm{OH})_{2}--->\mathrm{CaF} 2+2 \mathrm{H}_{2} \mathrm{O}$

The resulting $\mathrm{CaF} 2$ precipitate is separated by filtering, washed with water, dried and loaded into bins and are transferred to the $\mathrm{CaF} 2$ Storage Building. The CaF2 is expected to contain less than $1 \mathrm{ppm}$ uranium.

\subsection{Design Basis and Assumptions}

This section summarizes the major design bases and assumptions impacting the results of the preconceptual design, cost estimates, and scheduling. Detailed bases and assumptions are contained in Sections 4-7 for each study option.

Significant design bases for the conversion plants include:

- The plants will convert DUF6 by a dry process.

- The plant capacity will be designed to process a DUF6 inventory of 36,910 cylinders $(450,000 \mathrm{MT}$ DUF6) over the life of the plant (about 64\% of the DOE inventory of 700,000 MT).

- Storage will be provided for one year production of uranium oxide and calcium fluoride products and two months production of AHF.

- The AHF product is sold by the DOE (GOCO) or plant owner (POPO) (depending on the case options) to commercial users. The $\mathrm{U} 3 \mathrm{O} 8$ and $\mathrm{CaF} 2$ products are retained by the $\mathrm{DOE}$, if the plant is government owned, or returned to the DOE, if the plant is privately owned.

- To bound costs associated with empty cylinders, assume all empty cylinders will be washed, compacted, and returned to the DOE for disposal.

- The plant will be located at a DOE owned site at or near a gaseous diffusion plant and include the support facilities and infrastructures/utilities needed for a greenfield facility.

- The design will consider addition of future process and storage buildings.

The Conversion Facility is assumed to be constructed on a DOE site at a greenfield, constructable location at or near a gaseous diffusion plant. The Conversion Facility includes full and empty cylinder storage pads, the Process Building, a U3O8 Storage Building, an HF Storage Building, a CaF2 Storage Building, a Waste Storage Building and support facilities. The site plan should consider the addition of future process facilities such as uranium metal. 
The Conversion Facility will be designed and constructed in compliance with DOE Orders and applicable regulations and codes, and will meet the intent of NRC standards. In general, a graded approach as established in DOE Order 420.1 is used for the design of all structures, systems, and components (SSC) in the plant facilities. All SSC's will be assigned a Natural Phenomena Performance Category using the criteria in the DOE Standards DOE-STD-1020-94 and DOE-STD-1021-93 during the design phase. The more stringent requirements of the gaseous diffusion plant sites are used in this study.

The cost estimates are rough order of magnitude estimates based on a preconceptual level design information. The estimates include facility capital, O\&M, D\&D, and NEPA/Licensing costs. The estimates do not include costs for plant design criteria development, cost of land, site qualifications, or extension of local roads and utility lines to the site boundary. The estimates take into account the procurement pricing, labor productivity, and indirect cost factors for a government or private project. Detailed cost estimate bases are described in the Appendices.

Figure 2.3 summarizes the differences in cost factors used between the POPO and GOCO cases.

For the POPO cases, the assumed guaranteed maximum feed rate per annum is the total quantity of DUF6 (450,000 MT) divided by the product of the total number of years assumed to process this quantity and the plant availability factor. The guaranteed minimum feed rate per annum is $95 \%$ of the guaranteed maximum feed rate. It is also assumed there is no government financing, i.e., private financing only.

Private finance is used to raise the construction capital. The private finance is based on a construction loan with an assumed commercial interest rate to cover the design, construction, and startup expenditures. The loan is paid back during an assumed period after production start with operation revenues from conversion service payment and HF chemical sales.

The private operator will receive payment from the government for the conversion service. The payment is based on amount of DUF6 processed after production start at assumed rates such that the private operator's income is near break-even.

The DOE plan is based on an aggressive schedule to begin construction of conversion facilities in 2002. Thus, the schedule is based on a fast track premise with overlapping engineering phases and early procurement of some key equipment (most equipment is available in 12-18 month lead time) and a twophase construction plan. The reader is advised to consider these schedules illustrative, rather than definitive. There are large uncertainties in the timing or delays in the DOE regulatory processes leading from selection of contractor to full operations. 


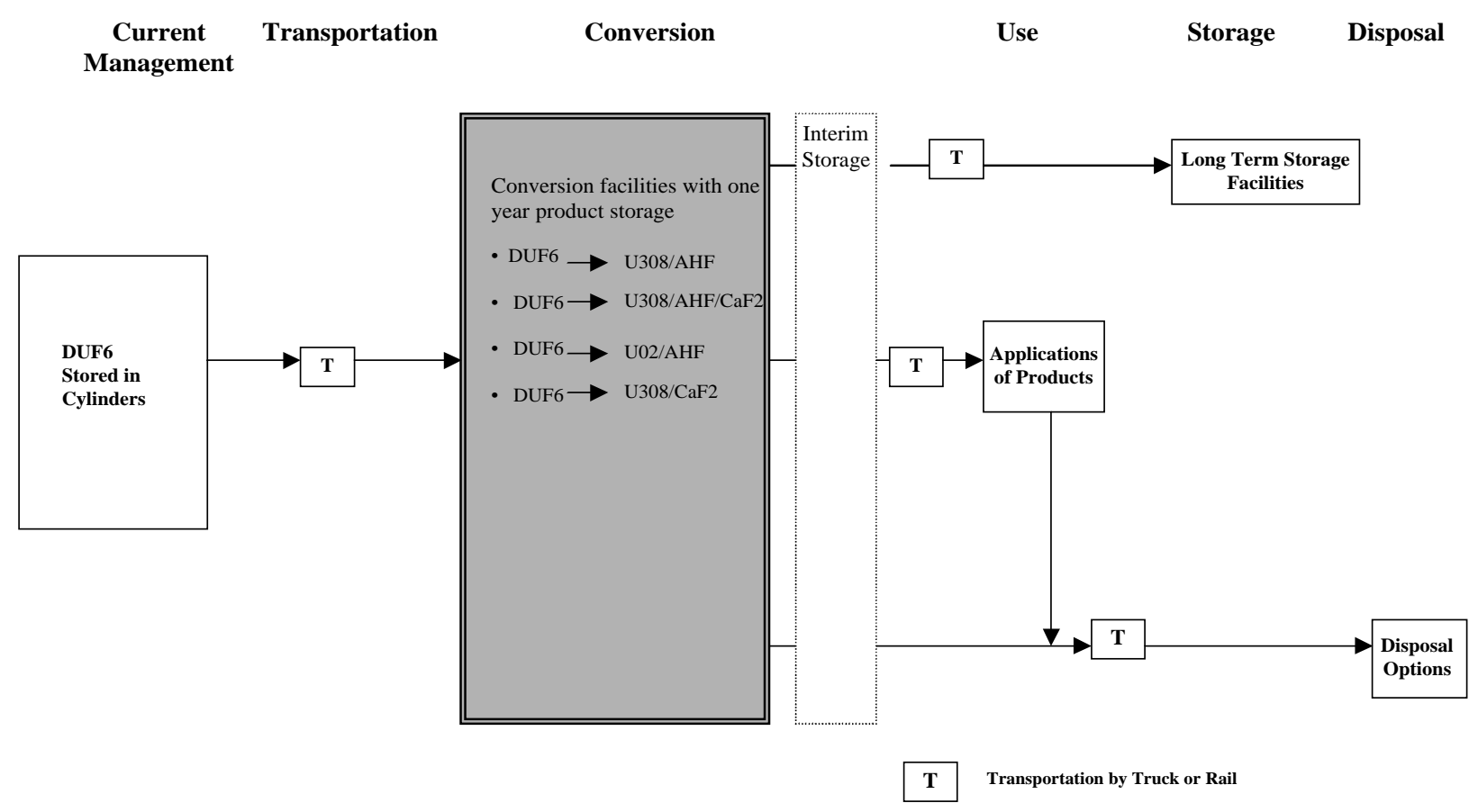

Figure 2.1 Scope of Study 


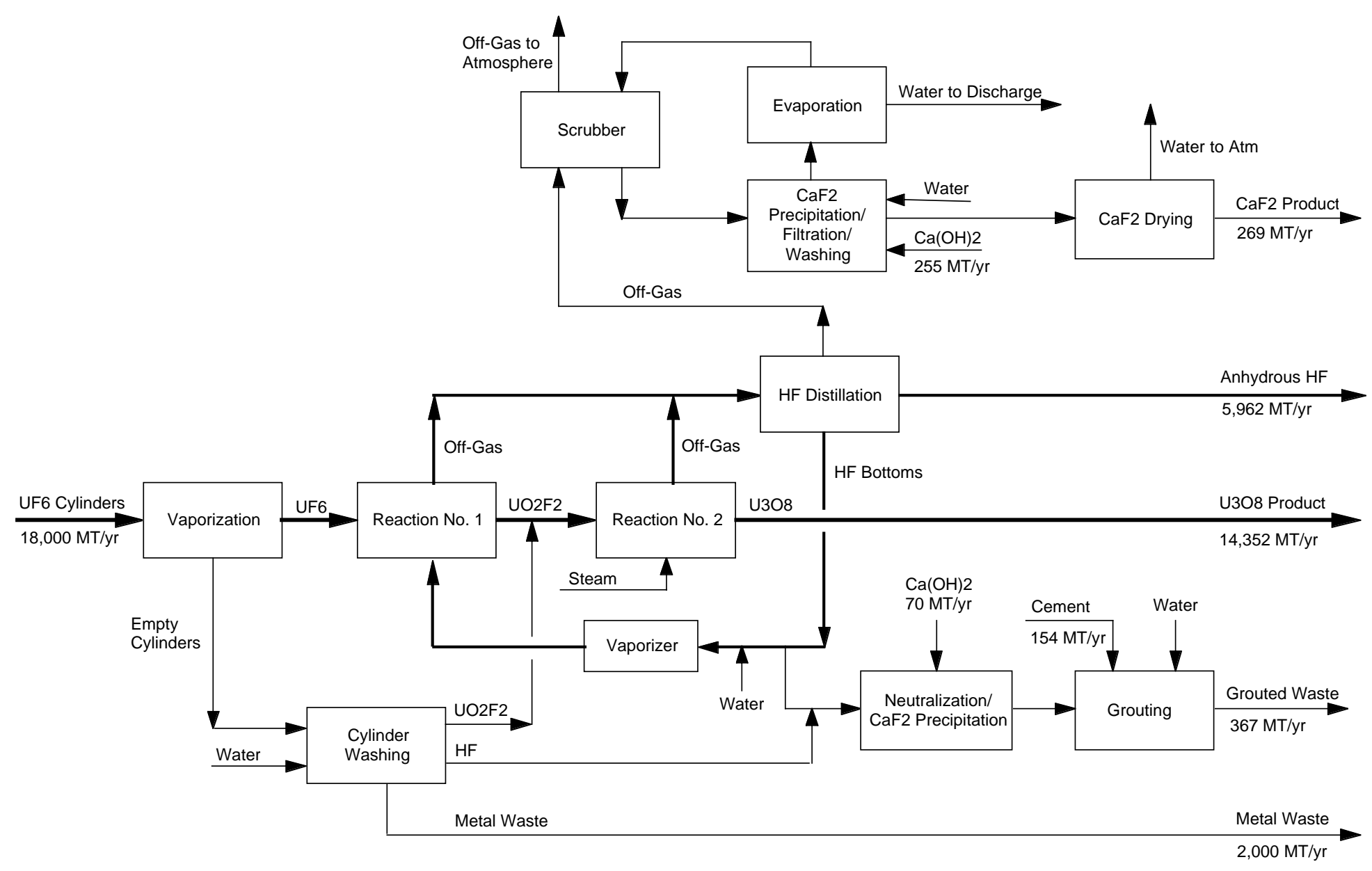

Figure 2.2 Process Block Flow Diagram Conversion to U3O8 and AHF 


\begin{tabular}{|c|c|}
\hline \multicolumn{2}{|l|}{ Capital Costs } \\
\hline Wages & Same for POPO and GOCO \\
\hline Materials & $5 \%$ less for POPO \\
\hline Productivity & $5 \%$ greater for $\mathrm{POPO}$ \\
\hline Engineering ( $\%$ capital costs) & $\begin{array}{l}14.4 \% \text { of capital costs for POPO } \\
18 \% \text { of capital cost for GOCO }\end{array}$ \\
\hline Construction indirects & $3 \%$ to $4 \%$ less for POPO \\
\hline \multicolumn{2}{|c|}{ Operating and Maintenance Costs } \\
\hline Wages & Same for POPO and GOCO \\
\hline Indirects & $2 \%$ less for POPO \\
\hline Labor & Increased security and administrative for GOCO \\
\hline
\end{tabular}

Figure 2.3 Cost Estimate Factors for POPO vs. GOCO 



\section{Summary Results}

This section contains illustrative results chosen to reflect the general outcomes of this study. More detailed and specific results for each case study can be found in Sections 4-7.

\subsection{Overall Description of Facilities}

Based on the preconceptual design considerations, a typical conversion facility conceptual site plan is shown in Figure 3.1. The Conversion Facility includes full and empty storage pads, the Process Building, a U3O8 Storage Building, a HF Storage Building, a CaF2 Storage Building, a Waste Storage Building and support facilities. The site plan shows addition of future process facilities.

A Process Building general arrangement for the base case U3O8/AHF conversion is provided in Figure 3.2 to illustrate the elements and their relationships incorporated in the conversion facility considerations. The arrangement maps to the process block flow diagram in Figure 2.2.

Some preconceptual facility design parameters are compared for the four conversion options in Table 3.1. This table also includes for comparison the 15-year operations for the base case U3O8/AHF conversion. In the 25-year operations all conversion plants process about 5 cylinders/day or 18,000 MT/yr of DUF6. In the 15-year configuration these numbers jump to 8.5 cylinders/day and to $30,000 \mathrm{MT} / \mathrm{yr}$. The uranium product rate is approximately $14,500 \mathrm{MT} / \mathrm{yr}$ for all the conversion processes when scaled for 25 -year operations. The productivity is $20 \%$ higher when scaled for 15 -year operations. The AHF product is about $6,000 \mathrm{MT} / \mathrm{yr}$ for all conversion processes at 25 -year operations, and increases by two-thirds for the 15year option. The number of plant employees ranges from 179 to 218 , depending on the conversion option and plant capacity.

\subsection{Cost Estimates}

The rolled-up costs (in FY 2000 dollars) for every preconceptual study case are provided and compared in Table 3.2. The life-cycle funding outlays for the various case options are summarized in the bottom line of Table 3.2. Note that byproduct sale revenue and construction loan interest are included. In the POPO cases, the total outlay is a break-even government payment that doesn't include profit, taxes and depreciation. In addition to a 10-year payback time for the POPO cases, the expenditure outlays for a 5year payback time were developed for the U3O8/AHF base cases. The break-even payment for 5-year payback in the 15 -year POPO case is $\$ 738 \mathrm{M}$ as opposed to $\$ 827 \mathrm{M}$ for a 10 -year payback; and $\$ 779 \mathrm{M}$ as opposed to $\$ 845 \mathrm{M}$ in the 25 -year POPO case.

The cost estimates vary depending on the scenario under discussion, and differ depending on whether the plant is government owned and contractor operated or privately owned and operated. The major contributors to the capital cost are the Process Building including the structure and service systems. Capital cost is very roughly $25 \%$ for process equipment, $25 \%$ process building, $25 \%$ product storage buildings and $25 \%$ site improvements and support facilities. The process equipment cost is roughly $30 \%$ cylinder handling and vaporization, 50\% conversion to oxide, 15\% AHF distillation and 5\% miscellaneous. Roughly $2 / 3$ of the annual O\&M cost is labor cost. The cost to dispose of empty cylinder metal is not included in this report. If it is disposed as LLW, the disposal cost could be significant.

The annual expenditures required to support the construction and operation of the conversion plants were also developed. The expenditure profiles are derived from loading the estimated capital and operating 
costs onto the project schedule. A constant FY2000 dollar value is used in the expenditure outlay, because of the difficulty in accurately predicting the inflation rate for future years. An illustrative funding profile comparison for GOCO versus POPO for the 15-year U3O8/AHF conversion facility is presented graphically in Figure 3.3.

For the funding distributions of Figure 3.3, the POPO case accumulates debt in years 0-5 (at an assumed rate of $8.5 \%$ ) and there is no financing (interest) cost for GOCO. The assumed loan payback period is 10 years, and it begins at plant operation start. Revenue from AHF sales is also assumed. All funding profiles are based on break-even cost/expenditure, i.e., there is no profit included in the POPO outlay. Figure 3.4 shows funding distributions with a 5-year loan payback period.

The government expenditure in the POPO case is minimal during the first five years and is steady at approximately $\$ 74 \mathrm{M} / \mathrm{yr}$ for years 5-15. This constant outlay reduces to approximately $\$ 21 \mathrm{M} / \mathrm{yr}$ between 15 and 20 years. The government outlay increases from $\$ 3 \mathrm{M}$ to $\$ 120 \mathrm{M}$ per year in the first five years, and then is steady at about $\$ 20 \mathrm{M} / \mathrm{yr}$ from 5 to 20 years. Note that, even though the government outlay in the first five years of POPO is minimal, the total break-even outlay is greater for POPO than for GOCO by approximately $\$ 170 \mathrm{M}$ over the plant lifetime. However, if a 5-year payback is used, the total POPO outlay exceeds the GOCO outlay by $\$ 80 \mathrm{M}$ over the plant lifetime.

\subsection{Schedules}

Estimated preliminary project schedules were developed for each conversion plant option. The schedules are based on a fast track premise, with overlapping engineering phases, early procurements, and a construction plan, in order to meet the desired objective of construction start in year 2002. A simplified schedule for the initial years of the project for GOCO 25-year operations is shown in Figure 3.5.

The 2002 construction start depends on the key milestone dates for site selection, selection of primary contractor and construction contractor, and construction approval. The schedule includes NEPA activities, as a site-specific EIS will be required, as well as DOE regulatory activities. The schedules show late 2001 to early 2002 construction start and 2004 start-up (the 15-year operation plant requires an additional six months before start-up in both the POPO and GOCO cases). This appears to be attainable if the key procurement, engineering, and construction approval milestones are met. The schedule differences between POPO and GOCO - on the order of six months longer for POPO - is probably not significant but strongly depends on the decision making process. There are large uncertainties in the timing or delays in the DOE regulatory processes leading to full operations.

\subsection{U308 Storage Issue}

A primary issue identified during this project was that the amount of $\mathrm{U} 3 \mathrm{O} 8$ storage provided affects cost and probably needs additional study to find less expensive storage modalities. The U3O8 storage design used in this preconceptual study is large and expensive for each year of storage capacity. It might be considered an upper bound on uranium oxide storage design.

A one-year capacity U3O8 storage building holds $1760,4 \times 4 \times 7$ foot high, bins stacked one high. Bins were used to package the U3O8 because of the space savings compared to 55-gallon drums. With no stacking, the U3O8 Storage building is $240 \mathrm{ft} \times 350 \mathrm{ft} \times 15 \mathrm{ft}$ high or $84,000 \mathrm{sq}$. $\mathrm{ft}$. A general storage arrangement in the U3O8 building is shown in Figure 4.4. The cost per storage building is estimated at \$23M (25 year case) and \$29M (15 year case) including engineering. Additional storage capacity would require about 5 acres (site improvements and utilities) for each year of additional U3O8 storage. 
The U3O8 storage buildings are assumed PC-2 to maintain storage function after the occurrence of a natural phenomena hazards event. These buildings are steel frame and concrete clad panel construction and are ventilated and lighted, but no heating, cooling or HEPA filtration is provided. Access aisles allow personnel to inspect the bins during storage.

Additional study is needed to determine the most cost effective storage method, including the best storage container to use with the cost considerations on facilities and transport. 


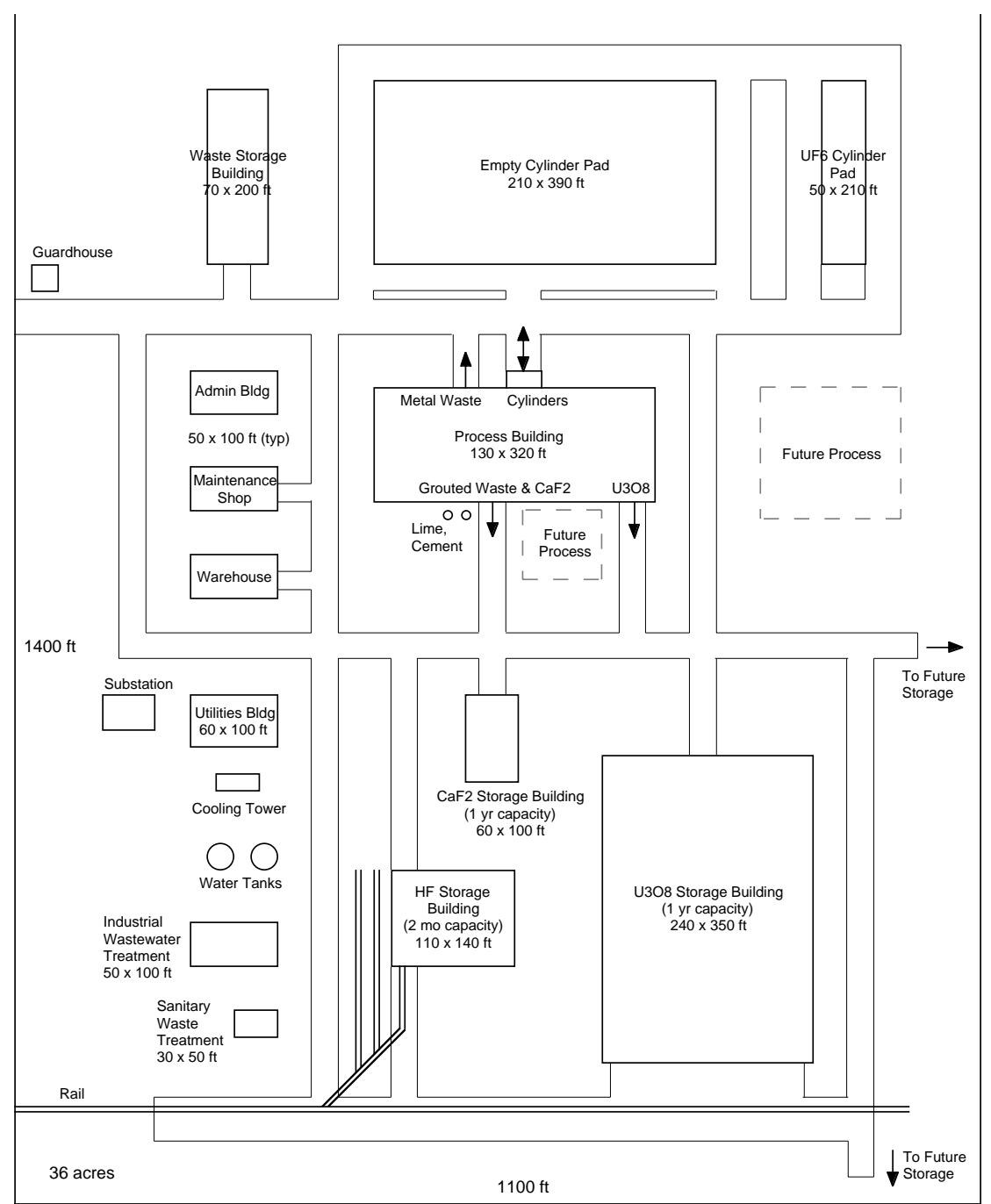

Figure 3.1 Conversion Facility and Storage Site Plan DUF6 Conversion to U3O8 and AHF 


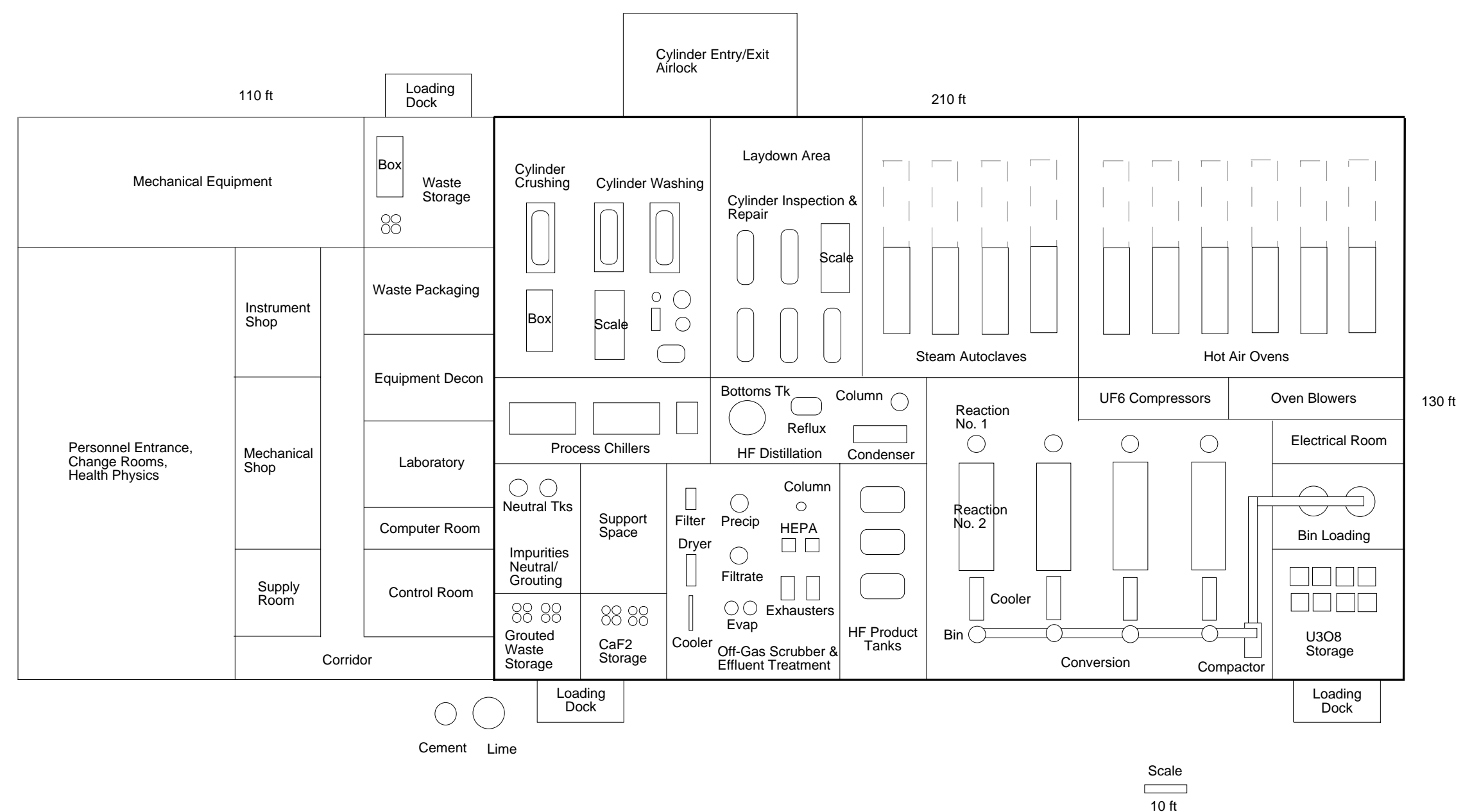

Figure 3.2 Process Building General Arrangement Conversion to U3O8 and AHF 




Figure 3.3 Funding Profiles GOCO vs. POPO - 15 Years U3O8/AHF (w/10 year loan payback time in POPO case) 


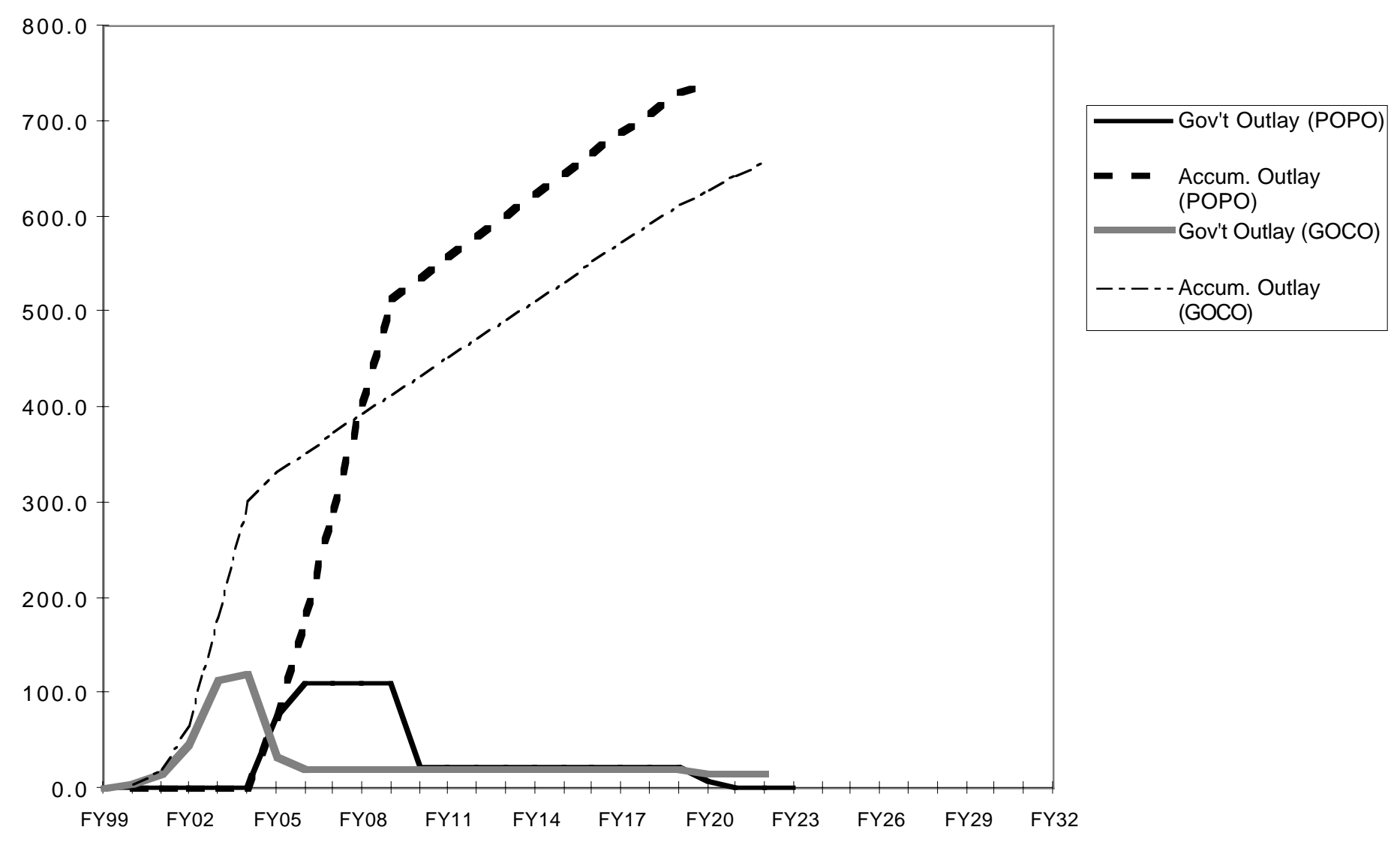

Figure 3.4 Funding profiles GOCO vs. POPO - U3O8/AHF 15 Operating Years (w/5 year loan payback time in POPO case) 


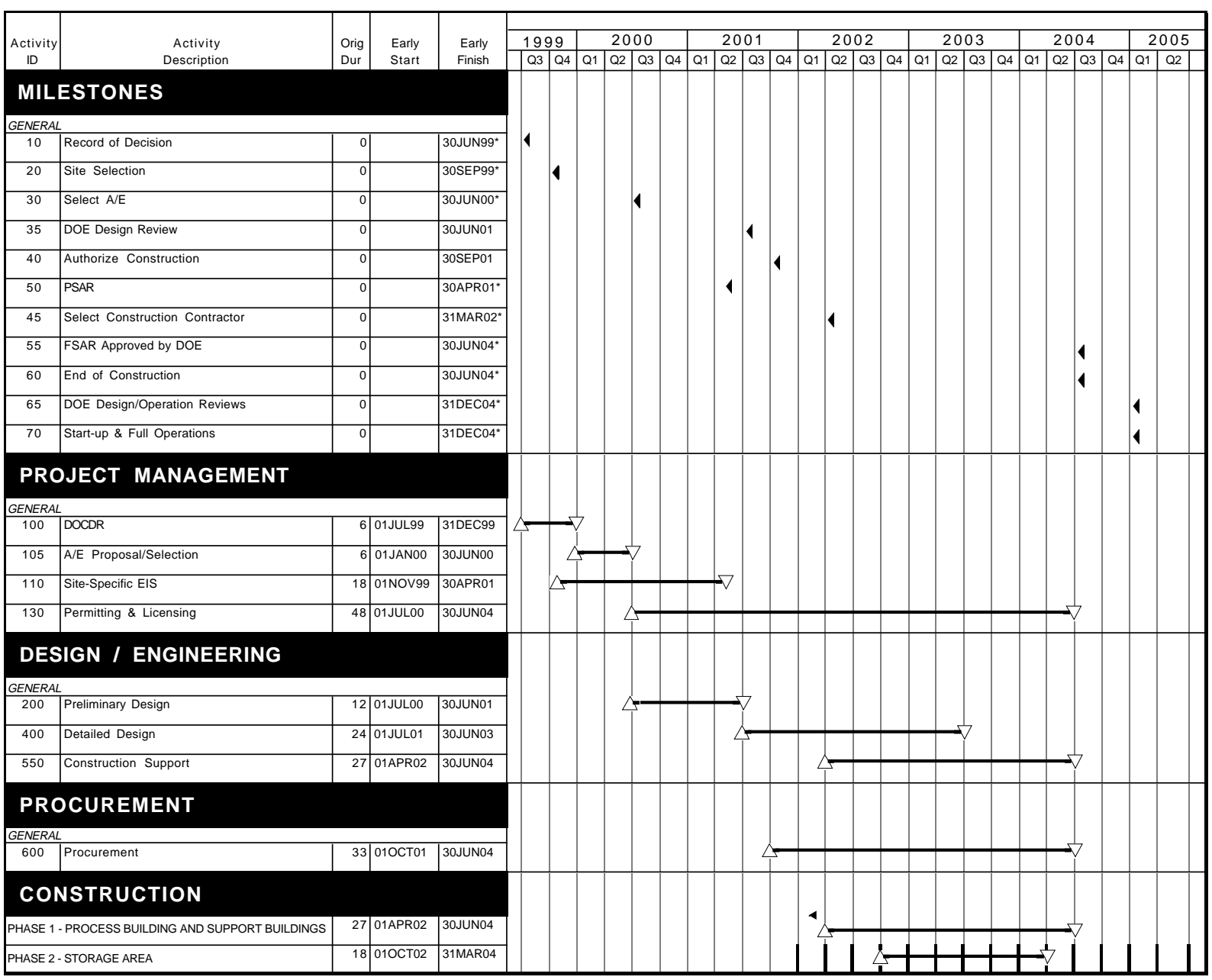

Figure 3.5 U3O8/AHF Plant, 25 Year Government Owned and Contractor Operated Preliminary Project Schedule 
Table 3.1 Preconceptual Facility Design Summary

\begin{tabular}{|c|c|c|c|c|c|}
\hline Description/case & U3O8/AHF & UO2/AHF & U3O8/AHF/CaF2 & U3O8/CaF2 & U3O8/AHF \\
\hline Operating Time & \multicolumn{4}{|c|}{25 yrs } & 15 yrs \\
\hline DUF6 Feed & \multicolumn{4}{|c|}{$18,000 \mathrm{MT} / \mathrm{yr}$} & $30,000 \mathrm{MT} / \mathrm{yr}$ \\
\hline DUF6 Cylinders & \multicolumn{4}{|c|}{$\begin{array}{l}1,472 \text { cylinders/yr } \\
\text { (5.1 cylinders/day) }\end{array}$} & $\begin{array}{l}2,461 \mathrm{cyl} / \mathrm{yr} \\
(8.5 \mathrm{cyl} / \mathrm{day})\end{array}$ \\
\hline Uranium Product & $\mathrm{U} 3 \mathrm{O} 8$ & 93\% UO2 agg. & $\mathrm{U} 3 \mathrm{O} 8$ & $\mathrm{U} 3 \mathrm{O} 8$ & $\mathrm{U} 3 \mathrm{O} 8$ \\
\hline Quantity (MT/yr) & 14,352 & 14,846 & 14,352 & 14,352 & 23,920 \\
\hline Packages (per yr) & $\begin{array}{c}1,7584 \times 4 \times 7 \mathrm{ft} \\
\text { bins }\end{array}$ & $\begin{array}{c}1,9264 \times 4 \times 4 \mathrm{ft} \\
\text { boxes }\end{array}$ & $1,7584 \times 4 \times 7 \mathrm{ft}$ bins & $\begin{array}{c}1,7584 \times 4 \times 7 \mathrm{ft} \\
\text { bins }\end{array}$ & $\begin{array}{c}2,9304 \times 4 \times 7 \mathrm{ft} \\
\text { bins }\end{array}$ \\
\hline On-Site Storage & $1 \mathrm{yr}$ & $1 \mathrm{yr}$ & $1 \mathrm{yr}$ & $1 \mathrm{yr}$ & $1 \mathrm{yr}$ \\
\hline Disposition & \multicolumn{5}{|c|}{ Return to DOE } \\
\hline Fluorine Product & AHF & AHF & $\mathrm{AHF} / \mathrm{CaF} 2$ & $\mathrm{CaF} 2$ & AHF \\
\hline Quantity (MT/yr) & 5,962 & 5,944 & $5,962 / 11,966$ & 11,966 & 9,936 \\
\hline Packages (per yr) & 1.6 million gal & 1.6 million gal & $\begin{array}{l}1.6 \text { million gal/ } \\
2,639 \text { bins }\end{array}$ & $\begin{array}{c}2,6394 \times 4 \times 7 \mathrm{ft} \\
\text { bins }\end{array}$ & 2.7 million gal \\
\hline On-Site Storage & 2 months & $1 \mathrm{yr}$ & $2 \mathrm{mo} . / 1 \mathrm{yr}$ & $1 \mathrm{yr}$ & 2 months \\
\hline Disposition & Sales & Sales & Sales/DOE & DOE & Sales \\
\hline Empty cylinders & \multicolumn{5}{|c|}{ Return to DOE } \\
\hline $\begin{array}{l}\text { No. of Employees } \\
\text { (POPO case) } \\
\text { (GOCO case) }\end{array}$ & $\begin{array}{l}179 \\
189\end{array}$ & $\begin{array}{l}191 \\
-\end{array}$ & $\begin{array}{l}183 \\
-\end{array}$ & $\overline{193}$ & $\begin{array}{l}208 \\
218\end{array}$ \\
\hline Site size (acres) & 36 & 37 & 39 & 36 & 45 \\
\hline Process Bldg. (sq ft) & 42,000 & 58,000 & 46,000 & 42,000 & 58,000 \\
\hline
\end{tabular}


Table 3.2 Comparison of DUF6 Integrated Plant Cost Estimates






\section{Base Case: DUF6 Conversion to U3O8/AHF}

\subsection{Introduction}

About 700,000 metric tons (MT) of depleted uranium hexafluoride (DUF6) are currently stored at the Paducah, Portsmouth and Oak Ridge sites. Public Law 105-204 requires the DOE to submit to Congress a plan to ensure that all funds accrued on the books of USEC for disposition of DUF6 will be used for the construction and operation of plants to treat and recycle the DUF6. The Department of Energy's Initial Plan calls for construction to begin in the year 2002 time frame.

A base case conversion plant is presented in this section to examine the costs and issues involved in a 2002 time frame for construction start. This study case is based on a conversion plant using a dry process to convert DUF6 to uranium oxide (U3O8) and anhydrous hydrogen fluoride (AHF) as final products.

A preconceptual plant design, rough cost estimate, and preliminary project schedule were developed for four base case options (see Section 4.2). The conversion plant includes capabilities for DUF6 cylinder preparation, conversion of DUF6 to uranium oxide and fluorine byproducts, empty cylinder treatment for disposal, and interim storage for oxide and byproducts.

Significant design bases for the conversion plant include:

- The plant will convert DUF6 to U3O8 by a dry process. Hydrogen fluoride (HF) off-gas will be treated to produce $\mathrm{AHF}$ and a minor quantity of calcium fluoride $(\mathrm{CaF} 2)$.

- The plant capacity will be designed to process a DUF6 inventory of 36,910 cylinders $(450,000 \mathrm{MT}$ DUF6) over the life of the plant.

- Storage will be provided for one year production of $\mathrm{U} 3 \mathrm{O} 8$ and $\mathrm{CaF} 2$ product and two months production of AHF.

- The AHF product is sold by the DOE or plant owner (depending on the case options described in Section 4.2) to commercial users. The $\mathrm{U} 3 \mathrm{O} 8$ and $\mathrm{CaF} 2$ products are retained by the DOE, if the plant is government owned, or returned to the DOE, if the plant is privately owned.

- To bound costs associated with empty cylinders, assume all empty cylinders will be washed, compacted, and returned to the DOE for disposal.

- The plant will be located at a DOE owned site at or near a gaseous diffusion plant and include the support facilities and infrastructures/utilities needed for a greenfield facility.

- The design will consider addition of future process and storage buildings.

\subsection{Description of Case Options}

The construction and operation of the U3O8/AHF conversion plant is based on one of two basic scenarios: the plant will be government-owned and contractor-operated in conformance with DOE standards (GOCO), or the plant will be under private ownership and operation with DOE regulations (POPO). In addition, case options were developed for both 25-year operations and 15-year operations, which gives a total of four options. Where applicable, the differences between these four case options are discussed. 
For the POPO cases, the assumed guaranteed maximum feed rate per annum is the total quantity of DUF6 (450,000 MT) divided by the product of the total number of years assumed to process this quantity and the plant availability factor. The guaranteed minimum feed rate per annum is $95 \%$ of the guaranteed maximum feed rate. It is also assumed there is no government financing, i.e., private financing only.

\subsection{Summary of Results}

A 2002 construction start depends on the key milestone dates for site selection, selection of primary contractor and construction contractor, and construction approval. The schedule includes NEPA activities, as a site-specific Environmental Impact Study (EIS) will be required, and DOE regulatory activities. The amount of U3O8 storage provided affects cost and may need additional study. Process design criteria for DUF6 cylinder vaporization, conversion reaction chamber, HF distillation, and empty cylinder treatment are necessary to ensure successful facility design and operation.

Typical production data for the DUF6 to U3O8/AHF conversion plants for both 25-year and 15-year operations are presented in Table 4.1. A summary comparison of DUF6 conversion plant cost estimates for the four case options is provided in Table 4.2. For more cost estimate details, see Section 4.6.

Specific results for each of the four case options are summarized below.

\subsubsection{Government Owned and Government Operated with 25 Year Operations (GOCO/25)}

The plant annually processes 18,000 MT of DUF6 contained in 1,476 cylinders to produce 14,352 MT of U3O8, 5,962 MT of AHF, $269 \mathrm{MT}$ of CaF2, and 2,000 MT of empty cylinder metal waste. The plant, which includes a one year storage capacity for $\mathrm{U} 3 \mathrm{O} 8$ and $\mathrm{CaF} 2$ and two months storage capacity for AHF, occupies about 36 acres. Additional storage capacity would require about 5 acres for each year of additional U3O8 storage.

The construction capital cost estimate is $\$ 188$ million for the plant facilities. The engineering cost is about $\$ 34$ million. Each year of additional storage would be \$22 million for U3O8. These costs are in 1st Quarter FY2000 dollars.

The annual operation and maintenance (O\&M) cost is about $\$ 28$ million. The O\&M cost does not include disposal of empty cylinder metal. Cost for NEPA, regulatory and licensing activities are estimated at $\$ 5$ million. Decontamination and decommissioning (D\&D) cost is estimated at \$22 million.

The preliminary schedule assumes selection of an A/E contractor in June 2000. The schedule shows plant engineering design starting in July 2000, construction beginning in April 2002, plant completion in June 2004, and full operation beginning in December 2004. Peak engineering personnel is 80 persons and peak employment during construction is about 430 persons. Plant employment during operations is 189 persons.

\subsubsection{Government Owned and Government Operated with 15 Year Operations (GOCO/15)}

The plant annually processes 30,000 MT of DUF6 contained in 2,461 cylinders to produce 23,920 MT of U3O8, 9,936 MT of AHF, 449 MT of CaF2, and 3300 MT of empty cylinder metal waste. The plant, which includes a one year storage capacity for $\mathrm{U} 3 \mathrm{O} 8$ and $\mathrm{CaF} 2$ and two months storage capacity for AHF, occupies about 45 acres. Additional storage capacity would require about 7 acres for each year of additional U3O8 storage. 
The construction capital cost estimate is $\$ 262$ million for the plant facilities. The engineering cost is about $\$ 47$ million. Each year of additional storage would be $\$ 33$ million for U3O8. These costs are in 1st Quarter FY2000 dollars.

The annual operation and maintenance (O\&M) cost is about $\$ 35$ million. The O\&M cost does not include disposal of empty cylinder metal. Cost for NEPA, regulatory and licensing activities are estimated at $\$ 5$ million. Decontamination and decommissioning (D\&D) cost is estimated at \$31 million.

The preliminary schedule assumes selection of an A/E contractor in June 2000. The schedule shows plant engineering design starting in July 2000, construction beginning in April 2002, plant completion in December 2004, and full operation beginning in June 2005. Peak engineering personnel is 110 persons and peak employment during construction is about 510 persons. Plant employment during operations is 218 persons.

\subsubsection{Privately Owned and Privately Operated with 25 Year Operations (POPO/25)}

The plant annually processes 18,000 MT of DUF6 contained in 1,476 cylinders to produce 14,352 MT of U3O8, 5,962 MT of AHF, $269 \mathrm{MT}$ of CaF2, and 2,000 MT of empty cylinder metal waste. The plant, which includes a one year storage capacity for $\mathrm{U} 3 \mathrm{O} 8$ and $\mathrm{CaF} 2$ and two months storage capacity for AHF, occupies about 36 acres. Additional storage capacity would require about 5 acres for each year of additional $\mathrm{U} 3 \mathrm{O} 8$ storage.

The construction capital cost estimate is $\$ 172$ million for the plant facilities. The engineering cost is about \$25 million. Each year of additional storage would be \$20 million for U3O8. These costs are in 1st Quarter FY2000 dollars.

The annual operation and maintenance (O\&M) cost is about \$26 million. The O\&M cost does not include disposal of empty cylinder metal. Cost for NEPA, regulatory and licensing activities are estimated at $\$ 5$ million. Decontamination and decommissioning (D\&D) cost is estimated at \$20 million.

The preliminary schedule assumes selection of a private plant contractor in April 2000. The schedule shows plant engineering design starting in May 2000, construction beginning in November 2001, plant completion in January 2004, and full operation beginning in July 2004. Peak engineering personnel is 70 persons and peak employment during construction is about 400 persons. Plant employment during operations is 179 persons.

\subsubsection{Privately Owned and Privately Operated with 15 Year Operations (POPO/15)}

The plant annually processes 30,000 MT of DUF6 contained in 2461 cylinders to produce 23,920 MT of U3O8, $9936 \mathrm{MT}$ of AHF, $449 \mathrm{MT}$ of CaF2, and $3300 \mathrm{MT}$ of empty cylinder metal waste. The plant, which includes a one year storage capacity for $\mathrm{U} 3 \mathrm{O} 8$ and $\mathrm{CaF} 2$ and two months storage capacity for AHF, occupies about 45 acres. Additional storage capacity would require about 7 acres for each year of additional U3O8 storage.

The construction capital cost estimate is $\$ 240$ million for the plant facilities. The engineering cost is about $\$ 34$ million. Each year of additional storage would be \$30 million for U3O8. These costs are in 1st Quarter FY2000 dollars.

The annual operation and maintenance (O\&M) cost is about $\$ 33$ million. The O\&M cost does not include disposal of empty cylinder metal. Cost for NEPA, regulatory and licensing activities are estimated at \$5 million. Decontamination and decommissioning (D\&D) cost is estimated at \$27 million. 
The preliminary schedule assumes selection of a private plant contractor in April 2000. The schedule shows plant engineering design starting in May 2000, construction beginning in November 2001, plant completion in July 2004, and full operation beginning in January 2005. Peak engineering personnel is 90 persons and peak employment during construction is about 480 persons. Plant employment during operations is 208 persons.

\subsection{Conversion Process Description}

Depleted uranium hexafluoride (DUF6) is processed to produce U3O8 and AHF. For 25-year operation, the average throughput is 5 cylinders per day $(5,670 \mathrm{lb} / \mathrm{hr}$ UF6). For 15 -year operation the average throughput is 8.5 cylinders per day $(9,450 \mathrm{lb} / \mathrm{hr}$ UF6). These figures are based on $80 \%$ plant availability (7,000 hours/yr or 292 days/yr). The process block flow diagrams are shown in Figures 4.1a and 4.1b, respectively. For 25-year operation, major process equipment includes four steam autoclaves, six hot air ovens, four reaction chamber lines, U3O8 compaction and bin loading system, an HF distillation system, off-gas scrubbing system, neutralization/grouting system, two empty cylinder washing machines and one cylinder crusher. For 15-year operation, major process equipment includes six steam autoclaves, nine hot air ovens, six reaction chamber lines, U3O8 compaction and bin loading system, two HF distillation systems, off-gas scrubbing system, neutralization/grouting system, four empty cylinder washing machines and one cylinder crusher.

The DUF6 is shipped by truck from the cylinder yards at the gaseous diffusion plant to an outdoor storage pad at the Conversion Facility. The cylinder is moved into the Process Building for inspection and preparation. The cylinders are loaded into steam-heated autoclaves to vaporize the DUF6 for feeding into the conversion process. Cylinders with questionable integrity are loaded into hot air ovens where the solid DUF6 sublimes into a gas under vacuum. This avoids melting the DUF6 and pressurizing the cylinder, which occurs when using an autoclave. Several of the cylinders may be substandard based on the DUF6 Engineering Analysis Report (p. 6.1-4-5). Four autoclaves and six ovens are provided for 25-year operation; six autoclaves and nine ovens are provided for 15-year operation.

The DUF6 gas is converted to U3O8 in a series of two reaction chambers, where it is mixed with an $\mathrm{HF} /$ water vapor mixture in the first reaction chamber and with steam in the second reaction chamber. The chemical reactions are:

$\mathrm{UF} 6+2 \mathrm{H}_{2} \mathrm{O}--->\mathrm{UO}_{2} \mathrm{~F}_{2}+4 \mathrm{HF}$

$3 \mathrm{UO}_{2} \mathrm{~F}_{2}+3 \mathrm{H}_{2} \mathrm{O}--->\mathrm{U} 3 \mathrm{O} 8+6 \mathrm{HF}+0.5 \mathrm{O}_{2}$

For 25-year operation, four reaction lines are provided to meet the required throughput. (Six lines are provided in the 15-year scenario). The U3O8 product is cooled, compacted to increase its bulk density, and packaged in metal bins. The $100 \mathrm{cu} f t$ bins are about $4 \times 4 \times 7 \mathrm{ft}$ tall and hold 9 tons (8.16 MT) of U3O8. The filled bins are transferred to the U3O8 Storage Building.

Reaction chamber off-gas containing HF, steam and oxygen is filtered to remove uranium particulates. The off-gas then flows to an HF distillation system, which concentrates the mixture to produce anhydrous HF in the overhead product. The AHF is collected, sampled, and pumped to large storage tanks in the HF Storage Building, where the AHF is loaded into railcars or tank trucks for delivery to customers. The AHF is expected to contain less than $1 \mathrm{ppm}$ uranium.

The aqueous hydrogen fluoride bottoms stream from HF distillation is collected, vaporized and recycled to the first reaction chamber. To prevent the buildup of impurities in the recycle stream, a small fraction is 
withdrawn. This purge stream is neutralized with hydrated lime, mixed with cement and water to form a grout, and packaged in drums for disposal.

Off-gas from the distillation column, primarily oxygen and air inleakage, flows to the scrubber system. Residual HF in the off-gas is removed by scrubbing with a potassium hydroxide (KOH) solution. The offgas is then HEPA-filtered and discharged to the atmosphere. The spent scrub solution is regenerated with hydrated lime $\left(\mathrm{Ca}(\mathrm{OH})_{2}\right)$, which produces a calcium fluoride $(\mathrm{CaF} 2)$ byproduct. The chemical reactions are:

$\mathrm{HF}+\mathrm{KOH}--->\mathrm{KF}+\mathrm{H}_{2} \mathrm{O}$

$2 \mathrm{KF}+\mathrm{Ca}(\mathrm{OH})_{2}--->\mathrm{CaF} 2+2 \mathrm{KOH}$

The CaF2 is separated by filtering, washed with water, dried and loaded into drums. The drums, containing $700 \mathrm{lb}$ of $\mathrm{CaF} 2$, are transferred to the $\mathrm{CaF} 2$ Storage Building. The $\mathrm{CaF} 2$ is expected to contain less than 1 ppm uranium.

After vaporization, the empty cylinders are transferred to an outdoor pad and stored for three months. This allows for radioactive decay of non-volatile daughter products in the cylinder. The cylinders are then brought into the Process Building, washed with water, crushed, and loaded into boxes. Each $6 \times 14 \times 3 \mathrm{ft}$ high box contains about 9,000 lb of metal from three crushed cylinders. The filled boxes are stored in the Waste Storage Building and transported to the gaseous diffusion plant for disposition. The cylinder wash effluents are fed into the main conversion processes. Major process materials and annual quantities are summarized below: 


\begin{tabular}{|c|c|}
\hline Major Input Streams & Major Output Streams \\
\hline \multicolumn{2}{|l|}{ GOCO and POPO 25 years } \\
\hline $\begin{array}{l}\text { Depleted Uranium Hexafluoride } \\
18,000 \mathrm{MT} / \mathrm{yr} \\
1476 \text { cylinders/yr }\end{array}$ & $\begin{array}{l}\text { Uranium Oxide (U3O8) } \\
14,352 \mathrm{MT} / \mathrm{yr} \\
17584 \times 4 \times 7(\mathrm{H}) \mathrm{ft} \text { bins/yr }(18,000 \mathrm{lb} / \mathrm{bin}) \\
\text { or } 24,34455 \text {-gal drums/yr }(1300 \mathrm{lb} / \mathrm{drum})\end{array}$ \\
\hline $\begin{array}{l}\text { Hydrated Lime } \mathrm{Ca}(\mathrm{OH}) 2 \\
325 \mathrm{MT} / \mathrm{yr} \\
8700 \mathrm{ft} 3 / \mathrm{yr}\end{array}$ & $\begin{array}{l}\text { Anhydrous Hydrogen Fluoride (HF) } \\
5962 \mathrm{MT} / \mathrm{yr} \\
1.64 \mathrm{million} \mathrm{gal} / \mathrm{yr}\end{array}$ \\
\hline \multirow[t]{3}{*}{$\begin{array}{l}\text { Cement } \\
154 \mathrm{MT} / \mathrm{yr} \\
2900 \mathrm{ft} 3 / \mathrm{yr}\end{array}$} & $\begin{array}{l}\text { Calcium Fluoride }(\mathrm{CaF} 2) \\
269 \mathrm{MT} / \mathrm{yr} \\
848 \text { 55-gal drums/yr }(700 \mathrm{lb} / \mathrm{drum})\end{array}$ \\
\hline & $\begin{array}{l}\text { Empty Cylinder Metal Waste } \\
2000 \mathrm{MT} / \mathrm{yr} \\
4926 \mathrm{x} 14 \mathrm{x} 3(\mathrm{H}) \mathrm{ft} \text { boxes/yr }(9000 \mathrm{lb} / \text { box })\end{array}$ \\
\hline & $\begin{array}{l}\text { Grouted Waste } \\
367 \mathrm{MT} / \mathrm{yr} \\
101255 \text {-gal drums/yr (800 lb/drum) }\end{array}$ \\
\hline \multicolumn{2}{|l|}{ GOCO and POPO 15 years } \\
\hline $\begin{array}{l}\text { Depleted Uranium Hexafluoride } \\
30,000 \mathrm{MT} / \mathrm{yr} \\
2461 \text { cylinders/yr }\end{array}$ & $\begin{array}{l}\text { Uranium Oxide (U3O8) } \\
23,920 \mathrm{MT} / \mathrm{yr} \\
29304 \times 4 \times 7(\mathrm{H}) \mathrm{ft} \text { bins/yr }(18,000 \mathrm{lb} / \mathrm{bin}) \\
\text { or } 40,57255 \text {-gal drums/yr }(1300 \mathrm{lb} / \mathrm{drum})\end{array}$ \\
\hline $\begin{array}{l}\text { Hydrated Lime } \mathrm{Ca}(\mathrm{OH}) 2 \\
542 \mathrm{MT} / \mathrm{yr} \\
14,500 \mathrm{ft} 3 / \mathrm{yr}\end{array}$ & $\begin{array}{l}\text { Anhydrous Hydrogen Fluoride (HF) } \\
9936 \mathrm{MT} / \mathrm{yr} \\
2.73 \mathrm{million} \mathrm{gal} / \mathrm{yr}\end{array}$ \\
\hline \multirow[t]{3}{*}{$\begin{array}{l}\text { Cement } \\
257 \mathrm{MT} / \mathrm{yr} \\
4900 \mathrm{ft} 3 / \mathrm{yr}\end{array}$} & $\begin{array}{l}\text { Calcium Fluoride (CaF2) } \\
449 \mathrm{MT} / \mathrm{yr} \\
141455 \text {-gal drums/yr (700 lb/drum) }\end{array}$ \\
\hline & $\begin{array}{l}\text { Empty Cylinder Metal Waste } \\
3300 \mathrm{MT} / \mathrm{yr} \\
8206 x 14 \mathrm{x} 3(\mathrm{H}) \mathrm{ft} \text { boxes/yr }(9000 \mathrm{lb} / \mathrm{box})\end{array}$ \\
\hline & $\begin{array}{l}\text { Grouted Waste } \\
612 \mathrm{MT} / \mathrm{yr} \\
168755 \text {-gal drums/yr (800 lb/drum) }\end{array}$ \\
\hline
\end{tabular}




\subsection{Conversion Plant Description}

The Conversion Facility is assumed to be constructed on a DOE site at a greenfield location at or near a gaseous diffusion plant. The Conversion Facility occupies about 36 acres (25-year operation) or about 45 acres (15-year operation). Additional storage buildings for U3O8 could be built adjacent or at a nearby location. Each additional one year increment of U3O8 storage occupies 5 acres (25-year operation) or about 7 acres (15-year operation). Conceptual site plans for the Conversion Facility are shown in Figures $4.2 \mathrm{a}$ and $4.2 \mathrm{~b}$.

The Conversion Facility includes full and empty cylinder storage pads, the Process Building, a U3O8 Storage Building, an HF Storage Building, a CaF2 Storage Building, a Waste Storage Building and support facilities. The site plan considers addition of future process facilities such as uranium metal or sintered uranium pellets.

The Conversion Facility will be designed and constructed in compliance with DOE Orders and applicable regulations and codes, and will meet the intent of NRC standards. In general, a graded approach as established in DOE Order 420.1 is used for the design of all structures, systems, and components (SSC) in the plant facilities. All SSC's will be assigned a Natural Phenomena Performance Category using the criteria in the DOE Standards DOE-STD-1020-94 and DOE-STD-1021-93 during the design phase.

In the absence of a hazard analysis, it is assumed that the Process Building is performance category PC-3 to control and confine hazardous material. The building structure is reinforced concrete construction in the processing areas. The remainder of the building housing the personnel support area is steel frame, metal siding construction. The Process Building is $30 \mathrm{ft} \mathrm{high} \mathrm{in} \mathrm{the} \mathrm{processing} \mathrm{areas} \mathrm{and} 18 \mathrm{ft}$ high in the support areas. HVAC equipment is located on a mezzanine level. The process room air is filtered through one stage of HEPA filters prior to discharge to atmosphere. The Process Building general arrangements are shown in Figures 4.3a and 4.3b.

The U3O8 Storage Building and CaF2 Storage Building have a one year capacity. For 25-year operation, the U3O8 Building holds 1,760 bins stacked one high, and the CaF2 Building holds 850 drums stacked two high. For 15-year operation, the U3O8 Building holds 2,960 bins stacked one high, and the CaF2 Building holds 1,420 drums stacked two high. The Waste Building has a one month capacity for staging treated empty cylinders and process waste for transport offsite. The U3O8, CaF2, and waste storage buildings are assumed PC-2 to maintain storage function after the occurrence of a natural phenomena hazards event. These buildings are steel frame and concrete clad panel construction and are ventilated and lighted, but no heating, cooling or HEPA filtration is provided. Access aisles allow personnel to inspect the bins during storage. A general storage arrangement in the U3O8 Building is shown in Figure 4.4a and Figure 4.4b.

The HF Storage Building has a two month capacity with ten or sixteen 34,000-gallon storage tanks (25year operation and 15-year operation, respectively). The HF Storage Building is assumed PC-3 to control and confine hazardous material. The building structure is reinforced concrete construction. The HF storage tanks are housed separately in cell rooms.

Plant operations are assumed to be continuous for 24 hours/day, 7 days/week, 52 weeks/year. Due to seven day per week operation, a fourth shift is necessary to account for normal days off for employees. For GOCO 25-year operation, the number of employees during operation is estimated to be 189 persons, with 69 employees on day shift and 40 each of the other three shifts. For GOCO 15-year operation, the number of employees during operation is estimated to be 218 persons, with 77 employees on day shift and 47 each of the other three shifts. For POPO 25-year operation, the number of employees during operation is estimated to be 179 persons, with 65 employees on day shift and 38 each of the other three 
shifts. For POPO 15-year operation, the number of employees during operation is estimated to be 208 persons, with 73 employees on day shift and 45 each of the other three shifts.

No allowance is included for plant medical or fire fighting personnel.

The numbers are estimated based on process operation labor and facility support labor requirements needed to operate the plant. See Table 4.3 for typical manpower estimates.

\subsection{Cost Estimates}

The cost estimates are rough order of magnitude estimates based on a preconceptual level design information.

The estimates do not include costs for plant design criteria development, cost of land, site qualifications, or extension of local roads and utility lines to the site boundary. The estimates take into account the procurement pricing, labor productivity, and indirect cost factors for a government project. Cost estimate bases are described in the Appendix.

The cost estimate results are summarized below:

\begin{tabular}{|c|c|c|c|c|c|c|}
\hline & \multicolumn{6}{|c|}{ Government Owned and Government Operated Plant } \\
\hline & \multicolumn{3}{|c|}{ 15-Year Operation } & \multicolumn{3}{|c|}{ 25-Year Operation } \\
\hline & $\begin{array}{l}\text { Cost } \\
(\$ M)\end{array}$ & $\begin{array}{l}\text { Contin- } \\
\text { gency (\$M) }\end{array}$ & $\begin{array}{l}\text { Total Cost } \\
\quad \text { (\$M) }\end{array}$ & $\begin{array}{l}\text { Cost } \\
\text { \$M) }\end{array}$ & $\begin{array}{c}\text { Contin- } \\
\text { gency }(\$ \mathbf{M})\end{array}$ & $\begin{array}{c}\text { Total } \\
\text { Cost \$M }\end{array}$ \\
\hline \multicolumn{7}{|l|}{ Conversion Facility } \\
\hline Engineering & -- & -- & 47 & -- & -- & 34 \\
\hline $\begin{array}{l}\text { Plant Facilities } \\
\text { Construction Cost }\end{array}$ & 194 & 68 & 262 & 139 & 49 & 188 \\
\hline Startup Cost & -- & -- & 14 & -- & -- & 12 \\
\hline $\begin{array}{l}\text { Annual Operations and } \\
\text { Maintenance Cost (O\&M) }\end{array}$ & -- & -- & 35 & -- & -- & 28 \\
\hline $\begin{array}{l}\text { Decontamination and } \\
\text { Decommissioning (D\&D) }\end{array}$ & -- & -- & 31 & -- & -- & 22 \\
\hline \multicolumn{7}{|l|}{ Additional Storage } \\
\hline Engineering & -- & -- & 2.6 & -- & -- & 1.8 \\
\hline $\begin{array}{l}\text { U3O8 Storage } \\
\text { (1 yr capacity) } \\
\text { Construction Cost }\end{array}$ & 29 & 4 & 33 & 19 & 3 & 22 \\
\hline NEPA/Licensing & -- & -- & 5 & -- & -- & 5 \\
\hline
\end{tabular}




\begin{tabular}{|c|c|c|c|c|c|c|}
\hline & \multicolumn{6}{|c|}{ Privately Owned and Privately Operated Plant } \\
\hline & \multicolumn{3}{|c|}{ 15-Year Operation } & \multicolumn{3}{|c|}{ 25-Year Operation } \\
\hline & $\begin{array}{l}\text { Cost } \\
(\$ M)\end{array}$ & $\begin{array}{c}\text { Contin- } \\
\text { gency }(\$ M)\end{array}$ & $\begin{array}{l}\text { Total Cost } \\
\quad(\$ M)\end{array}$ & $\begin{array}{l}\text { Cost } \\
(\$ M)\end{array}$ & $\begin{array}{l}\text { Contin- } \\
\text { gency }(\$ M)\end{array}$ & $\begin{array}{c}\text { Total Cost } \\
\$ M\end{array}$ \\
\hline \multicolumn{7}{|l|}{ Conversion Facility } \\
\hline Engineering & -- & -- & 34 & -- & -- & 25 \\
\hline $\begin{array}{l}\text { Plant Facilities } \\
\text { Construction Cost }\end{array}$ & 178 & 62 & 240 & 128 & 44 & 172 \\
\hline Startup Cost & -- & -- & 14 & -- & -- & 12 \\
\hline $\begin{array}{l}\text { Annual Operations and } \\
\text { Maintenance Cost (O\&M) }\end{array}$ & -- & -- & 33 & -- & -- & 26 \\
\hline $\begin{array}{l}\text { Decontamination and } \\
\text { Decommissioning (D\&D) }\end{array}$ & -- & -- & 27 & -- & -- & 20 \\
\hline \multicolumn{7}{|l|}{ Additional Storage } \\
\hline Engineering & -- & -- & 2.4 & -- & -- & 1.6 \\
\hline $\begin{array}{l}\text { U3O } 8 \text { Storage } \\
\text { ( } 1 \text { yr capacity) Construction } \\
\text { Cost }\end{array}$ & 26 & 4 & 30 & 18 & 2 & 20 \\
\hline NEPA/Licensing & -- & -- & 5 & -- & -- & 5 \\
\hline
\end{tabular}

The construction capital costs are based on an engineering, procurement, and construction approach for a government project. Capital costs, see Tables 4.4a and 4.4b, are reported in 1st quarter fiscal year 2000 dollars (October 1999). Labor costs are based on local wage rates at a generic gaseous diffusion plant located in mid-U.S.A. The capital cost estimate utilized historical cost data, estimating manuals, allowances and budgetary quotations. A 35\% contingency was applied to the capital costs for the Conversion Facility and 15\% for the subsequent Storage Facilities. These contingency levels are based on previous risk analysis on projects of similar scope and level of design details. Engineering cost was estimated at $18 \%$ of the capital costs for the Conversion Facility and $8 \%$ for the subsequent Storage Facilities. The lower percentages are used for the subsequent Storage Facilities because previous building engineering design can be reused. Product and waste container costs are included in the O\&M costs. The D\&D cost was estimated as $10 \%$ of the capital cost.

The O\&M cost includes costs for materials, utilities, labor, waste disposal, and management and operation (M\&O) contractor fees, see Tables $4.5 \mathrm{a}$ and $4.5 \mathrm{~b}$. Plant startup cost was assumed to be $65 \%$ of the annual O\&M labor cost. The annual O\&M cost does not include the cost for disposal of empty cylinder metal waste. If the empty cylinder metal is to be disposed as low-level waste (LLW), the estimated disposal cost for 25-year operation would range from $\$ 1$ million to $\$ 12$ million annually, depending on the disposal sites. For 15-year operation, the corresponding estimated disposal cost ranges from $\$ 1.7$ million to $\$ 20$ million. Revenue from sales of AHF is also not included in the O\&M cost.

The annual expenditure required to support the construction and operation of the conversion plant case options are provided in Figures 4.6 through 4.11. The expenditure profiles are derived from loading the 
estimated capital and operating costs onto the project schedule. A constant FY2000 dollar value is used in the expenditure outlay because of the difficulty in accurately projecting the inflation rate for future years.

The life-cycle funding outlays for the various case options are summarized in the bottom line of Table 4.2. Note that byproduct sale revenue and construction loan interest are included. In the POPO cases, the total outlay is a break-even government payment that doesn't include profit. In addition to a 10-year payback time for the POPO cases, the expenditure outlays for a 5-year payback time were developed. The break-even payment for 5-year payback in the 15 -year POPO case is $\$ 738 \mathrm{M}$ as opposed to $\$ 827 \mathrm{M}$ for a 10 -year payback; and $\$ 779 \mathrm{M}$ as opposed to $\$ 845 \mathrm{M}$ in the 25 -year POPO case.

\subsection{Project Schedules}

The estimated preliminary project schedules are shown in Figures 4.5 to 4.8 . The schedule is based on a fast track premise with overlapping engineering phases and early procurement of some key equipment (most equipment is available in 12-18 month lead time) and a two-phase construction plan.

The reader is advised to consider these schedules illustrative, rather than definitive. There are large uncertainties in the timing or delays in the DOE regulatory processes leading to full operations.

\subsubsection{GOCO/25}

The schedule allows 3 years for engineering design and 2 years for construction. The estimated peak engineering personnel is 80 persons and peak employment during construction is 430 persons.

\subsubsection{GOCO/15}

The schedule allows 3 years for engineering design and 2.5 years for construction. The estimated peak engineering personnel is 110 persons and peak employment during construction is 510 persons.

\subsubsection{POPO/25}

The schedule allows 2.5 years for engineering design and 2 years for construction. The estimated peak engineering personnel is 70 persons and peak employment during construction is 400 persons.

\subsubsection{POPO/15}

The schedule allows 2.5 years for engineering design and 2.5 years for construction. The estimated peak engineering personnel is 90 persons and peak employment during construction is 480 persons.

\subsection{Discussion and Issues}

\subsubsection{Process}

Bins were used to package the U3O8 because of the space savings compared to 55-gallon drums. Using bins instead of drums reduces the storage building area by about $35 \%$. Additional study is needed to determine the best storage container to use with the cost considerations on facilities and transport.

In cylinder washing, the empty cylinders are cleaned to remove the reactive fluoride materials inside the cylinder. It was assumed that the metal from washed empty cylinders is returned to the DOE for disposal. The residual uranium contaminated cylinders might require the cylinder metal to be disposed of as LLW. Alternate dispositions include recycling and reusing the radioactively-contaminated carbon steel for LLW 
containers for use in the nuclear industry or sufficiently decontaminating the metal for disposal as nonhazardous waste or scrap.

\subsubsection{Facilities}

Buildings for processing and storage were assumed to be performance category PC-2 or PC-3. A safety and accident analysis was not performed and is needed to determine the hazard classification and performance category. The appropriate structure, confinement and ventilation for buildings housing large quantities of U3O8 needs study.

The DUF6 Engineering Analysis Report has identified issues with federal (49CFR173.420) or ANSI N14.1 transportation requirements and overpressured, overfilled or substandard cylinders. The Report suggests that a new overpack be designed and licensed if filled substandard cylinders must be shipped from off-site. The cost of overpacks is not considered in the report. This transportation issue still needs to be resolved.

The preconceptual plant design is essentially a single line plant. Multiple autoclaves, ovens, and conversion reaction chambers are provided to obtain the design throughput. The HF distillation system, off-gas scrubber, and impurity neutralization units are single line systems with installed spares on maintenance-prone items such as pumps and filters. A RAM (reliability, availability, maintainability) analysis may help determine if this configuration is satisfactory and whether independent parallel lines might be desirable.

\subsubsection{Cost Estimates}

The cost estimates vary depending on the scenario under discussion, and differ depending on whether the plant is government owned and contractor operated or privately owned and operated. The major contributors to the capital cost are the Process Building including the structure and service systems. The major process equipment costs are the cylinder handling crane, autoclaves, hot air ovens and DUF6 compressors, conversion reaction chambers, distillation equipment, and cylinder tilt and roll wash stands. The cost to dispose of empty cylinder metal is not included in this report. If it is disposed as LLW, the disposal cost could be significant.

\subsubsection{Schedule}

The schedule shows a construction start early in the second quarter of year 2002. This appears to be attainable if the site selection, selection of contractor, and early approval for construction dates are met. The Record of Decision is expected to be issued by the end of June per the schedule shown in this report.

\subsection{References}

Initial Plan for the Conversion of Depleted Uranium Hexafluoride, as Required by Public Law 105-204, U.S. Department of Energy, 1999

Draft Engineering Analysis Report for the Long-Term Management of Depleted Uranium Hexafluoride, UCRL-AR-124080, Lawrence Livermore National Laboratory, May 1997

Uranium Hexafluoride: A Manual of Good Handling Practices, ORO-651, U.S. Department of Energy, October 1991 




Figure 4.1a Process Block Flow Diagram

Conversion to U3O8 and AHF (25 yr) 


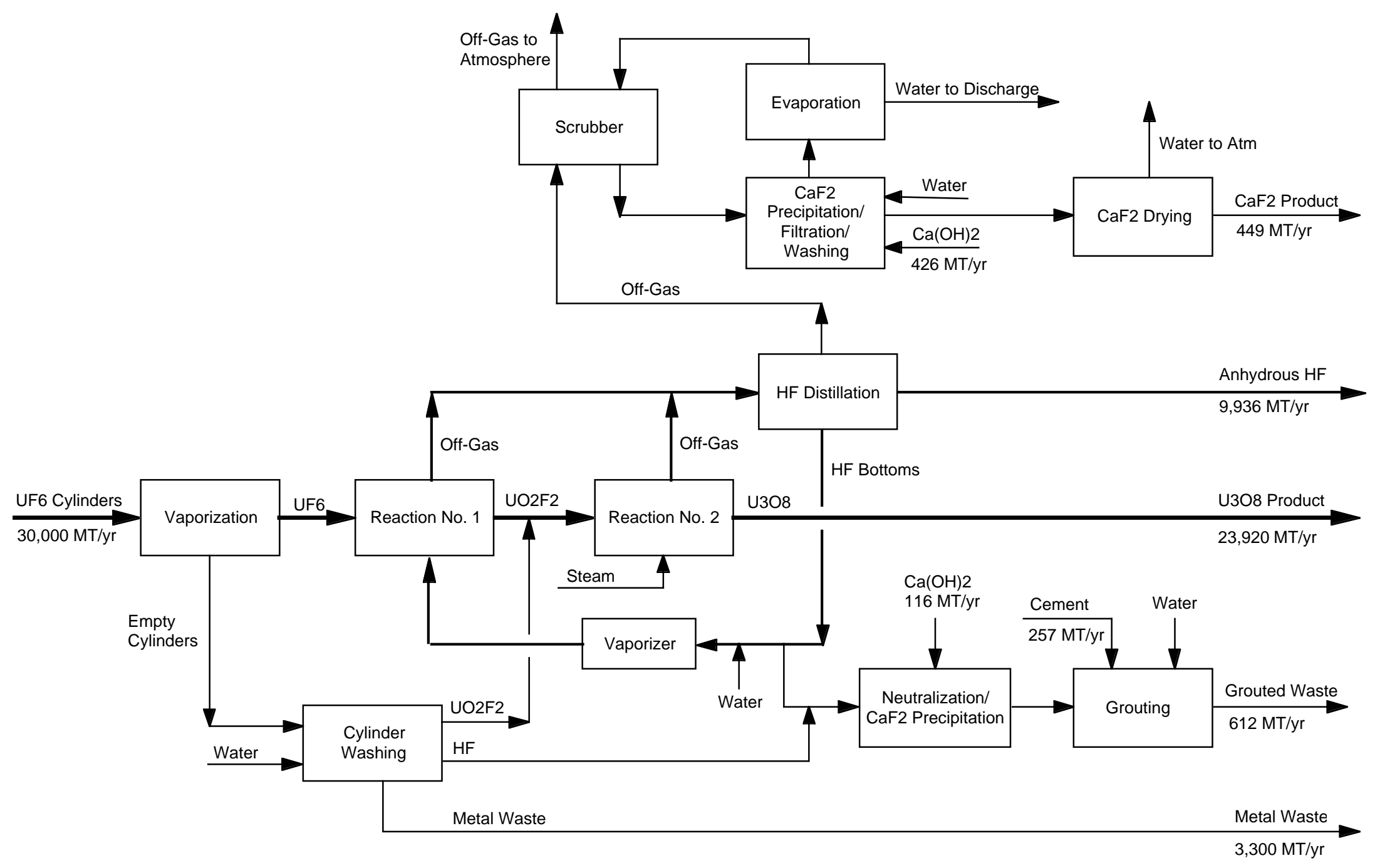

Figure 4.1b Process Block Flow Diagram

Conversion to U3O8 and AHF (15 yr) 


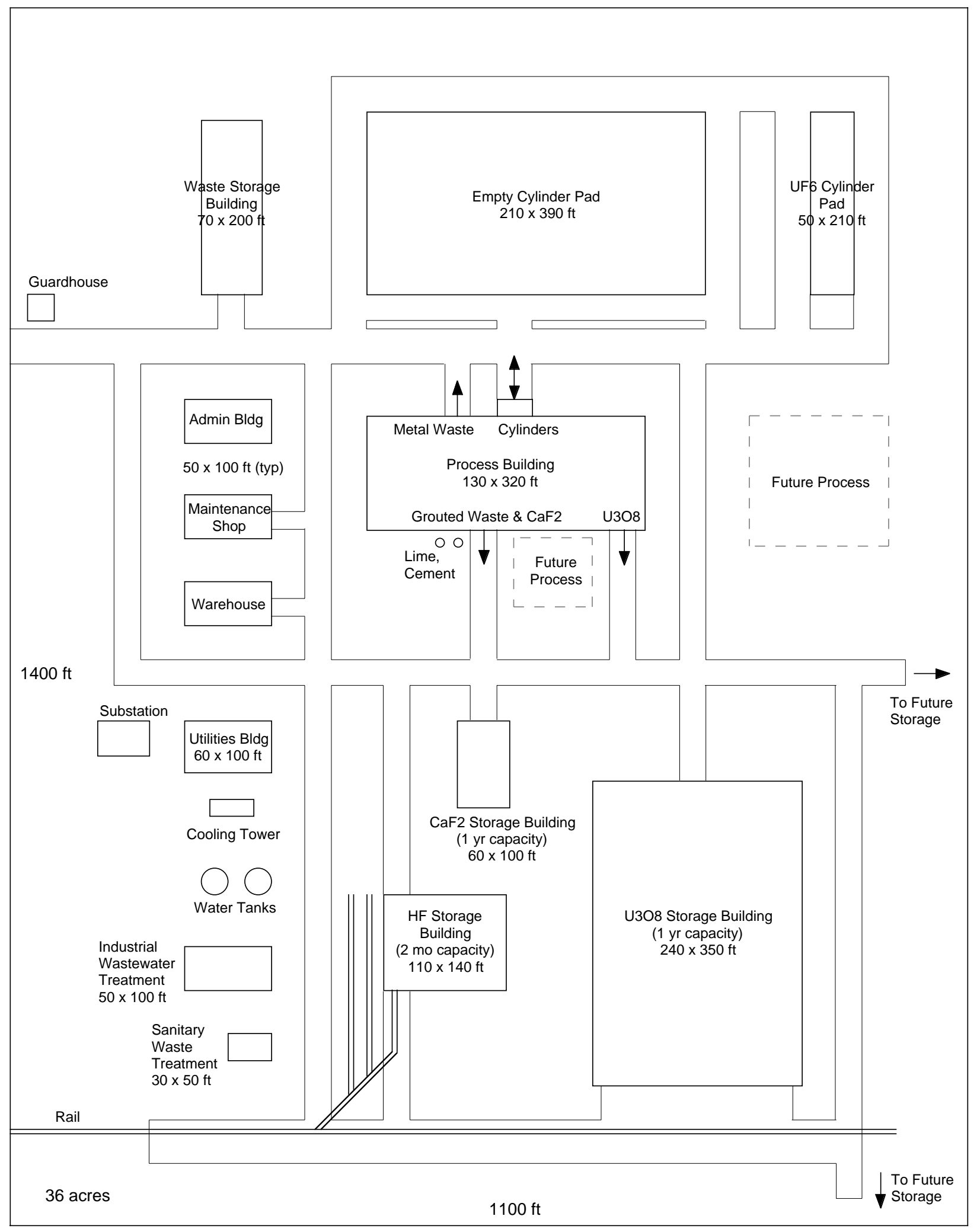

Figure 4.2a Facility Site Plan

Conversion to U3O8 and AHF (25 yr) 


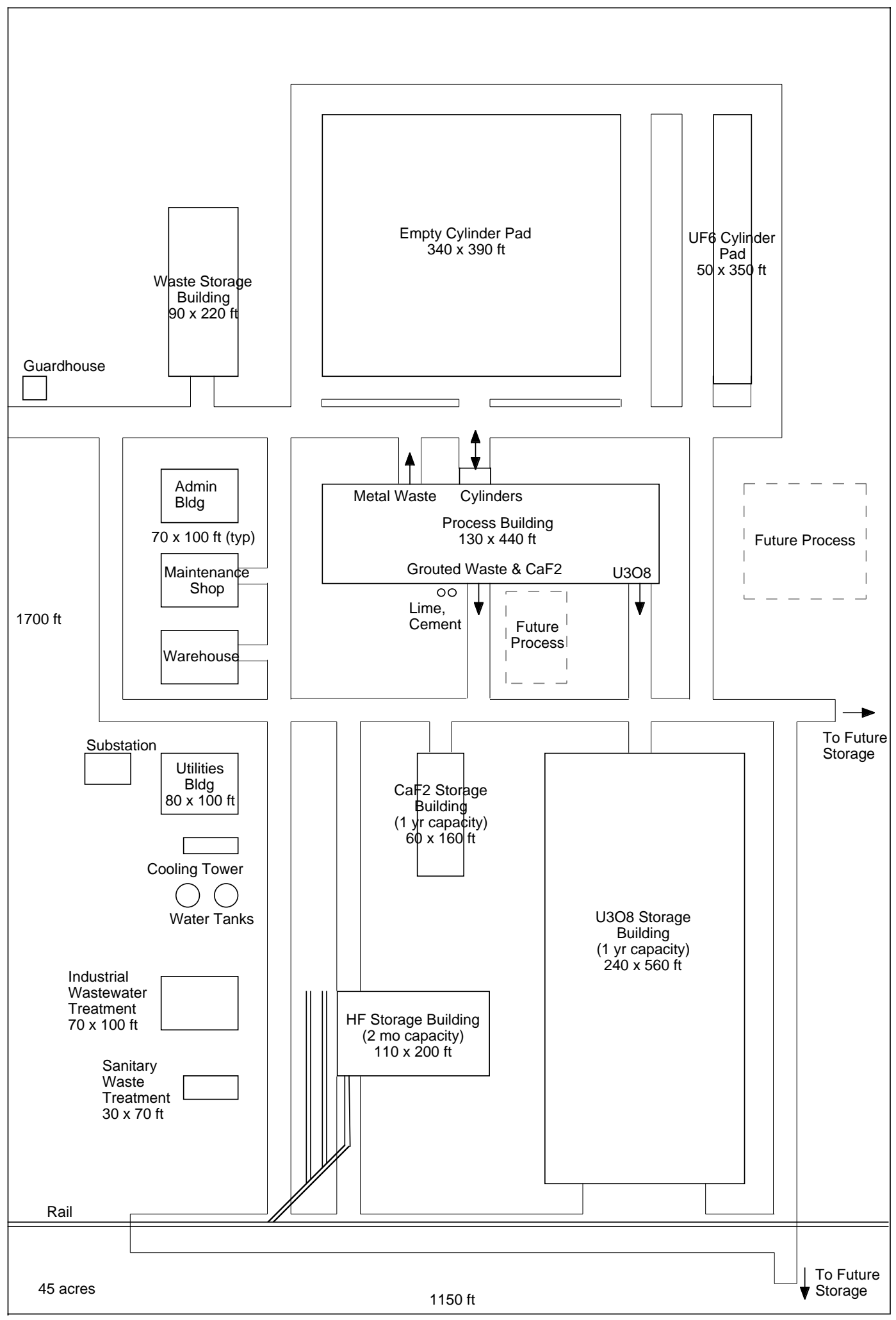

Figure 4.2b Facility Site Plan

Conversion to U3O8 and AHF (15 yr) 


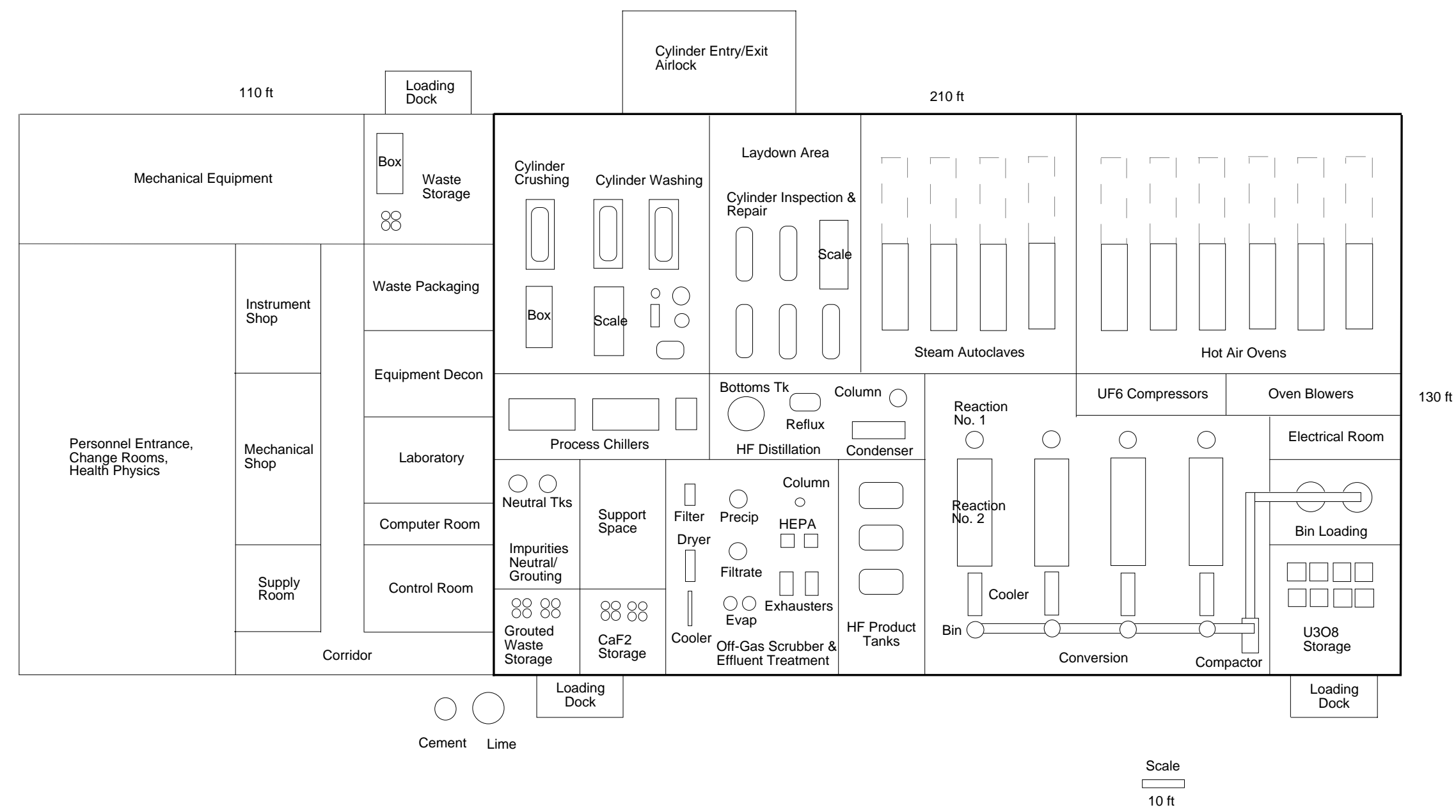

Figure 4.3a Process Building General Arrangement Conversion to U3O8 and AHF (25 yr) 


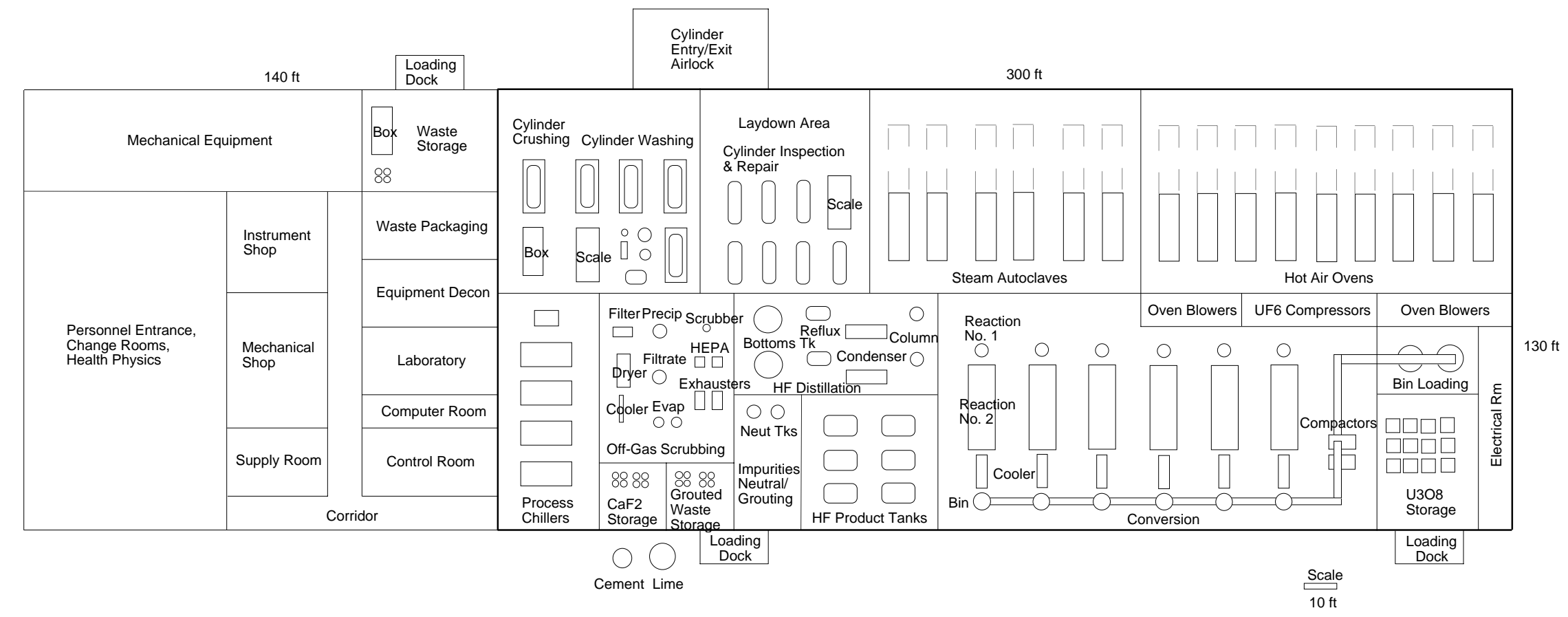

Figure 4.3b Process Building General Arrangement

Conversion to U3O8 and AHF (15 yr) 


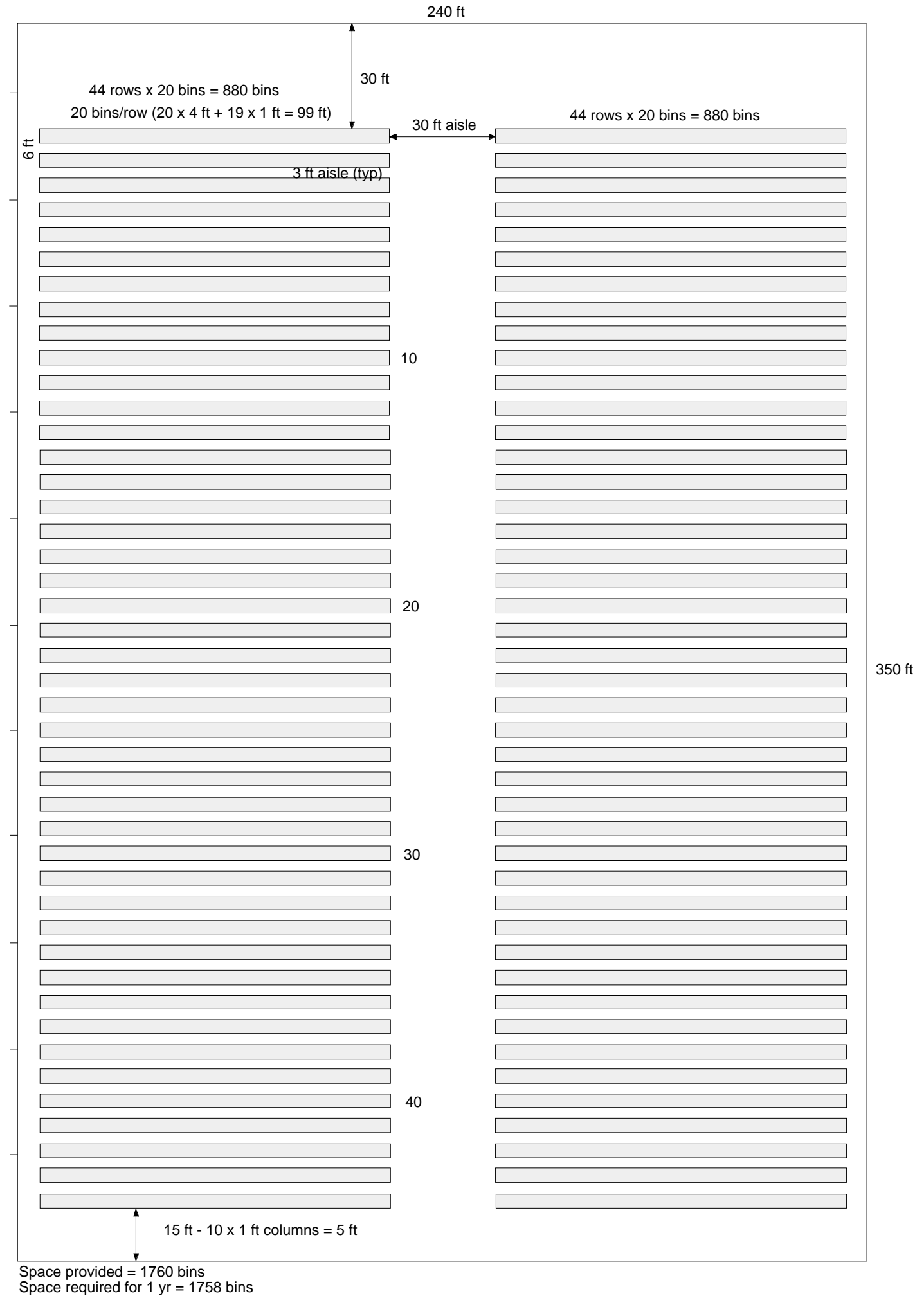

Figure 4.4a U3O8 Storage Building Plan

Conversion to U3O8 and AHF (25 yr) 


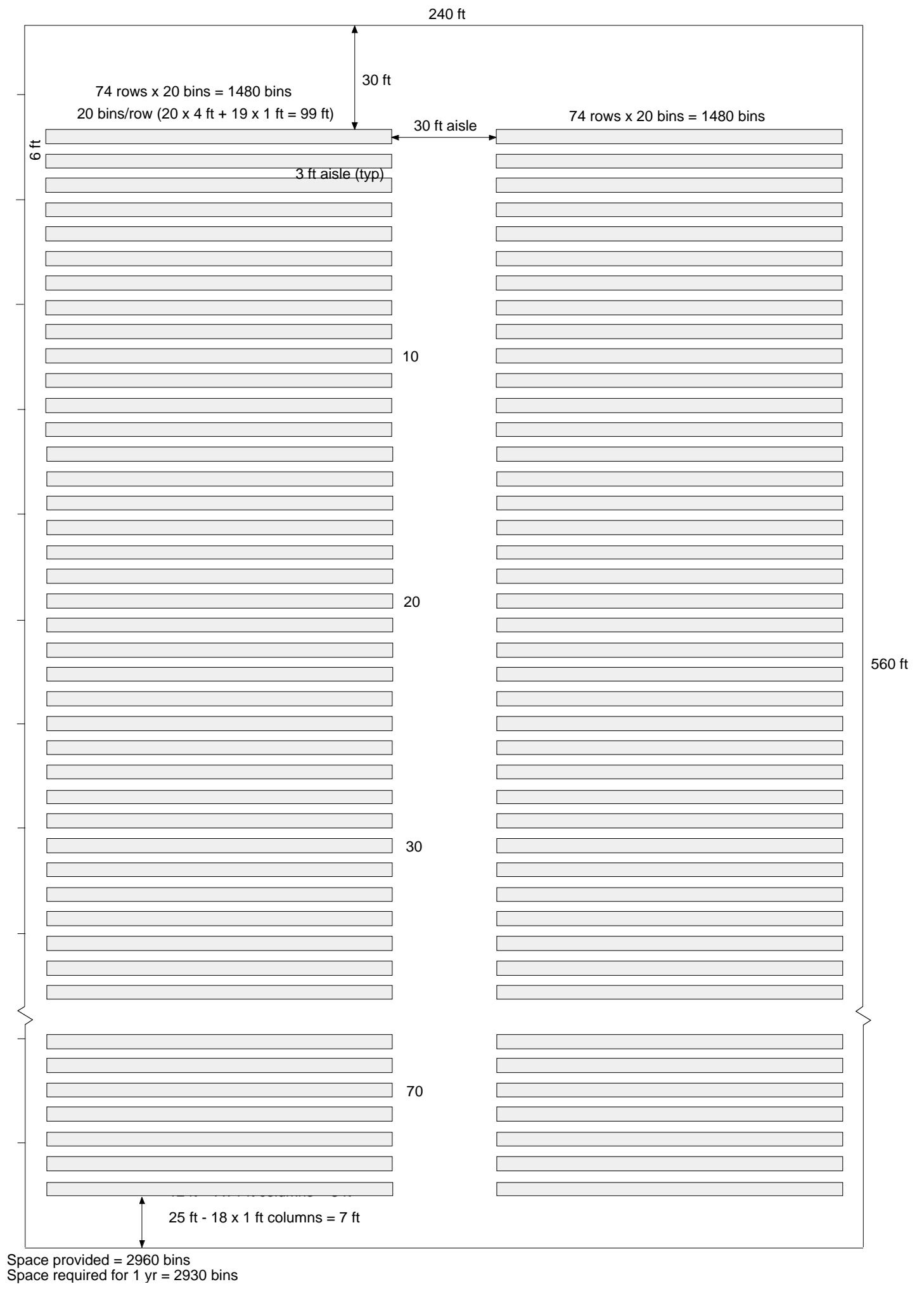

Figure 4.4b U3O8 Storage Building Plan Conversion to U3O8 and AHF (15 yr) 


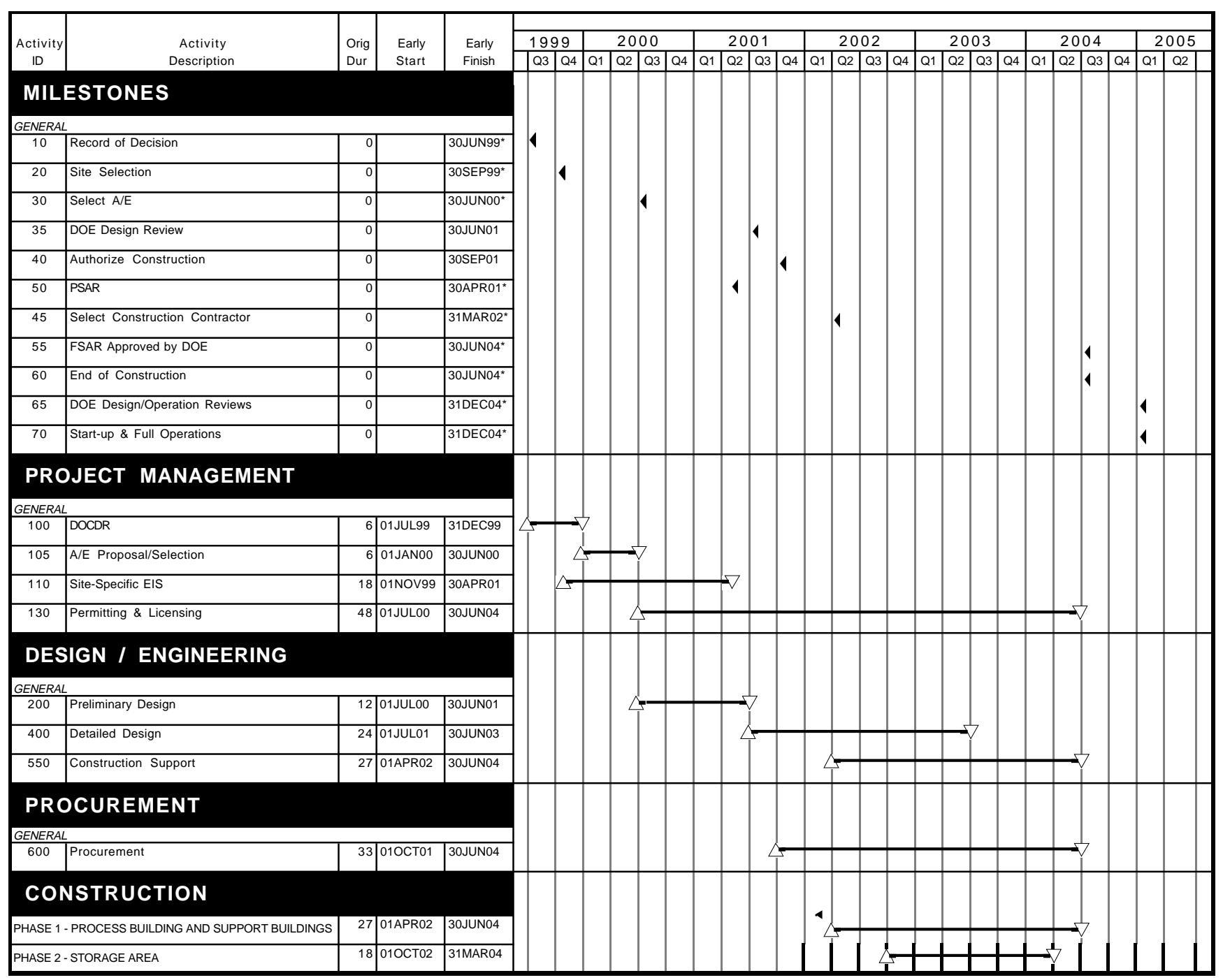

Figure 4.5 U3O8/AHF Plant, 25 Year Government Owned and Contractor Operated Preliminary Project Schedule 




Figure 4.6 U3O8/AHF Plant, 15 Year Government Owned and Contractor Operated Preliminary Project Schedule 




Figure 4.7 U3O8/AHF Plant, 25 Year Privately Owned and Operated Preliminary Project Schedule 


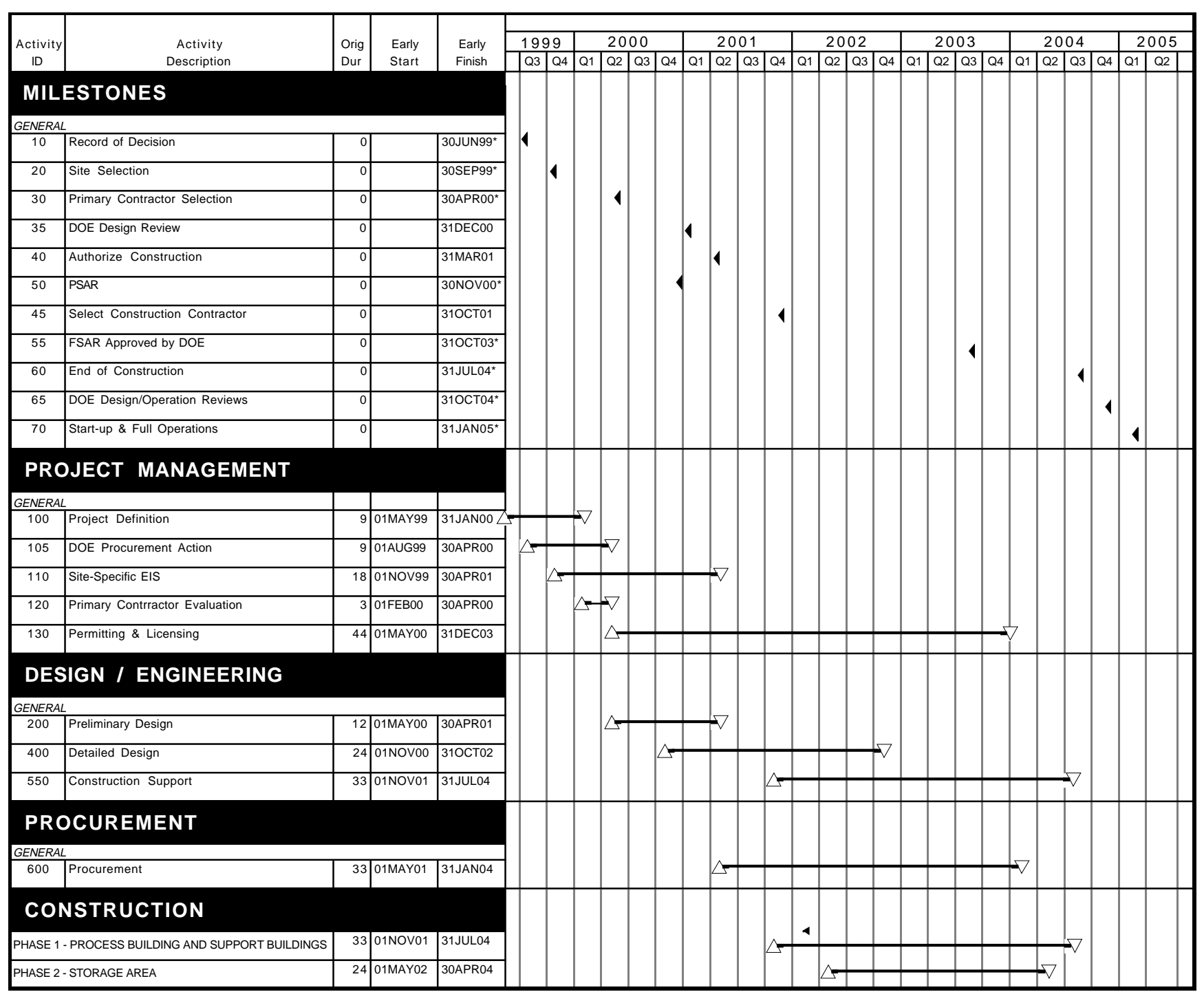

Figure 4.8 U3O8/AHF Plant, 15 Year Privately Owned and Operated Preliminary Project Schedule 
Table 4.1 Typical Production Data-25 and 15 Years

\begin{tabular}{|l|c|c|}
\hline & \multicolumn{2}{|c|}{ DUF6 to U3O8/AHF } \\
\hline Annual Production & 25 Years Operations & 15 Years Operations \\
\hline No. cylinders/years & $18,000 \mathrm{MT}$ DUF6 & $30,000 \mathrm{MT}$ DUF6 \\
\hline Cylinders/day & 1,476 & 2,461 \\
\hline Reaction chambers & 5.1 & 8.5 \\
\hline Process Building size & 4 & 6 \\
\hline Site area & $320 \mathrm{x} 130 \mathrm{ft}$ & $440 \mathrm{x} 130 \mathrm{ft}$ \\
\hline Personnel during operations & 36 acres & $45 \mathrm{acres}$ \\
\hline U3O8 & $179(\mathrm{POPO})$ & $208(\mathrm{POPO})$ \\
\hline AHF & $189(\mathrm{GOCO})$ & $218(\mathrm{GOCO})$ \\
\hline CaF2 & $14,352 \mathrm{MT} / \mathrm{yr}$ & $23,920 \mathrm{MT} / \mathrm{yr}$ \\
\hline
\end{tabular}


Table 4.2 Comparison of DUF6 Plant Cost Estimates (in million FY2000 dollars)

\begin{tabular}{|l|c|c|c|c|}
\cline { 2 - 5 } \multicolumn{1}{c|}{} & U3O8/AHF & U3O8/AHF & U3O8/AHF & U3O8/AHF \\
\cline { 2 - 5 } \multicolumn{1}{c|}{} & 25 Years POPO & $\mathbf{1 5}$ Years POPO & 25 Years GOCO & 15 Years GOCO \\
\hline Facility Capital Cost & 197 & 274 & 222 & 309 \\
\hline Annual O\&M Cost & 26 & 33 & 28 & 35 \\
\hline Total Operating Cost & 672 & 510 & 717 & 541 \\
\hline Decon \& Decommissioning & 20 & 27 & 5 & 31 \\
\hline NEPA/Licensing & 5 & 5 & $\mathbf{9 6 6}$ & $\mathbf{8 8 6}$ \\
\hline Lifecycle Cost & $\mathbf{8 9 4}$ & 229 & 229 & 229 \\
\hline Byproduct Sale Revenue & 229 & 240 & $\mathbf{8 1 6}$ & - \\
\hline Construction Loan Interest & 179 & $\mathbf{8 2 7}$ & $\mathbf{7 3 8}$ & $\mathbf{6 5 7}$ \\
\hline Total Funding Outlay & $\mathbf{8 4 5}$ & & \\
\hline
\end{tabular}

Notes: Capital cost includes facility design and construction costs

Total operating cost includes startup and O\&M costs over plant operating years

Revenue assumes $70 \notin / \mathrm{lb}$ from AHF sales

Construction loan assumes @ $8.5 \%$ interest and 10 years payback time for privately owned cases

Funding outlay in POPO cases is payment to cover break-even cost only, no profits included. 
Table 4.3 Typical Manpower Loading of a GOCO and POPO Facility

\begin{tabular}{|l|c|c|c|c|}
\cline { 2 - 5 } \multicolumn{1}{c|}{} & $\begin{array}{c}\text { 25 years } \\
\text { U308/AHF } \\
\text { GOCO }\end{array}$ & $\begin{array}{c}\text { 25 years } \\
\text { U308/AHF } \\
\text { POPO }\end{array}$ & $\begin{array}{c}\text { 15 years } \\
\text { U308/AHF } \\
\text { GOCO }\end{array}$ & $\begin{array}{c}\text { 15 years } \\
\text { U308/AHF } \\
\text { POPO }\end{array}$ \\
\hline Officials and Managers & 6 & 6 & 6 & 6 \\
\hline Professionals & 10 & 10 & 10 & 10 \\
\hline Technicians & 16 & 16 & 16 & 16 \\
\hline Office and Clericals & 12 & 10 & 12 & 10 \\
\hline Craft workers (Maint.) & 24 & 24 & 100 & 32 \\
\hline Operators & 80 & 80 & 18 & 100 \\
\hline Line Supervisor & 17 & 17 & 24 & 16 \\
\hline Security & 24 & 16 & 218 & 208 \\
\hline Total FTEs & 189 & 179 & & 18 \\
\hline
\end{tabular}


Table 4.4a U3O8/AHF Project Capital Cost Estimate

Government Owned and Contractor Operated Plant

\begin{tabular}{|l|c|c|}
\hline Facility/Cost Items & 15-year Operation & 25-year Operation \\
\hline Process Equipment & $59,814,000$ & $41,839,000$ \\
\hline Process Facilities & $141,522,000$ & $101,017,000$ \\
\hline Balance of Plant & $60,497,000$ & $45,566,000$ \\
\hline Subtotal & $\mathbf{2 6 1 , 8 3 3 , 0 0 0}$ & $\mathbf{1 8 8 , 4 2 2 , 0 0 0}$ \\
\hline Engineering and Design @ 18\% & $47,130,000$ & $33,916,000$ \\
\hline Total & $\mathbf{3 0 8 , 9 6 3 , 0 0 0}$ & $\mathbf{2 2 2 , 3 3 8 , 0 0 0}$ \\
\hline
\end{tabular}

Table 4.4b U3O8/AHF Project Capital Cost Estimate Privately Owned and Privately Operated Plant

\begin{tabular}{|l|c|c|}
\hline Facility/Cost Items & 15-year Operation & 25-year Operation \\
\hline Process Equipment & $55,526,000$ & $38,815,000$ \\
\hline Process Facilities & $128,943,000$ & $92,036,000$ \\
\hline Balance of Plant & $55,104,000$ & $41,523,000$ \\
\hline Subtotal & $\mathbf{2 3 9 , 5 7 3 , 0 0 0}$ & $\mathbf{1 7 2 , 3 7 4 , 0 0 0}$ \\
\hline Engineering and Design @ $14.4 \%$ & $34,498,000$ & $24,822,000$ \\
\hline Total & $\mathbf{2 7 4 , 0 7 1 , 0 0 0}$ & $\mathbf{1 9 7 , 1 9 6 , 0 0 0}$ \\
\hline
\end{tabular}


Table 4.5a Operation and Maintenance Cost Estimate Government Owned and Contractor Operated Plant




Table 4.5b Operation and Maintenance Cost Estimate Privately Owned and Privately Operated Plant

\begin{tabular}{|c|c|c|c|}
\hline \multicolumn{2}{|r|}{ DESCRIPTION } & JOTAL ANNUAL COST 15-Year Operatiof & IOTAL ANNUAL COST 25-year Operatio \\
\hline \multicolumn{4}{|c|}{ 1. Consumable and Materials } \\
\hline & Process Chemicals & 117,146 & 70,218 \\
\hline & Cooling Tower Water Treatment Chemicals & 42,400 & 38,160 \\
\hline & Product and Waste Containers & $5,606,581$ & $3,373,326$ \\
\hline & Scheduled Replaceable Equipment for Reaction Chambers & 949,760 & 771,680 \\
\hline & Facility Maintenance & 761,957 & 566,563 \\
\hline & Equipment Spares & $1,110,520$ & 776,300 \\
\hline & Total Materials & $8,588,360$ & $5,596,246$ \\
\hline & \multicolumn{3}{|c|}{ 2. Utilities \& Service } \\
\hline \multirow[t]{4}{*}{3.} & Labor & & \\
\hline & Plant operation labors & $18,455,094$ & $15,929,696$ \\
\hline & Off-site overhead labor & $2,214,611$ & $1,911,564$ \\
\hline & Total Labor & $20,669,705$ & $17,841,260$ \\
\hline \multicolumn{4}{|c|}{ 4. Waste Management \& Disposal } \\
\hline & Low Level Wastes & $1,766,300$ & $1,169,600$ \\
\hline & Mixed Low Level Wastes & 4,100 & 4,100 \\
\hline & Hazardous Wastes & 5,180 & 5,180 \\
\hline & Total Waste Management/Disposal & $1,775,580$ & $1,178,880$ \\
\hline Total & I Operation \& Maintenance Annual Cost & $33,100,616$ & $26,400,512$ \\
\hline Start- & $\begin{array}{l}\text { t-Up Cost } \\
\text { Facility start-up cost based on allowance of } 65 \% \text { of one year O\&M total } \\
\text { labor cost. }\end{array}$ & $13,435,308$ & $11,596,819$ \\
\hline Total & $10 \& M$ Cost for 25 years & $509,944,548$ & $671,609,619$ \\
\hline
\end{tabular}


Table 4.6 Expenditure Cost Funding Profile

(GOCO 15 Year Operation)

(in million FY2000 dollars)

\begin{tabular}{|c|c|c|c|c|c|c|c|c|c|c|c|c|}
\hline & TOTAL & FY99 & FY00 & FY01 & FY02 & FY03 & FY04 & FY05 & FY06 & FY07 & FY08 & FY09 \\
\hline NEPA/Licensing & 5.0 & & 0.5 & 1.2 & 1.2 & 1.2 & 0.9 & & & & & \\
\hline Engineering & 47.1 & & 1.4 & 11.8 & 19.8 & 10.4 & 3.1 & 0.7 & & & & \\
\hline Construction & $\underline{261.8}$ & 0.2 & 1.9 & 3.0 & 25.2 & 102.2 & 117.2 & 12.1 & & & & \\
\hline Total Capital Cost: & 314.0 & 0.2 & 3.8 & 16.0 & 46.2 & 113.8 & 121.2 & 12.8 & & & & \\
\hline Startup & 14.2 & & & & & & & 14.2 & & & & \\
\hline Operations & 527.1 & & & & & & & 8.8 & 35.1 & 35.1 & 35.1 & 35.1 \\
\hline Decon \&Decommission & $\underline{30.9}$ & & & & & & & & & & & \\
\hline Total Operation Cost: & 572.1 & & & & & & & 22.9 & 35.1 & 35.1 & 35.1 & 35.1 \\
\hline Revenue from Chemical Sale: & 228.6 & & & & & & & 3.8 & 15.2 & 15.2 & 15.2 & 15.2 \\
\hline Total Budget Outlay: & 657.5 & 0.2 & 3.8 & 16.0 & 46.2 & 113.8 & 121.2 & 31.9 & 19.9 & 19.9 & 19.9 & 19.9 \\
\hline \multicolumn{13}{|c|}{ Assumption: } \\
\hline \multicolumn{13}{|c|}{ Chemical Sale Price: } \\
\hline
\end{tabular}


Table 4.6, continued Expenditure Cost Funding Profile

(GOCO 15 Year Operation)

(in million FY2000 dollars)

\begin{tabular}{|c|c|c|c|c|c|c|c|c|c|c|c|c|c|}
\hline & FY10 & FY11 & FY12 & FY13 & FY14 & FY15 & FY16 & FY17 & FY18 & FY19 & FY20 & FY21 & FY22 \\
\hline $\begin{array}{l}\text { NEPA/Licensing } \\
\text { Engineering } \\
\text { Construction } \\
\end{array}$ & & & & & & & & & & & & & \\
\hline Startup & 35.1 & 35.1 & 35.1 & 35.1 & 35.1 & 35.1 & 35.1 & 35.1 & 35.1 & 35.1 & 26.4 & & \\
\hline $\begin{array}{l}\text { Decon \&Decommission } \\
\text { Total Operation Cost: }\end{array}$ & 35.1 & 35.1 & 35.1 & 35.1 & 35.1 & 35.1 & 35.1 & 35.1 & 35.1 & 35.1 & 26.4 & $\begin{array}{l}15.4 \\
15.4\end{array}$ & $\begin{array}{l}15.4 \\
15.4\end{array}$ \\
\hline Revenue from Chemical Sale: & 15.2 & 15.2 & 15.2 & 15.2 & 15.2 & 15.2 & 15.2 & 15.2 & 15.2 & 15.2 & 11.4 & & \\
\hline Total Budget Outlay: & 19.9 & 19.9 & 19.9 & 19.9 & 19.9 & 19.9 & 19.9 & 19.9 & 19.9 & 19.9 & 14.9 & 15.4 & 15.4 \\
\hline
\end{tabular}


Table 4.7 Expenditure Cost Funding Profile

(GOCO 25 Year Operation)

(in million FY2000 dollars)

\begin{tabular}{|c|c|c|c|c|c|c|c|c|c|c|c|c|}
\hline & TOTAL & FY99 & FY00 & FY01 & FY02 & FY03 & FY04 & FY05 & FY06 & FY07 & FY08 & FY09 \\
\hline NEPA/Licensing & 5.0 & & 0.5 & 1.2 & 1.2 & 1.2 & 0.9 & & & & & \\
\hline Engineering & 33.9 & & 1.1 & 8.6 & 14.3 & 7.8 & 2.1 & & & & & \\
\hline Construction & $\underline{188.4}$ & 0.1 & 1.4 & 2.2 & 28.8 & 90.3 & 65.6 & & & & & \\
\hline Total Capital Cost: & $\overline{227.3}$ & 0.1 & 3.0 & 12.0 & 44.2 & 99.3 & 68.6 & & & & & \\
\hline Startup & 12.3 & & & & & & 6.1 & 6.1 & & & & \\
\hline Operations & 704.7 & & & & & & & 21.1 & 28.2 & 28.2 & 28.2 & 28.2 \\
\hline Decon \&Decommission & $\underline{22.2}$ & & & & & & & & & & & \\
\hline Total Operation Cost: & $\overline{739.2}$ & & & & & & 6.1 & 27.3 & 28.2 & 28.2 & 28.2 & 28.2 \\
\hline Revenue from Chemical Sale: & 228.6 & & & & & & & 6.9 & 9.1 & 9.1 & 9.1 & 9.1 \\
\hline Total Budget Outlay: & 737.9 & 0.1 & 3.0 & 12.0 & 44.2 & 99.3 & 74.8 & 20.4 & 19.0 & 19.0 & 19.0 & 19.0 \\
\hline \multicolumn{13}{|c|}{ Assumption: } \\
\hline \multicolumn{13}{|c|}{ Chemical Sale Price: } \\
\hline
\end{tabular}


Table 4.7, continued Expenditure Cost Funding Profile

(GOCO 25 Year Operation)

(in million FY2000 dollars)

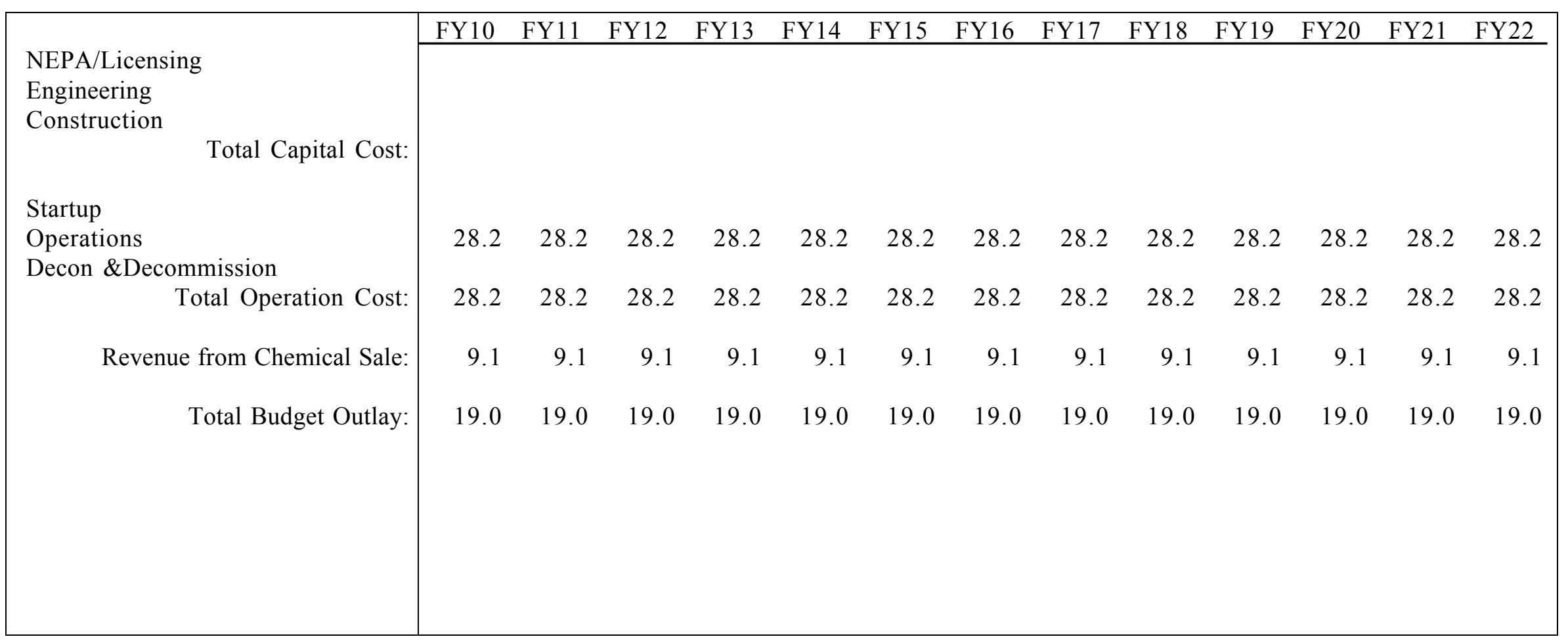


Table 4.7, continued Expenditure Cost Funding Profile

(GOCO 25 Year Operation)

(in million FY2000 dollars)

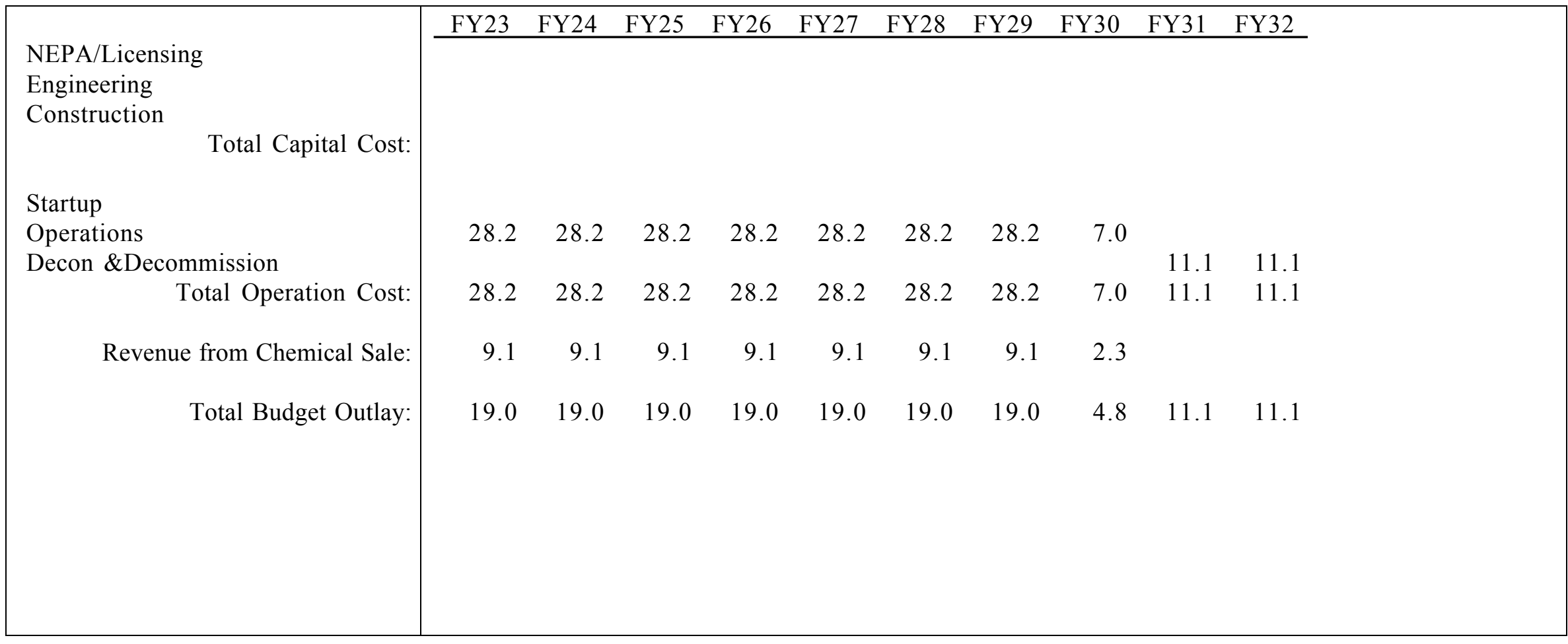


Table 4.8 Expenditure Funding Profile

(POPO 15 Year Operation)

10-year payback

(in million FY2000 dollars)

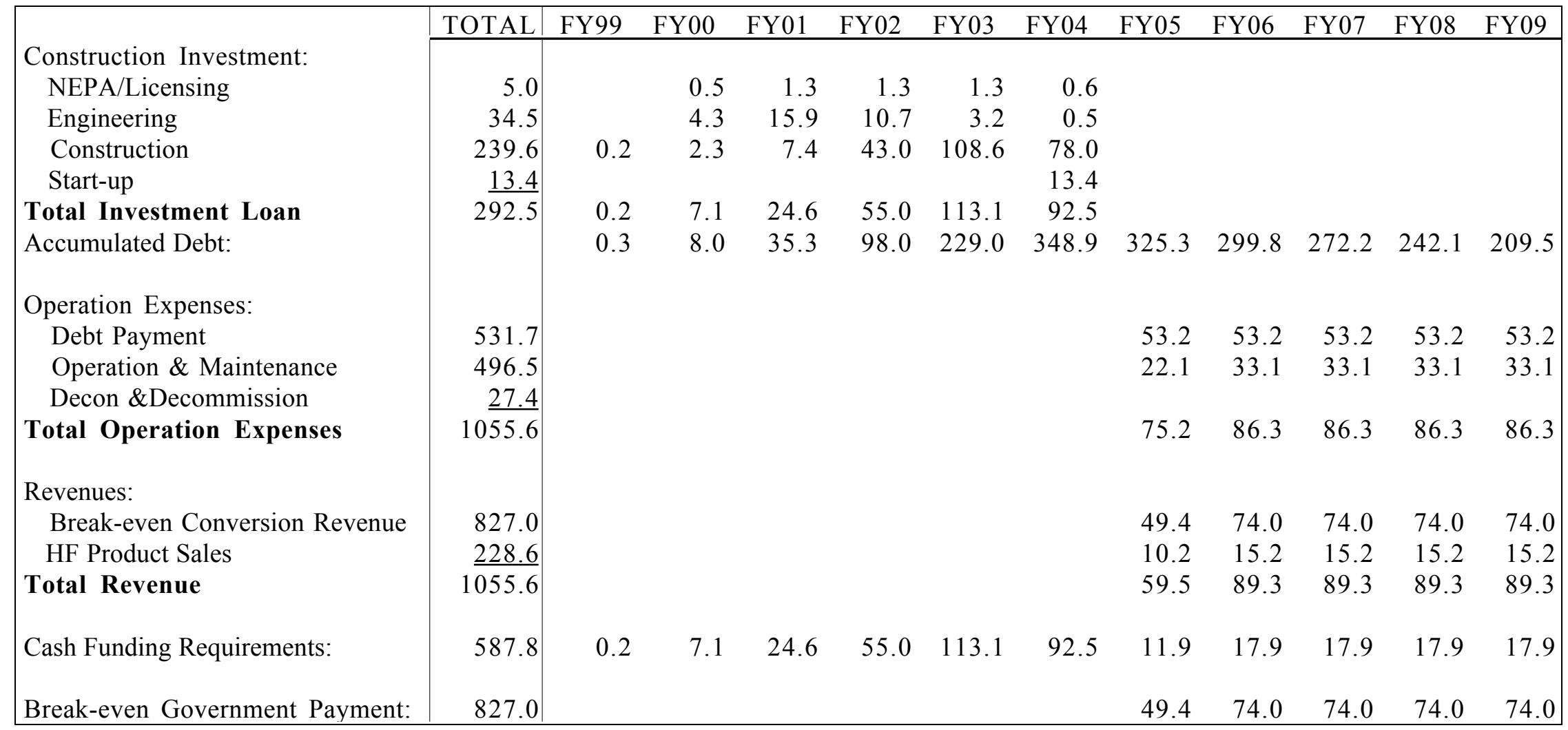

Notes: Cash funding requirements reflect cash flow required for construction and operating minus revenue from AHF sales. Break-even government payment is the funding from DOE paid to the private plant owner for the conversion service to cover the break-even cost for construction loan payment, operation, and D\&D only; no profits included.

Assumptions:

Loan Interest Rate @ 8.5\% for Construction Loan during construction period

Loan Interest Rate @ 8.5\% for payback in 10 years at start of operation

Chemical Sale Price: $\quad 70 \propto / \mathrm{lb}$ of HF 
Table 4.8, continued Expenditure Funding Profile

(POPO 15 Year Operation)

10-year payback

(in million FY2000 dollars)

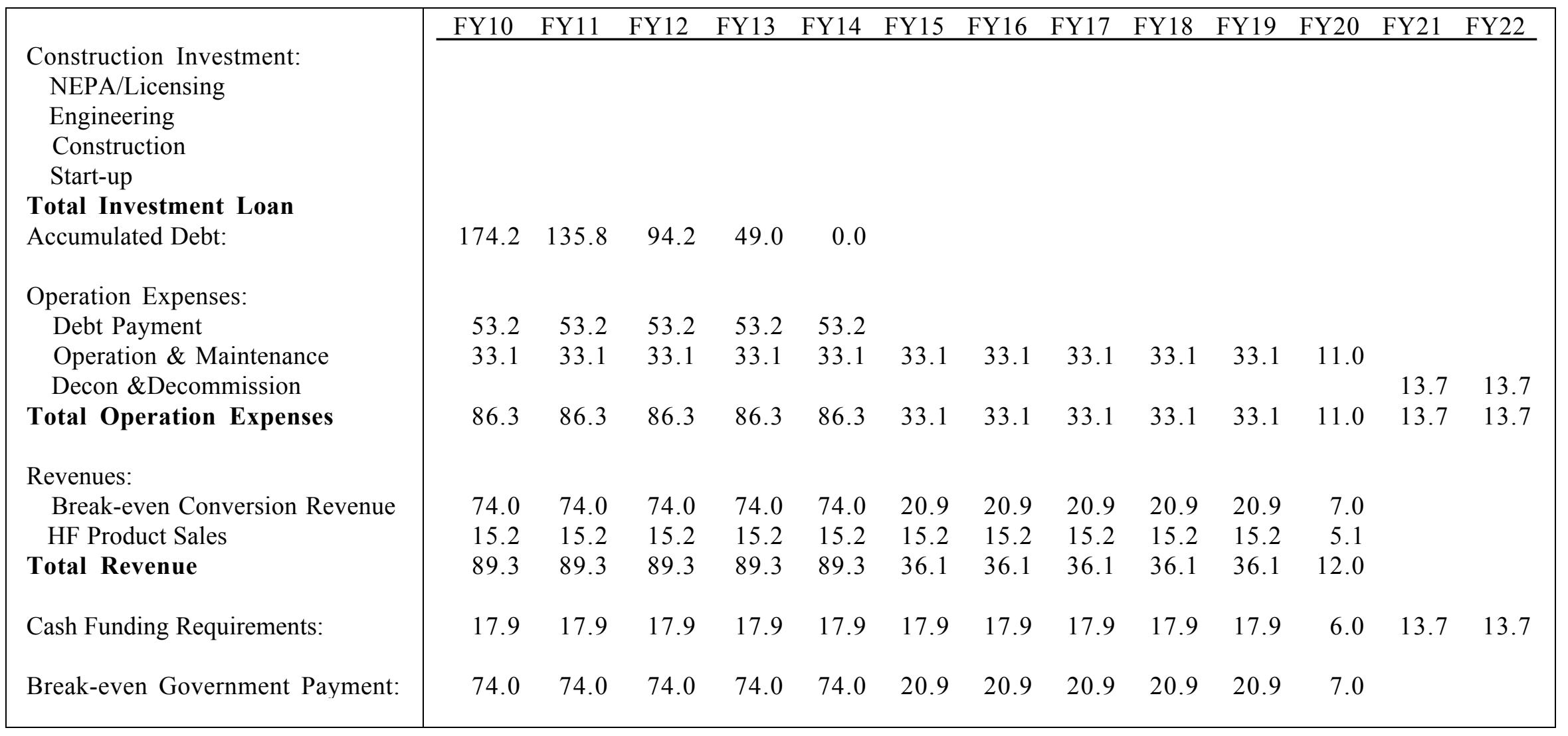


Table 4.9 Expenditure Funding Profile

U3O8/AHF (POPO 25 Year Operation)

10-year payback

(in million FY2000 dollars)

\begin{tabular}{|c|c|c|c|c|c|c|c|c|c|c|c|c|}
\hline \multirow{2}{*}{ Construction Investment: } & TOTAL & FY99 & FY00 & FY01 & FY02 & $\mathrm{FY} 03$ & FY04 & FY05 & FY06 & FY07 & FY08 & FY09 \\
\hline & & & & & & & & & & & & \\
\hline Engineering & 24.8 & & 3.1 & 11.5 & 7.7 & 2.3 & 0.3 & & & & & \\
\hline Start-up & $\underline{12.6}$ & & & & & & 12.6 & & & & & \\
\hline Total Investment Loan & 214.8 & 0.2 & 5.2 & 17.3 & 40.5 & 106.5 & 45.0 & & & & & \\
\hline Accumulated Debt: & & 0.2 & 5.9 & 25.2 & 71.3 & 192.9 & 258.2 & 240.8 & 221.9 & 201.4 & 179.2 & 155.1 \\
\hline Operation \& Maintenance & 660.0 & & & & & & 4.4 & 26.4 & 26.4 & 26.4 & 26.4 & 26.4 \\
\hline Decon \&Decommission & $\underline{19.7}$ & & & & & & & & & & & \\
\hline Total Operation Expenses & 1073.2 & & & & & & 4.4 & 65.7 & 65.7 & 65.7 & 65.7 & 65.7 \\
\hline Revenues: & & & & & & & & & & & & \\
\hline Break-even Conversion Revenue & 844.6 & & & & & & 9.5 & 57.1 & 57.1 & 57.1 & 57.1 & 57.1 \\
\hline Break-even Government Payment: & 844.6 & & & & & & 9.5 & 57.1 & 57.1 & 57.1 & 57.1 & 57.1 \\
\hline
\end{tabular}

Notes: Cash funding requirements reflect cash flow required for construction and operating minus revenue from AHF sales. Break-even government payment is the funding from DOE paid to the private plant owner for the conversion service

to cover the break-even cost for construction loan payment, operation, and D\&D only; no profits included.

\section{Assumptions:}

Loan Interest Rate@ 8.5\% for Construction Loan during construction period

Loan Interest Rate @ 8.5\% for payback in 10 years at start of operation

Chemical Sale Price: $\quad 70 £ /$ lb of HF 
Table 4.9, continued Expenditure Funding Profile

U3O8/AHF (POPO 25 Year Operation)

10-year payback

(in million FY2000 dollars)

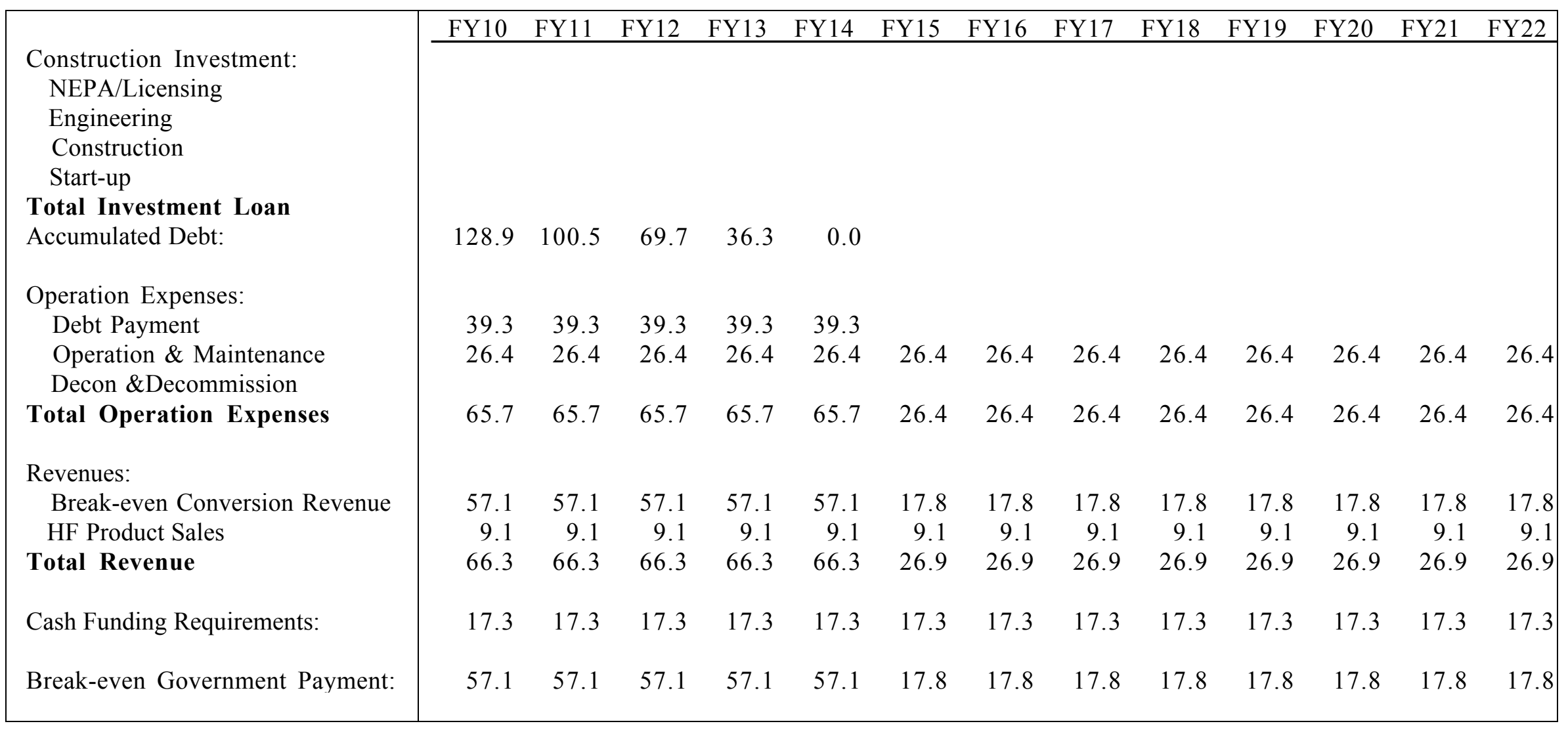


Table 4.9, continued Expenditure Funding Profile

U3O8/AHF (POPO 25 Year Operation)

10-year payback

(in million FY2000 dollars)

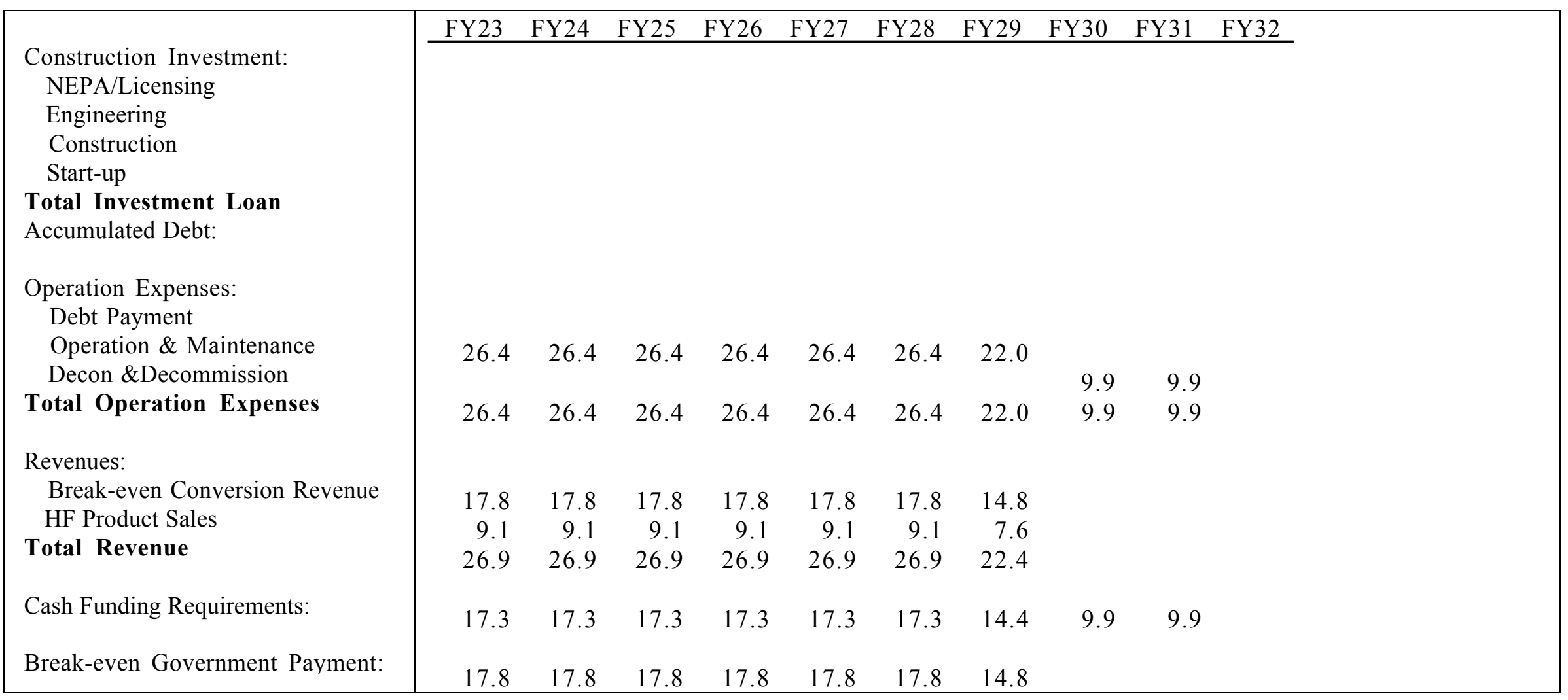


Table 4.10 Expenditure Funding Profile

U3O8/AHF (POPO 15 Year Operation)

5-year payback

(in million FY2000 dollars)

Construction Investment:

NEPA/Licensing

Engineering

Construction

Start-up

Total Investment Loan

Accumulated Debt:

Operation Expenses:

Debt Payment

Operation \& Maintenance

Decon \&Decommission

Total Operation Expenses

\section{Revenues:}

Break-even Conversion Revenue

HF Product Sales

Total Revenue

Cash Funding Requirements:

Break-even Government Payment:

\begin{tabular}{|c|c|c|c|c|c|c|c|c|c|c|c|}
\hline TOTAL & FY99 & FY00 & FY01 & $\mathrm{FY} 02$ & FY03 & FY04 & FY05 & FY06 & FY07 & FY08 & FY09 \\
\hline 5.0 & & 0.5 & 1.3 & 1.3 & 1.3 & 0.6 & & & & & \\
\hline 34.5 & & 4.3 & 15.9 & 10.7 & 3.2 & 0.5 & & & & & \\
\hline 239.6 & 0.2 & 2.3 & 7.4 & 43.0 & 108.6 & 78.0 & & & & & \\
\hline 13.4 & & & & & & 13.4 & & & & & \\
\hline $2 \overline{92.5}$ & 0.2 & 7.1 & 24.6 & 55.0 & 113.1 & 92.5 & & & & & \\
\hline & 0.3 & 8.0 & 35.3 & 98.0 & 229.0 & 348.9 & 290.0 & 226.1 & 156.8 & 81.6 & 0.0 \\
\hline 442.7 & & & & & & & 88.5 & 88.5 & 88.5 & 88.5 & 88.5 \\
\hline 496.5 & & & & & & & 22.1 & 33.1 & 33.1 & 33.1 & 33.1 \\
\hline 27.4 & & & & & & & & & & & \\
\hline $9 \overline{66.6}$ & & & & & & & 110.6 & 121.6 & 121.6 & 121.6 & 121.6 \\
\hline 738.0 & & & & & & & 73.5 & 110.2 & 110.2 & 110.2 & 110.2 \\
\hline 228.6 & & & & & & & 10.2 & 15.2 & 15.2 & 15.2 & 15.2 \\
\hline$\overline{966.6}$ & & & & & & & 83.6 & 125.4 & 125.4 & 125.4 & 125.4 \\
\hline 587.8 & 0.2 & 7.1 & 24.6 & 55.0 & 113.1 & 92.5 & 11.9 & 17.9 & 17.9 & 17.9 & 17.9 \\
\hline 738.0 & & & & & & & 73.5 & 110.2 & 110.2 & 110.2 & 110.2 \\
\hline
\end{tabular}

Notes: Cash funding requirements reflect cash flow required for construction and operating minus revenue from AHF sales. Break-even government payment is the funding from DOE paid to the private plant owner for the conversion service

\section{Assumptions:} to cover the break-even cost for construction loan payment, operation and D\&D; no profits included.

Loan Interest Rate@ 8.5\% for Construction Loan during construction period

Loan Interest Rate @ 8.5\% for payback in 5 years at start of operation

Chemical Sale Price: $\quad 70 \notin / \mathrm{lb}$ of $\mathrm{HF}$ 
Table 4.10, continued Expenditure Funding Profile

U3O8/AHF (POPO 15 Year Operation)

5-year payback

(in million FY2000 dollars)

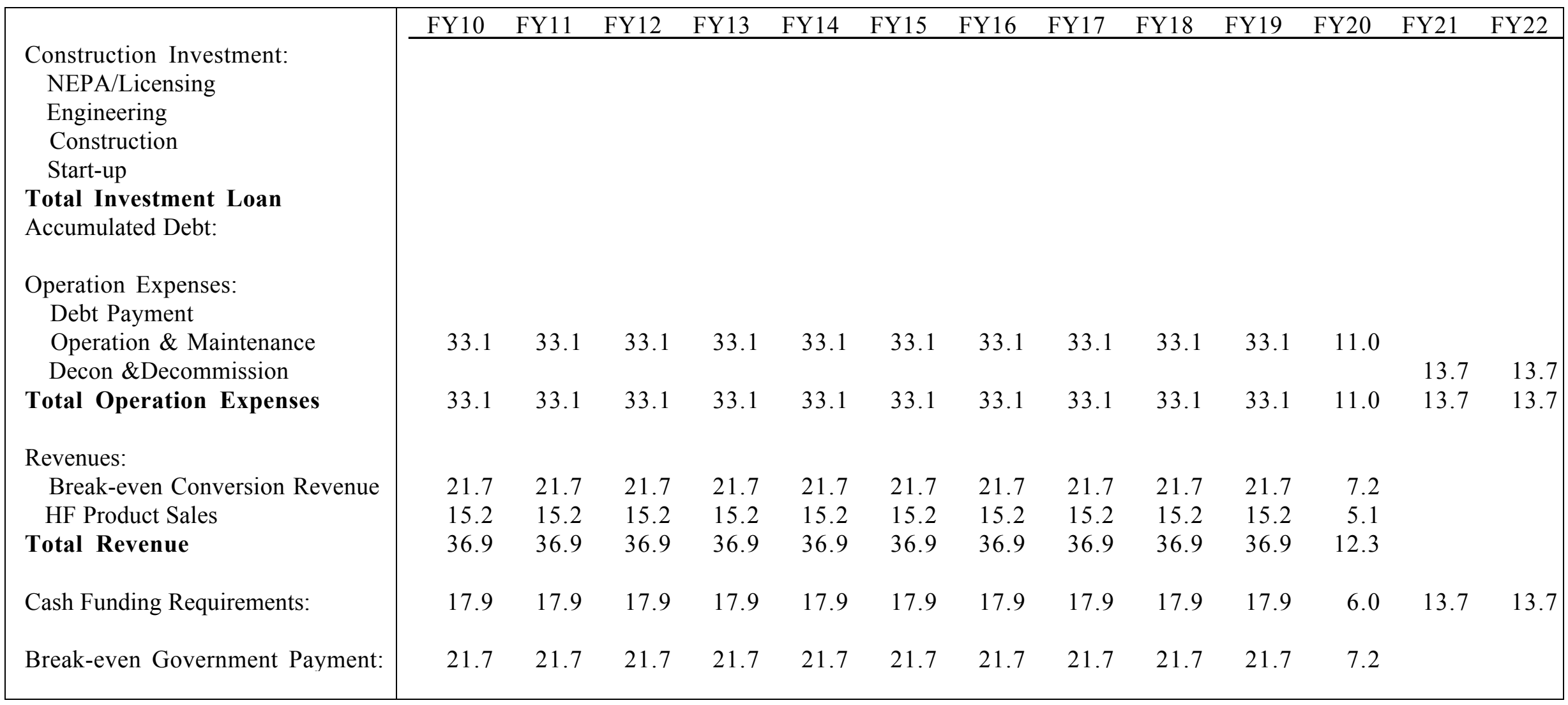


Table 4.11 Expenditure Funding Profile

U3O8/AHF (POPO 25 Year Operation)

5-year payback

(in million FY2000 dollars)

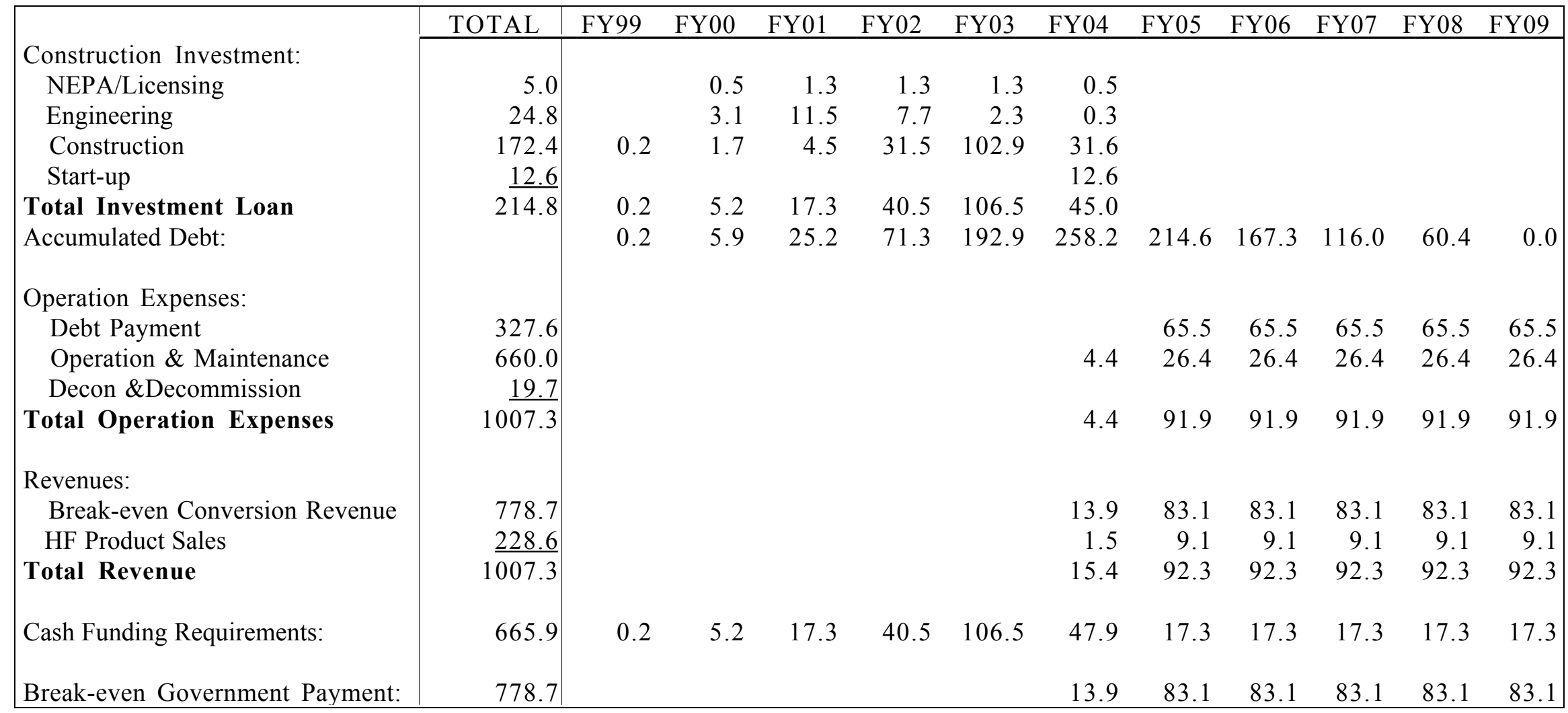


Table 4.11, continued Expenditure Funding Profile

U3O8/AHF (POPO 25 Year Operation)

5-year payback

(in million FY2000 dollars)

\begin{tabular}{|c|c|c|c|c|c|c|c|c|c|c|c|c|c|}
\hline \multirow[b]{2}{*}{$\begin{array}{l}\text { Construction Investment: } \\
\text { NEPA/Licensing } \\
\text { Engineering } \\
\text { Construction } \\
\text { Start-up } \\
\text { Total Investment Loan } \\
\text { Accumulated Debt: }\end{array}$} & FY10 & FY11 & FY12 & FY13 & FY14 & FY15 & FY16 & FY17 & FY18 & FY19 & FY20 & FY21 & FY22 \\
\hline & & & & & & & & & & & & & \\
\hline $\begin{array}{l}\text { Operation Expenses: } \\
\text { Debt Payment }\end{array}$ & & & & & & & & & & & & & \\
\hline $\begin{array}{l}\text { Operation \& Maintenance } \\
\text { Decon \&Decommission }\end{array}$ & 26.4 & 26.4 & 26.4 & 26.4 & 26.4 & 26.4 & 26.4 & 26.4 & 26.4 & 26.4 & 26.4 & 26.4 & 26.4 \\
\hline Total Operation Expenses & 26.4 & 26.4 & 26.4 & 26.4 & 26.4 & 26.4 & 26.4 & 26.4 & 26.4 & 26.4 & 26.4 & 26.4 & 26.4 \\
\hline Revenues: & & & & & & & & & & & & & \\
\hline Break-even Conversion Revenue & 17.6 & 17.6 & 17.6 & 17.6 & 17.6 & 17.6 & 17.6 & 17.6 & 17.6 & 17.6 & 17.6 & 17.6 & 17.6 \\
\hline HF Product Sales & 9.1 & 9.1 & 9.1 & 9.1 & 9.1 & 9.1 & 9.1 & 9.1 & 9.1 & 9.1 & 9.1 & 9.1 & 9.1 \\
\hline Total Revenue & 26.7 & 26.7 & 26.7 & 26.7 & 26.7 & 26.7 & 26.7 & 26.7 & 26.7 & 26.7 & 26.7 & 26.7 & 26.7 \\
\hline Cash Funding Requirements: & 17.3 & 17.3 & 17.3 & 17.3 & 17.3 & 17.3 & 17.3 & 17.3 & 17.3 & 17.3 & 17.3 & 17.3 & 17.3 \\
\hline Break-even Government Payment: & 17.6 & 17.6 & 17.6 & 17.6 & 17.6 & 17.6 & 17.6 & 17.6 & 17.6 & 17.6 & 17.6 & 17.6 & 17.6 \\
\hline
\end{tabular}


Table 4.11, continued Expenditure Funding Profile

U3O8/AHF (POPO 25 Year Operation)

5-year payback

(in million FY2000 dollars)

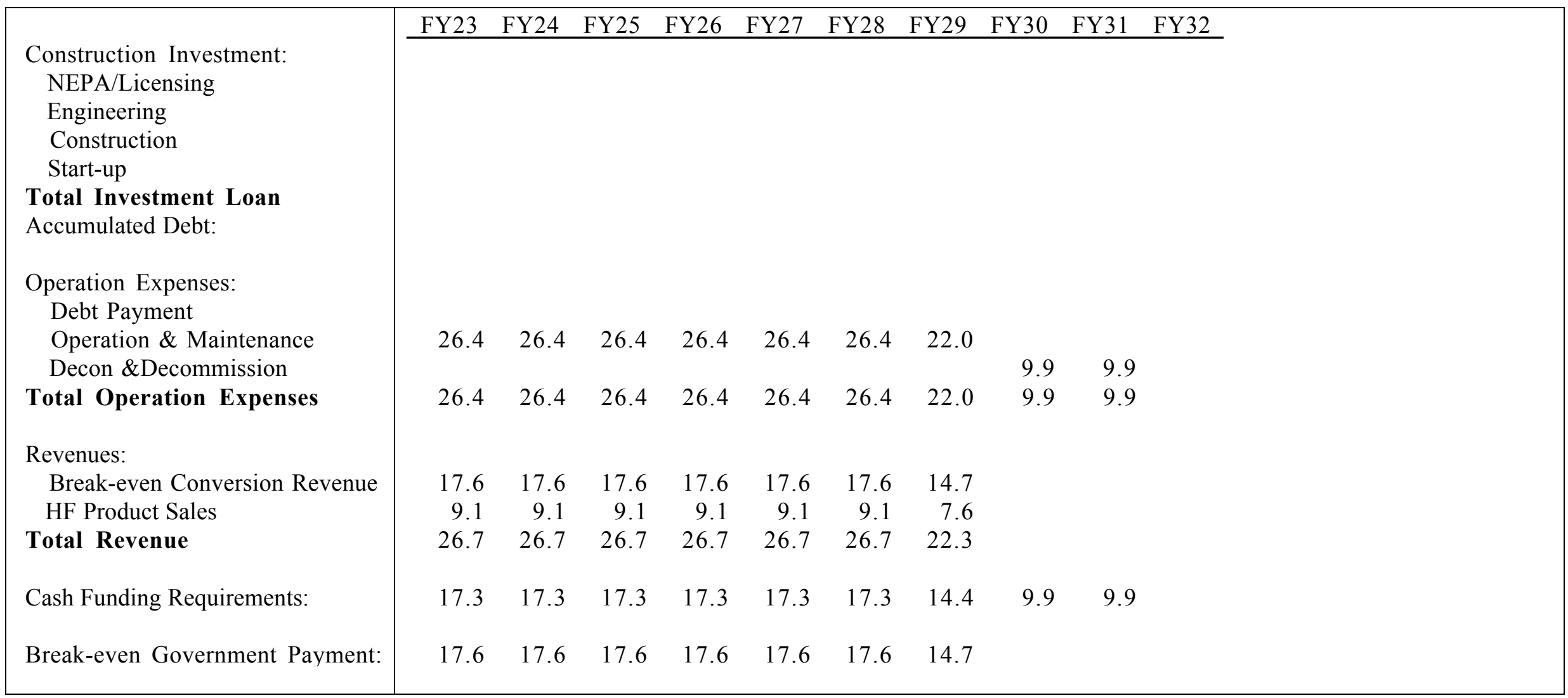




\section{DUF6 Conversion to U3O8/AHF/CaF2}

\section{$5.1 \quad$ Introduction}

About 700,000 metric tons (MT) of depleted uranium hexafluoride (DUF6) are currently stored at the Paducah, Portsmouth and Oak Ridge sites. Public Law 105-204 requires the DOE to submit to Congress a plan to ensure that all funds accrued on the books of USEC for disposition of DUF6 will be used for the construction and operation of plants to treat and recycle the DUF6. The Department of Energy's Initial Plan calls for construction to begin in the year 2002 time frame.

This report section examines the costs and issues for plant construction based on a conversion plant using a dry process to convert DUF6 to uranium oxide (U3O8), anhydrous hydrogen fluoride (AHF) and calcium fluoride $(\mathrm{CaF} 2)$ as final products. The plant has two operating modes: $100 \%$ production of AHF only or $100 \%$ production of only $\mathrm{CaF} 2$. The construction and operation of the conversion plant is based on private ownership and operation with DOE regulations and operating for 25 years.

A preconceptual plant design, rough cost estimate, and preliminary project schedule were developed. The conversion plant includes capabilities for DUF6 cylinder preparation, conversion of DUF6 to uranium oxide and fluorine byproducts, empty cylinder treatment for disposal, and interim storage for oxide and byproducts.

Significant design bases for the conversion plant include:

- The plant will convert DUF6 to U3O8 by a dry process. Hydrogen fluoride (HF) off-gas will be treated to produce $\mathrm{AHF}$ and a minor quantity of calcium fluoride (CaF2). Capability to treat the HF off-gas to produce calcium fluoride only (and no AHF) is also provided.

- The plant capacity will be based on a 25 year operating period to process a DUF6 inventory of 36,910 cylinders (450,000 MT DUF6) over the life of the plant.

- Storage will be provided for one year production of $\mathrm{U} 3 \mathrm{O} 8$ and $\mathrm{CaF} 2$ product and two months production of AHF.

- The AHF product is available for sale by plant owner to commercial users. The U3O8 and CaF2 products are returned to the DOE.

- To bound costs associated with empty cylinders, assume all empty cylinders will be washed, compacted, and returned to the DOE for disposal.

- The plant will be located on a DOE owned site at or near a gaseous diffusion plant and include the support facilities and infrastructures/utilities needed for a greenfield facility.

- The design will consider addition of future process and storage buildings.

\subsection{Summary of Results}

The plant annually processes 18,000 MT of DUF6 contained in 1,476 cylinders to produce 14,352 MT of U3O8 and 2,000 MT of empty cylinder metal waste. The plant produces 5,962 MT of AHF and 269 MT of $\mathrm{CaF} 2$ in the AHF mode, or 11,966 MT of $\mathrm{CaF} 2$ and no AHF in the $\mathrm{CaF} 2$ mode. The plant, which includes a one year storage capacity for $\mathrm{U} 3 \mathrm{O} 8$ and $\mathrm{CaF} 2$ and two months storage capacity for $\mathrm{AHF}$, 
occupies about 39 acres. Additional storage capacity would require about 5 acres for each year of additional $\mathrm{U} 3 \mathrm{O} 8$ or $\mathrm{CaF} 2$ storage.

The construction capital cost estimate is \$202 million for the plant facilities. The engineering cost is about \$29 million. Each year of additional storage would be \$20 million for U3O8 and \$16 million for CaF2. These costs are in 1st Quarter FY2000 dollars.

The annual operation and maintenance (O\&M) cost is about $\$ 27$ million in the AHF production mode and $\$ 30$ million in the CaF2 production mode. The O\&M cost does not include disposal of empty cylinder metal. Cost for NEPA, regulatory and licensing activities is estimated at $\$ 5$ million. Decontamination and decommissioning (D\&D) cost is estimated at $\$ 23$ million.

The preliminary schedule assumes selection of a private plant contractor in April 2000. The schedule shows plant engineering design starting in May 2000, construction beginning in November 2001, plant completion in January 2004, and full operation beginning in July 2004. Peak engineering personnel is 80 persons and peak employment during construction is about 480 persons. Plant employment during operations is 183 persons.

The 2002 construction start depends on the key milestone dates for site selection, selection of primary contractor and construction contractor, and construction approval. The schedule includes NEPA activities, as a site-specific EIS will be required, and DOE regulatory activities. The amount of U3O8 storage provided affects cost and may need additional study. Process design criteria for DUF6 cylinder vaporization, conversion reaction chamber, HF distillation, and empty cylinder treatment are necessary to ensure successful facility design and operation.

\subsection{Conversion Process Description}

Depleted uranium hexafluoride (DUF6) is processed to produce U3O8, AHF and CaF2. The average throughput is 5 cylinders per day $(5,670 \mathrm{lb} / \mathrm{hr}$ DUF6) based on $80 \%$ plant availability $(7,000$ hours/yr or 292 days/yr). The process block flow diagram for AHF production is shown in Figure 5.1. The diagram for $\mathrm{CaF} 2$ production is shown in Figure 5.2.

The plant is designed to produce AHF or CaF2, but not both simultaneously. Production would be shut down during the transition between the $\mathrm{AHF}$ and $\mathrm{CaF} 2$ production modes. The desired mix of $\mathrm{AHF}$ and $\mathrm{CaF} 2$ product is obtained by campaigning operations. Much of the equipment is common and would be used during both production modes.

The DUF6 is shipped by truck from the cylinder yards at the gaseous diffusion plant to an outdoor storage pad at the Conversion Facility. The cylinder is moved into the Process Building for inspection and preparation. The cylinders are loaded into steam-heated autoclaves to vaporize the DUF6 for feeding into the conversion process. Cylinders with questionable integrity are loaded into hot air ovens where the solid DUF6 sublimes into a gas under vacuum. This avoids melting the UF6 and pressurizing the cylinder, which occurs when using an autoclave. Several of the cylinders may be substandard based on the DUF6 Engineering Analysis Report (p. 6.1-4-5).

After vaporization, the empty cylinders are transferred to an outdoor pad and stored for three months. This allows for radioactive decay of non-volatile daughter products in the cylinder. The cylinders are then brought into the Process Building, washed with water, crushed, and loaded into boxes. Each $6 \times 14 \times 3 \mathrm{ft}$ high box contains about 9,000 lb of metal from three crushed cylinders. The filled boxes are stored in the Waste Storage Building and transported to the gaseous diffusion plant for disposition. The cylinder wash effluents are fed into the main conversion processes. 


\subsubsection{Anhydrous HF Production Mode}

The DUF6 gas is converted to U3O8 in a series of two reaction chambers, where it is mixed with an $\mathrm{HF} /$ water vapor mixture in the first chamber and with steam in the second chamber. The chemical reactions are:

$\mathrm{UF} 6+2 \mathrm{H}_{2} \mathrm{O}--->\mathrm{UO}_{2} \mathrm{~F}_{2}+4 \mathrm{HF}$

$3 \mathrm{UO}_{2} \mathrm{~F}_{2}+3 \mathrm{H}_{2} \mathrm{O}--->\mathrm{U} 3 \mathrm{O} 8+6 \mathrm{HF}+0.5 \mathrm{O}_{2}$

Four reaction lines are provided to meet the required throughput. The U3O8 product is cooled, compacted to increase its bulk density, and packaged in metal bins. The $100 \mathrm{cu} f t$ bins are about $4 \mathrm{x} 4 \mathrm{x} 7 \mathrm{ft}$ high and hold 9 tons (8.16 MT) of U3O8. The filled bins are transferred to the U3O8 Storage Building.

Reaction chamber off-gas containing HF, steam and oxygen is filtered to remove uranium particulates. The off-gas then flows to the HF distillation system, which concentrates the mixture to produce anhydrous HF in the overhead product. The AHF is collected, sampled, and pumped to large storage tanks in the HF Storage Building, where the AHF is loaded into railcars or tank trucks for delivery to customers. The AHF is expected to contain less than 1 ppm uranium.

The aqueous hydrogen fluoride bottoms stream from HF distillation is collected, vaporized and recycled to the first reaction chamber. To prevent the buildup of impurities in the recycle stream, a small fraction is withdrawn. This purge stream is neutralized with hydrated lime, mixed with cement and water to form a grout, and packaged in drums for disposal.

Off-gas from the distillation column, primarily oxygen and air inleakage, flows to the scrubber system. Residual HF in the off-gas is removed by scrubbing with a potassium hydroxide (KOH) solution. The offgas is then HEPA-filtered and discharged to the atmosphere. The spent scrub solution is regenerated with hydrated lime $\left(\mathrm{Ca}(\mathrm{OH})_{2}\right)$, which produces a calcium fluoride $(\mathrm{CaF} 2)$ byproduct. The chemical reactions are:

$\mathrm{HF}+\mathrm{KOH}--->\mathrm{KF}+\mathrm{H}_{2} \mathrm{O}$

$2 \mathrm{KF}+\mathrm{Ca}(\mathrm{OH})_{2}--->\mathrm{CaF} 2+2 \mathrm{KOH}$

The CaF2 is separated by filtering, washed with water, dried and loaded into drums. The drums, containing $700 \mathrm{lb}$ of $\mathrm{CaF} 2$, are transferred to the $\mathrm{CaF} 2$ Storage Building. The $\mathrm{CaF} 2$ is expected to contain less than 1 ppm uranium.

\subsubsection{Calcium Fluoride Production Mode}

The DUF6 gas is converted to U3O8 in a series of two reaction chambers, where it is mixed with steam and nitrogen in the first chamber and steam and hydrogen in the second chamber. The chemical reactions are:

$\mathrm{UF} 6+2 \mathrm{H}_{2} \mathrm{O}--->\mathrm{UO}_{2} \mathrm{~F}_{2}+4 \mathrm{HF}$

$3 \mathrm{UO}_{2} \mathrm{~F}_{2}+3 \mathrm{H}_{2} \mathrm{O}--->\mathrm{U} 3 \mathrm{O} 8+6 \mathrm{HF}+0.5 \mathrm{O}_{2}$

$\mathrm{H}_{2}+0.5 \mathrm{O}_{2}--->\mathrm{H}_{2} \mathrm{O}$ 
The U3O8 product is cooled, compacted to increase its bulk density, packaged in metal bins, and transferred to the U3O8 Storage Building. Reaction chamber off-gas containing HF, excess steam, and nitrogen is filtered to remove uranium particulates. The reaction chambers, filters and $\mathrm{U} 3 \mathrm{O} 8$ handling equipment are the same ones used in the AHF production mode.

After filtration, the reaction off-gas flows to the HF absorption columns, where the HF and steam are contacted with a liquid solution and condensed. Off-gas from the absorption columns then flows to the same scrubber system described above. The aqueous HF solution that is produced from absorption is transferred to neutralization tanks and neutralized with slaked lime according to the reaction:

$2 \mathrm{HF}+\mathrm{Ca}(\mathrm{OH})_{2}--->\mathrm{CaF} 2+2 \mathrm{H}_{2} \mathrm{O}$

The resulting $\mathrm{CaF} 2$ precipitate is separated by filtering, washed with water, dried and loaded into bins. The $100 \mathrm{cu} \mathrm{ft}$ bins are about $4 \times 4 \times 7 \mathrm{ft}$ high and hold 5 tons (4.54 MT) of CaF2. The filled bins are transferred to the $\mathrm{CaF} 2$ Storage Building. The $\mathrm{CaF} 2$ is expected to contain less than $1 \mathrm{ppm}$ uranium.

\subsubsection{Major Feeds and Products, and Process Equipment}

Major process materials and annual quantities are summarized below:

\begin{tabular}{|c|c|}
\hline Major Input Streams & Major Output Streams \\
\hline $\begin{array}{l}\text { Depleted Uranium Hexafluoride } \\
18,000 \mathrm{MT} / \mathrm{yr} \\
1476 \text { cylinders/yr }\end{array}$ & $\begin{array}{l}\text { Uranium Oxide (U3O8) } \\
14,352 \mathrm{MT} / \mathrm{yr} \\
1,7584 \times 4 \times 7 \mathrm{ft} \mathrm{H} \text { bins/yr }(18,000 \mathrm{lb} / \mathrm{bin}) \\
\text { or } 24,34455 \text {-gal drums/yr }(1300 \mathrm{lb} / \mathrm{drum})\end{array}$ \\
\hline $\begin{array}{l}\text { Lime }(\mathrm{CaO}) \\
\text { CaF2 Production Mode only } \\
8,505 \mathrm{MT} / \mathrm{yr} \\
312,600 \mathrm{ft} 3 / \mathrm{yr}\end{array}$ & $\begin{array}{l}\text { Anhydrous Hydrogen Fluoride (HF) } \\
\text { AHF Production Mode only } \\
5,962 \mathrm{MT} / \mathrm{yr} \\
1.64 \mathrm{million} \mathrm{gal} / \mathrm{yr}\end{array}$ \\
\hline $\begin{array}{l}\text { Hydrated Lime } \mathrm{Ca}(\mathrm{OH}) 2 \\
\text { AHF Production Mode } \\
325 \mathrm{MT} / \mathrm{yr} \\
8,700 \mathrm{ft} 3 / \mathrm{yr} \\
\text { CaF2 Production Mode } \\
113 \mathrm{MT} / \mathrm{yr} \\
3,000 \mathrm{ft} 3 / \mathrm{yr}\end{array}$ & $\begin{array}{l}\text { Calcium Fluoride }(\mathrm{CaF} 2) \\
\text { AHF Production Mode } \\
269 \mathrm{MT} / \mathrm{yr} \\
84855 \text {-gal drums } / \mathrm{yr}(700 \mathrm{lb} / \mathrm{drum}) \\
\text { CaF2 Production Mode } \\
11,966 \mathrm{MT} / \mathrm{yr} \\
2,6394 \times 4 \times 7(\mathrm{~h}) \mathrm{ft} \text { bins } / \mathrm{yr}(10,000 \mathrm{lb} / \mathrm{bin})\end{array}$ \\
\hline $\begin{array}{l}\text { Cement } \\
\text { AHF Production Mode only } \\
154 \mathrm{MT} / \mathrm{yr} \\
2,900 \mathrm{ft} 3 / \mathrm{yr}\end{array}$ & $\begin{array}{l}\text { Empty Cylinder Metal Waste } \\
2000 \mathrm{MT} / \mathrm{yr} \\
4926 \mathrm{x} 14 \mathrm{x} 3(\mathrm{~h}) \mathrm{ft} \text { boxes/yr }(9,000 \mathrm{lb} / \mathrm{box})\end{array}$ \\
\hline $\begin{array}{l}\text { Ammonia }(\mathrm{NH} 3) \\
\text { CaF2 Production Mode only } \\
193 \mathrm{MT} / \mathrm{yr} \\
84,000 \mathrm{gal} / \mathrm{yr}\end{array}$ & $\begin{array}{l}\text { Grouted Waste } \\
\text { AHF Production Mode only } \\
367 \mathrm{MT} / \mathrm{yr} \\
1,01255 \text {-gal drums/yr }(800 \mathrm{lb} / \text { drum })\end{array}$ \\
\hline
\end{tabular}


Major process equipment used in both the $\mathrm{AHF}$ and $\mathrm{CaF} 2$ production modes includes four steam autoclaves, six hot air ovens, four reaction chamber lines, U3O8 compacting and bin loading system, offgas scrubbing system, two empty cylinder washing machines and one cylinder crusher. Major equipment used for AHF production only includes the HF distillation system and neutralization/grouting system. Equipment for $\mathrm{CaF} 2$ production only includes the $\mathrm{HF}$ absorption and neutralization system, and calcium fluoride drying and packaging system.

\subsection{Conversion Plant Description}

The Conversion Facility is assumed to be constructed on a DOE site at a greenfield location at or near a gaseous diffusion plant. The Conversion Facility occupies about 39 acres. Additional storage buildings for $\mathrm{U} 3 \mathrm{O} 8$ and $\mathrm{CaF} 2$ could be built adjacent or at a nearby location. Each additional one year increment of $\mathrm{U} 3 \mathrm{O} 8$ or $\mathrm{CaF} 2$ storage occupies about 5 acres. A conceptual site plan for the Conversion Facility is shown in Figure 5.3.

The Conversion Facility includes full and empty cylinder storage pads, the Process Building, a U3O8 Storage Building, an HF Storage Building, a CaF2 Storage Building, a Waste Storage Building and support facilities. The site plan considers addition of future process facilities such as uranium metal or sintered uranium pellets.

The Conversion Facility will be designed and constructed in compliance with DOE Orders and applicable regulations and codes, and will meet the intent of NRC standards. In general, a graded approach as established in DOE Order 420.1 is used for the design of all structures, systems, and components (SSC) in the plant facilities. All SSC's will be assigned a Natural Phenomena Performance Category using the criteria in the DOE Standards DOE-STD-1020-94 and DOE-STD-1021-93 during the design phase.

In the absence of a hazard analysis, it is assumed that the Process Building is performance category PC-3 to control and confine hazardous material. The building structure is reinforced concrete construction in the processing areas. The remainder of the building housing the personnel support area is steel frame, metal siding construction. The Process Building is $30 \mathrm{ft}$ high in the processing areas and $18 \mathrm{ft}$ high in the support areas. HVAC equipment is located on a mezzanine level. The process room air is filtered through one stage of HEPA filters prior to discharge to atmosphere. The Process Building general arrangement is shown in Figure 5.4.

The U3O8 Storage Building and CaF2 Storage Building have a one year capacity. The U3O8 Building holds 1,760 bins stacked one high, and the CaF2 Building holds 2,640 bins stacked two high. The Waste Storage Building has a one month capacity for staging treated empty cylinders and process waste for transport offsite. The U3O8, CaF2, and Waste Storage Buildings are assumed PC-2 to maintain storage function after the occurrence of a natural phenomena hazards event. These buildings are steel frame and concrete clad panel construction. They are ventilated and lighted, but no heating, cooling or HEPA filtration is provided. Access aisles allow personnel to inspect the bins during storage. A general storage arrangement for the $\mathrm{U} 3 \mathrm{O} 8$ Building is shown in Figure 5.5. A general storage arrangement for the $\mathrm{CaF} 2$ Building is shown in Figure 5.6.

The HF Storage Building has a two month capacity with ten 34,000-gallon storage tanks. The HF Storage Building is assumed to be PC-3 to control and confine hazardous material. The building structure is reinforced concrete construction. The HF storage tanks are housed separately in cell rooms.

Plant operations are assumed to be continuous for 24 hours/day, 7 days/week, 52 weeks/year. Due to seven day per week operation, a fourth shift is necessary to account for normal days off for employees. The number of employees during operation is estimated to be 183 persons, with 66 employees on day 
shift and 39 each of the other three shifts. The numbers are estimated based on process operation labor and facility support labor requirements needed to operate the plant. A breakdown of the plant operation employees by category and by shift is shown in Table 5.1.

\subsection{Cost Estimate}

The cost estimates are rough order of magnitude estimates based on a preconceptual level design information. The cost estimate results are summarized below:

\begin{tabular}{|c|c|c|c|}
\hline & $\begin{array}{c}\text { Cost } \\
\text { (\$million) }\end{array}$ & $\begin{array}{c}\text { Contingency } \\
\text { (\$million) }\end{array}$ & $\begin{array}{l}\text { Total Cost } \\
\text { (\$million) }\end{array}$ \\
\hline \multicolumn{4}{|l|}{ Conversion Facility } \\
\hline Engineering & -- & -- & 29 \\
\hline $\begin{array}{l}\text { Plant Facilities } \\
\text { Construction Cost }\end{array}$ & 150 & 52 & 202 \\
\hline Startup Cost & -- & -- & 12 \\
\hline $\begin{array}{l}\text { Annual Operations and } \\
\text { Maintenance Cost (O\&M) }\end{array}$ & -- & -- & $\begin{array}{c}27 \\
\text { (for AHF mode) } \\
30 \\
\text { (for CaF2 mode) }\end{array}$ \\
\hline $\begin{array}{l}\text { Decontamination and } \\
\text { Decommissioning (D\&D) }\end{array}$ & -- & -- & 23 \\
\hline \multicolumn{4}{|l|}{ Additional Storage } \\
\hline Engineering & -- & -- & 3 \\
\hline $\begin{array}{l}\text { U3O8 Storage ( } 1 \text { yr capacity) } \\
\text { Construction Cost }\end{array}$ & 17 & 3 & 20 \\
\hline $\begin{array}{l}\text { CaF2 Storage ( } 1 \text { yr capacity) } \\
\text { Construction Cost }\end{array}$ & 14 & 2 & 16 \\
\hline NEPA/Licensing & -- & -- & 5 \\
\hline
\end{tabular}

The estimates do not include costs for plant design criteria development, cost of land, site qualifications, or extension of local roads and utility lines to the site boundary. The estimates take into account the labor productivity and indirect cost factors for a privately run project. Cost estimate bases are described in the Appendix.

The construction capital costs are based on an engineering, procurement and construction management (EPCM) approach. Capital costs, see Table 5.2, are reported in 1st quarter fiscal year 2000 dollars (October 1999). Labor costs are based on local wage rates at a generic gaseous diffusion plant located in mid-U.S.A. The capital cost estimate utilized historical cost data, estimating manuals, allowances and budgetary quotations. A 35\% contingency was applied to the capital costs for the Conversion Facility and $15 \%$ for the subsequent Storage Facilities. These contingency levels are based on previous risk analysis on projects of similar scope and level of design details. Engineering cost was estimated at $14.4 \%$ of the capital costs for the Conversion Facility and 8\% for the subsequent Storage Facilities. The lower percentages are used for the subsequent Storage Facilities because previous building engineering design 
can be reused. Product and waste container costs are included in the O\&M costs. The D\&D cost was estimated as $10 \%$ of the capital cost.

The O\&M cost includes costs for materials, utilities, labor, and waste disposal, see Table 5.3. Plant startup cost was assumed to be $65 \%$ of the annual O\&M labor cost. The difference in O\&M cost for AHF or $\mathrm{CaF} 2$ production mode reflects the added cost for $\mathrm{CaF} 2$ storage bins in the $\mathrm{CaF} 2$ production mode or added cost for process grout waste disposal in the AHF production mode. The annual O\&M cost does not include the cost for disposal of empty cylinder metal waste. If the empty cylinder metal is to be disposed as low-level waste (LLW), the estimated disposal cost would range from \$1 million to \$12 million annually, depending on the disposal sites. Revenue from sales of AHF is also not included in the O\&M cost.

The annual expenditure required to support the construction and operation of the conversion plant for the initial years is shown in Table 5.4a and 5.4b. The expenditure profile for all years is shown below. The expenditure profiles are derived from loading the estimated capital and operating costs onto the project schedule. A constant FY2000 dollar value is used in the expenditure outlay because of the difficulty in accurately projecting the inflation rate for future years.

\subsection{Project Schedule}

An estimated preliminary project schedule is shown in Figure 5.7. The schedule allows 2.5 years for engineering design and 2 years for construction. The schedule is based on a fast track premise with overlapping engineering phases and early procurement of some key equipment (most equipment is available in 12-18 month lead time) and a two-phase construction plan. The estimated peak engineering personnel is 80 persons and peak employment during construction is 480 persons.

\subsection{Discussion and Issues}

\subsubsection{Process}

Bins were used to package the U3O8 because of the space savings compared to 55-gallon drums. Using bins instead of drums reduces the storage building area by about $35 \%$. Additional study is needed to determine the best storage container to use with the cost considerations on facilities and transport.

The $\mathrm{CaF} 2$ product is not a hazardous waste, but $\mathrm{CaF} 2$ powder is a health hazard and containment is required during handling. Packaging the $\mathrm{CaF} 2$ in sealed bins is appropriate for long-term storage or transport to customers. Other methods of handling the CaF2 include bulk storage in vaults or silos and shipment in rail hopper cars or tank trucks.

In cylinder washing, the empty cylinders are cleaned to remove the reactive fluoride materials inside the cylinder. It was assumed that the metal from washed empty cylinders is returned to the DOE for disposal. The residual uranium contaminated cylinders might require the cylinder metal to be disposed of as LLW. Alternate dispositions include recycling and reusing the radioactively-contaminated carbon steel for LLW containers for use in the nuclear industry or sufficiently decontaminating the metal for disposal as nonhazardous waste or scrap.

The purity of the calcium oxide ( $\mathrm{CaO}$, quicklime) fed to lime slaking and used to neutralize the $\mathrm{HF}$ affects the purity of the $\mathrm{CaF} 2$ product. Typical high calcium quicklime contains up to $5 \%$ impurities (mainly $\mathrm{MgO}$ and $\mathrm{CaCO}_{3}$ ), which could end up in the $\mathrm{CaF} 2$ product. If this impurity is objectionable, high purity calcium oxide could be used. 


\subsubsection{Facility}

Buildings for processing and storage were assumed to be performance category PC-2 or PC-3. A safety and accident analysis was not performed is needed to determine the hazard classification and performance category. The appropriate structure, confinement and ventilation for buildings housing large quantities of U3O8 needs study.

The DUF6 Engineering Analysis Report has identified issues with federal (49CFR173.420) or ANSI N14.1 transportation requirements and overpressured, overfilled or substandard cylinders. The Report suggests that a new overpack be designed and licensed if filled substandard cylinders must be shipped from off-site. The cost of overpacks is not considered in the report. This transportation issue still needs to be resolved.

The preconceptual plant design is essentially a single line plant. Multiple autoclaves, ovens, and conversion reaction chambers are provided to obtain the design throughput. The HF distillation system, absorption system, scrubber and neutralization systems are single line systems with installed spares on maintenance-prone items such as pumps and filters. A RAM (reliability, availability, maintainability) analysis may help determine if this configuration is satisfactory and whether independent parallel lines might be desirable.

\subsubsection{Cost Estimate}

The cost estimate is based on a privately owned and privately operated plant located on a government facility site. The major contributors to the capital cost are the Process Building including the structure and service systems. The major process equipment costs are the cylinder handling crane, autoclaves, hot air ovens and DUF6 compressors, conversion reaction chambers, distillation equipment, and cylinder tilt and roll wash stands. The cost to dispose of empty cylinder metal is not included in this report. If it is disposed as LLW, the disposal cost could be significant.

\subsubsection{Schedule}

The schedule shows a construction start early in the year 2002. This appears to be attainable if the site selection, selection of contractor, and early approval for construction dates are met. The Record of Decision is expected to be issued by the end of June.

\subsection{References}

Initial Plan for the Conversion of Depleted Uranium Hexafluoride, as Required by Public Law 105-204, U.S. Department of Energy, 1999

Draft Engineering Analysis Report for the Long-Term Management of Depleted Uranium Hexafluoride, UCRL-AR-124080, Lawrence Livermore National Laboratory, May 1997

Uranium Hexafluoride: A Manual of Good Handling Practices, ORO-651, U.S. Department of Energy, October 1991 


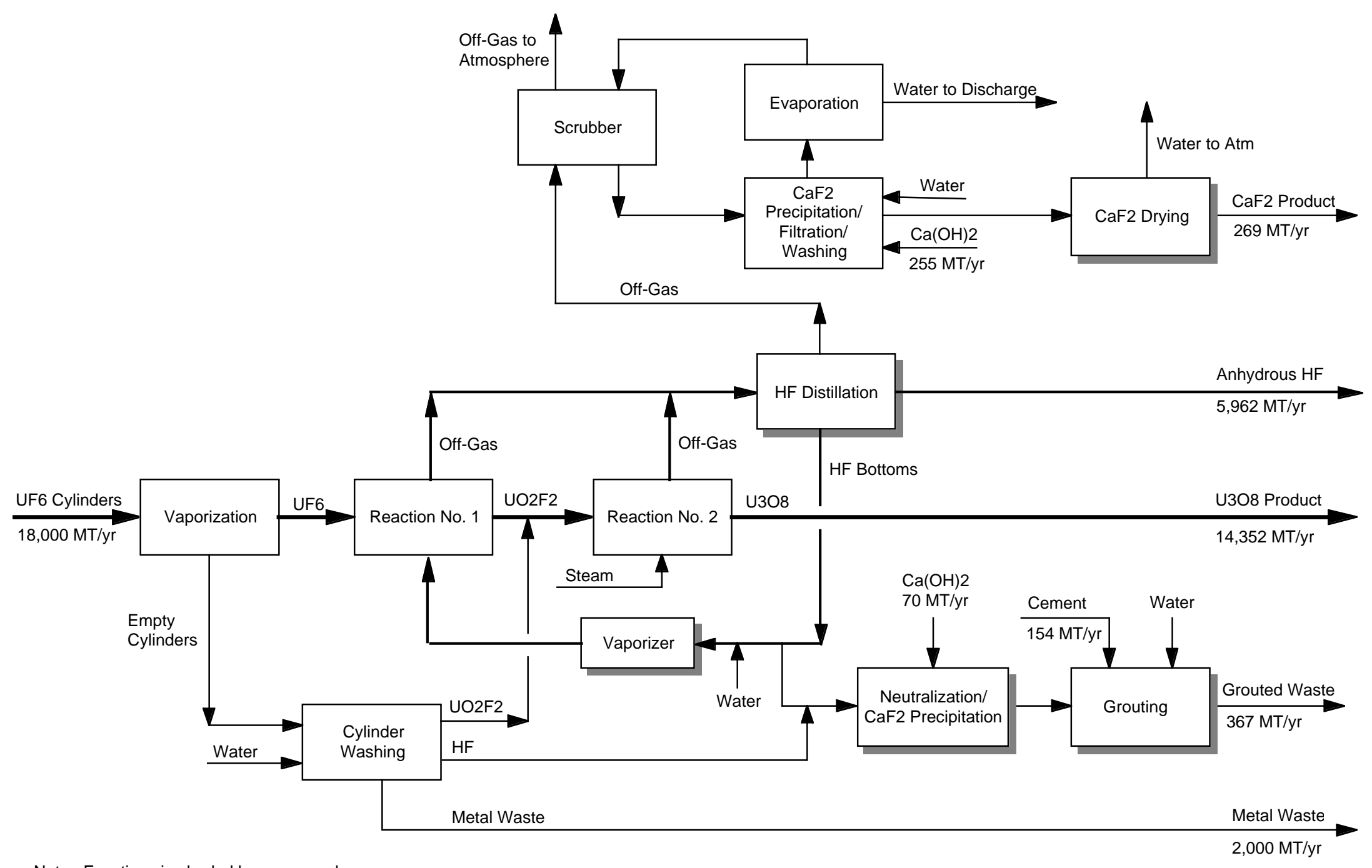

Note: Functions in shaded boxes are only

used during the AHF production mode.

Figure 5.1 Process Block Flow Diagram-AHF Production

Conversion to U3O8, AHF and CaF2 


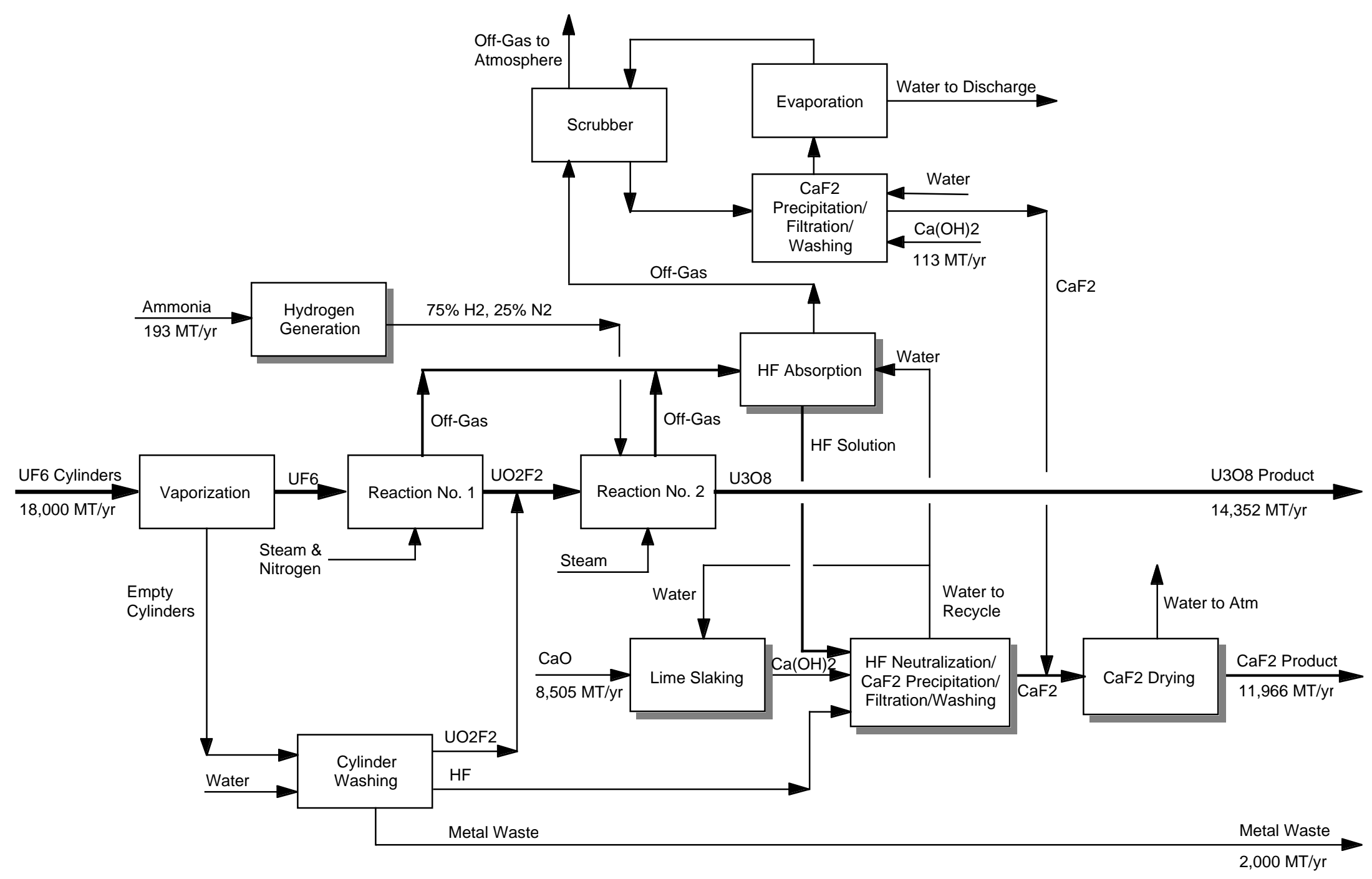

Note: Functions in the shaded boxes are

only used during the $\mathrm{CaF} 2$ production mode.

Figure 5.2 Process Block Flow Diagram - CaF2 Production

Conversion to U3O8, AHF and CaF2 


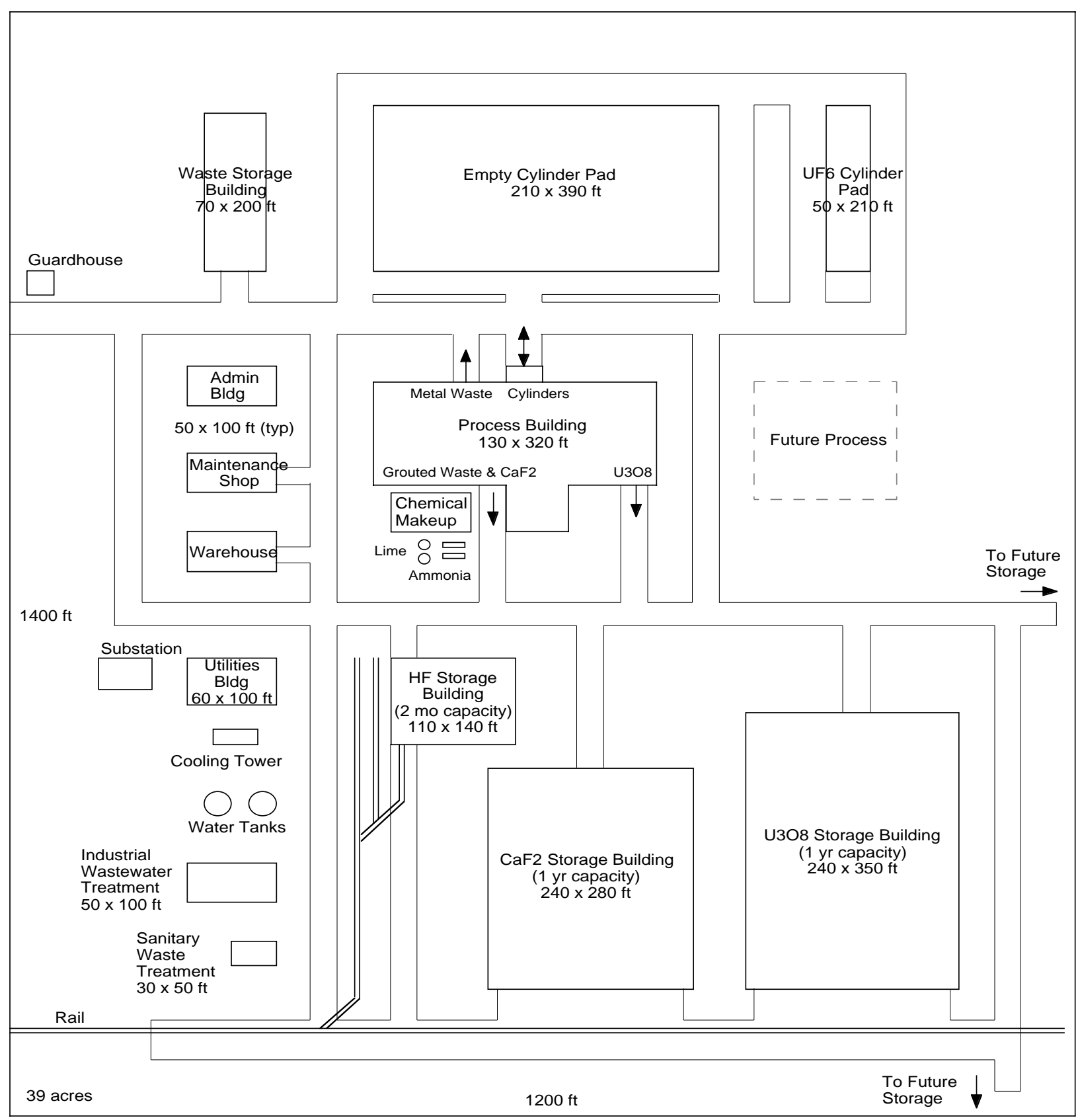

Figure 5.3 Facility Site Plan

Conversion to U3O8, AHF and CaF2 




Figure 5.4 Process Building General Arrangement Conversion to U3O8, AHF and CAF2 
$240 \mathrm{ft}$

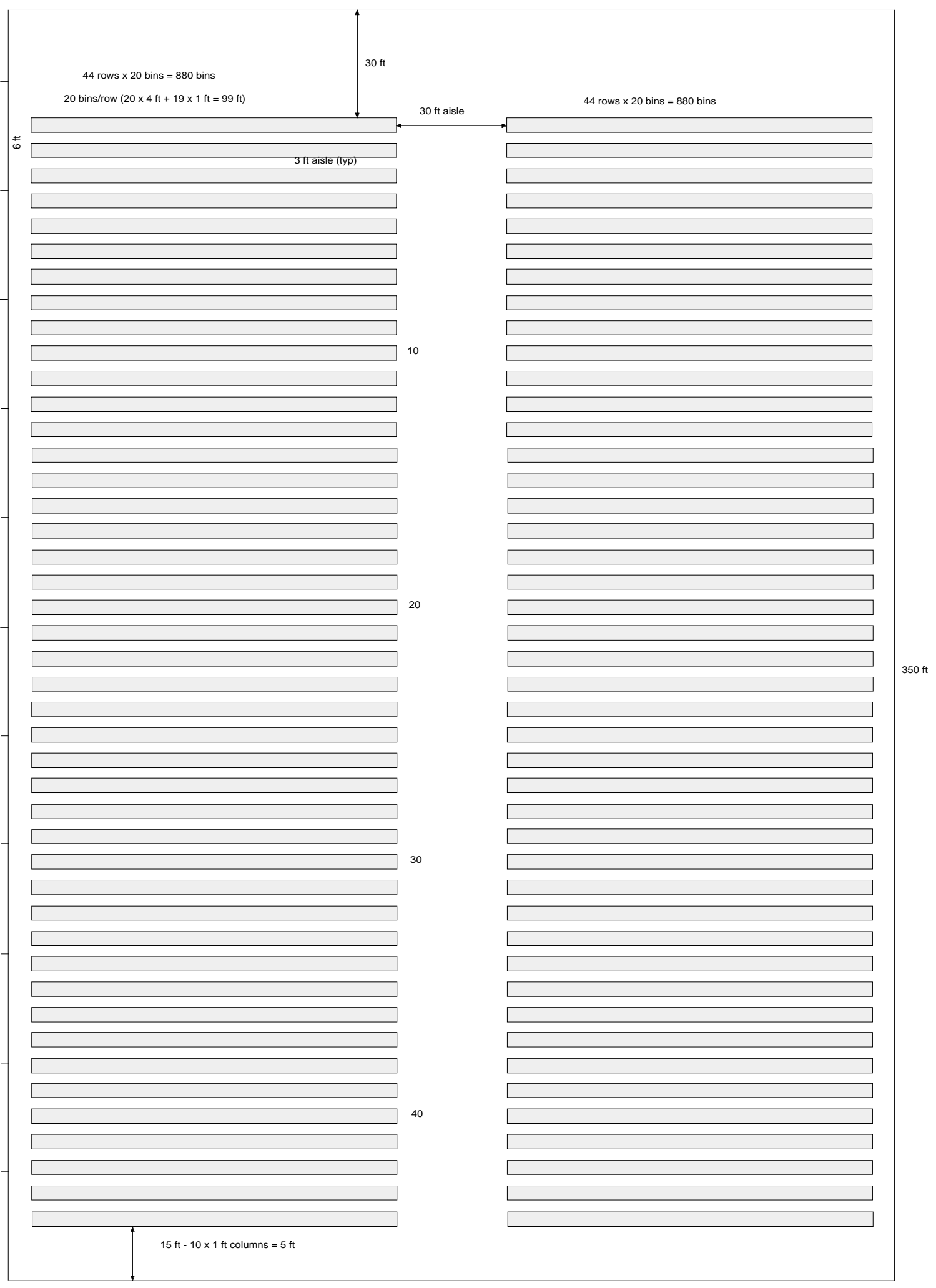

Figure 5.5 U308 Storage Building Plan

Conversion to $\mathrm{U} 3 \mathrm{O} 8$, $\mathrm{AHF}$ and $\mathrm{CaF} 2$ 


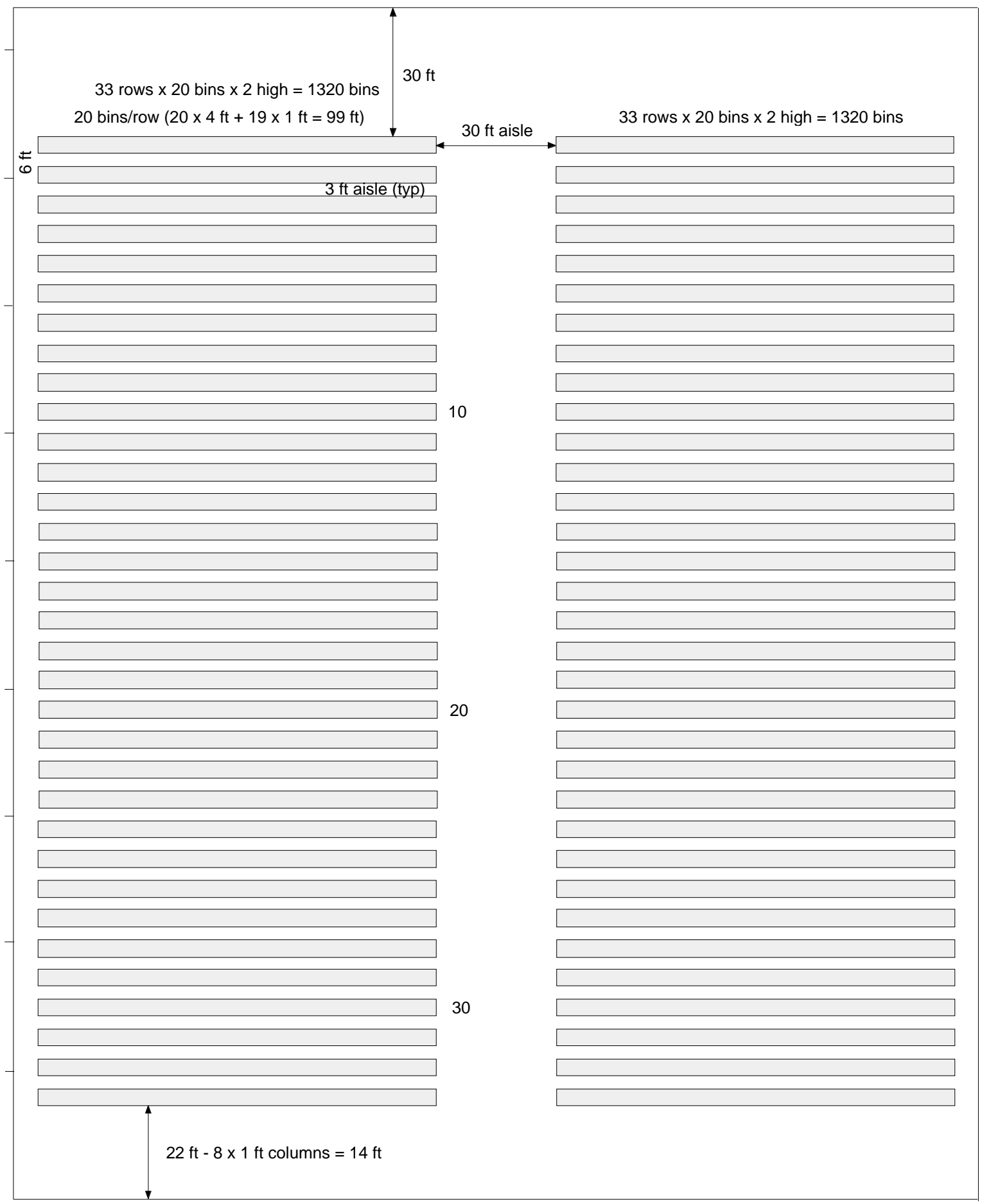




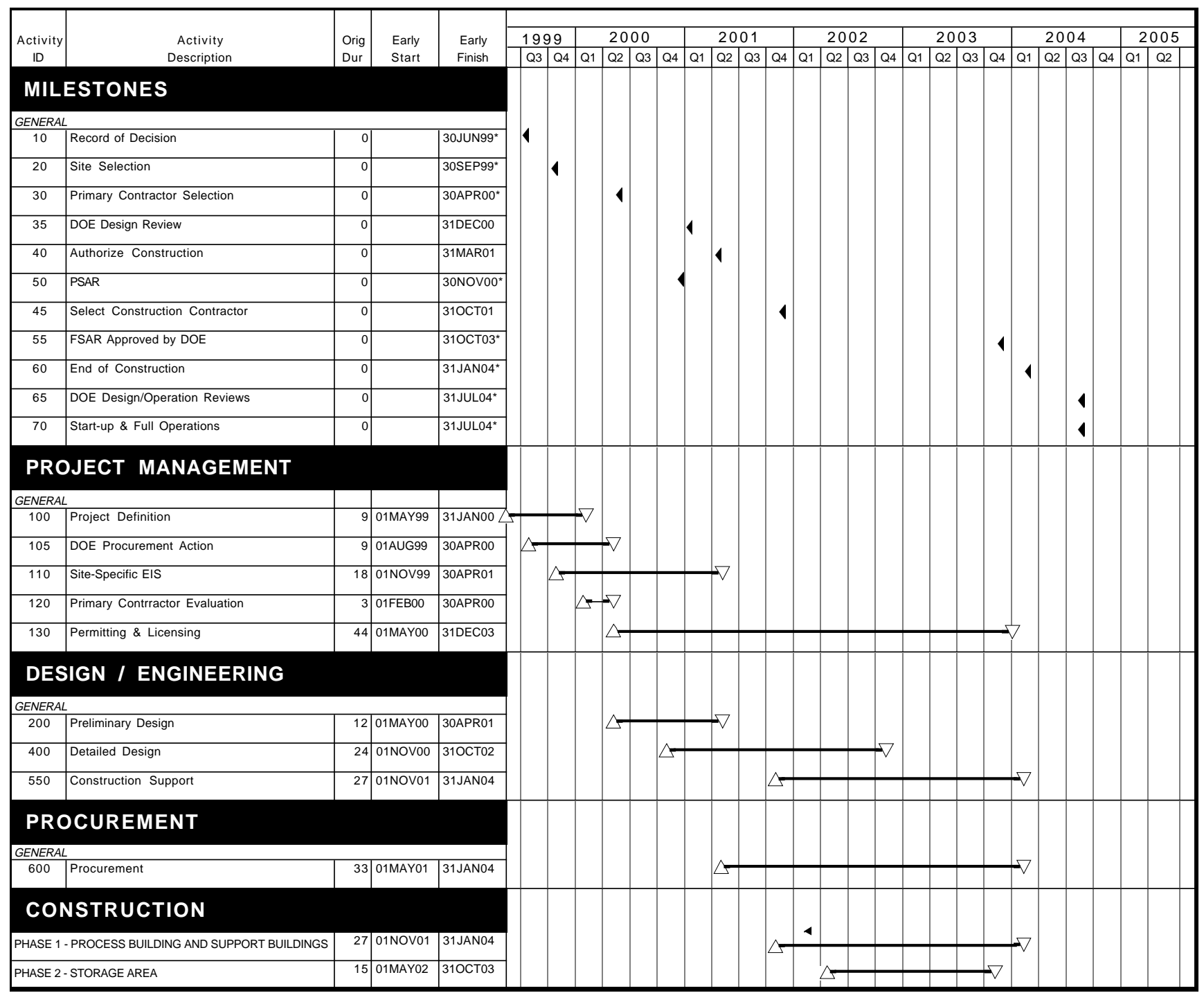

Figure 5.7 U3O8/AHF/CaF2 Plant, 25 Year Privately Owned and Operated Preliminary Project Schedule 
Table 5.1

Plant Operation Manpower Estimates for U3O8/AHF/CaF2 Conversion Facility

25 Years Privately Operated

\begin{tabular}{|l|c|}
\hline Labor Category & Total Employees \\
\hline Officials and Managers & 6 \\
\hline Professionals & 10 \\
\hline Technicians & 16 \\
\hline Office and Clericals & 10 \\
\hline Craft Workers (Maint./Production) & 24 \\
\hline Operators & 84 \\
\hline Line Supervision & 17 \\
\hline Security & 16 \\
\hline Total & $\mathbf{1 8 3}$ \\
\hline
\end{tabular}

Table 5.2

U3O8/AHF/CaF2 Project Capital Cost Estimate

\begin{tabular}{|l|r|r|r|}
\hline \multicolumn{1}{|c|}{ Facility/Cost Items } & \multicolumn{1}{c|}{ Subtotal } & \multicolumn{1}{c|}{ Contingency } & \multicolumn{1}{c|}{ Total } \\
\hline Process Equipment & $35,047,000$ & $12,266,000$ & $47,313,000$ \\
\hline Process Facilities & $82,581,000$ & $28,904,000$ & $111,485,000$ \\
\hline Balance of Plant & $32,176,000$ & $11,261,000$ & $43,437,000$ \\
\hline Subtotal & $149,804,000$ & $52,431,000$ & $202,235,000$ \\
\hline Engineering \& Design @ 14.4\% & $21,572,000$ & $7,550,000$ & $29,122,000$ \\
\hline Total & $\mathbf{1 7 1 , 3 7 6 , 0 0 0}$ & $\mathbf{5 9 , 9 8 1 , 0 0 0}$ & $\mathbf{2 3 1 , 3 5 7 , 0 0 0}$ \\
\hline
\end{tabular}


Table 5.3

Operation and Maintenance Cost Estimate U3O8 / AHF / CaF2

\begin{tabular}{|c|c|c|c|}
\hline \multicolumn{2}{|r|}{ DESCRIPTION } & \begin{tabular}{|c|} 
TOTAL ANNUAL COST \\
$\mathrm{U} 3 \mathrm{O} 8 / \mathrm{CaF} 2$ \\
\end{tabular} & $\begin{array}{c}\text { TOTAL ANNUAL COST } \\
\text { U3O8 / AHF }\end{array}$ \\
\hline \multicolumn{4}{|c|}{ 1. Consumable and Materials } \\
\hline & Process Chemicals & 667,617 & 70,957 \\
\hline & Cooling Tower Water Treatment Chemicals & 33,920 & 33,708 \\
\hline & Product and Waste Containers & $6,058,285$ & $3,373,326$ \\
\hline & Scheduled Replaceable Equipment for Reaction Chambers & 771,680 & 771,680 \\
\hline & Facility Maintenance & 655,329 & 655,329 \\
\hline & Equipment Spares & 946,260 & 946,260 \\
\hline & Total Materials & $9,133,091$ & $5,851,260$ \\
\hline 2. & Utilities \& Service & $1,821,994$ & $1,821,994$ \\
\hline 3. & Labor & & \\
\hline & Plant operation labors & $16,267,800$ & $16,267,800$ \\
\hline & Off-site overhead labor & $1,952,136$ & $1,952,136$ \\
\hline & Total Labor & $18,219,936$ & $18,219,936$ \\
\hline & Waste Management \& Disposal & & \\
\hline & Low Level Wastes & 424,500 & $1,169,600$ \\
\hline & Mixed Low Level Wastes & 4,100 & 4,100 \\
\hline & Hazardous Wastes & 5,180 & 5,180 \\
\hline & Total Waste Management/Disposal & 433,780 & $1,178,880$ \\
\hline Total & Operation \& Maintenance Annual Cost & $29,608,800$ & $27,072,070$ \\
\hline Start & $\begin{array}{l}\text {-Up Cost } \\
\text { Facility start-up cost based on allowance of } 65 \% \text { of one year O\&M } \\
\text { total labor cost. }\end{array}$ & $11,842,958$ & $11,842,958$ \\
\hline Total & O\&M Cost for 25 years & $752,062,967$ & $688,644,698$ \\
\hline
\end{tabular}


Table 5.5 Expenditure Funding Profile

U3O8/AHF/CaF2 25 Years POPO

10-year payback

AHF Production Mode (in million FY2000 dollars)

\begin{tabular}{|c|c|c|c|c|c|c|c|c|c|c|c|c|}
\hline \multirow[b]{2}{*}{ Construction Investment: } & TOTAL & FY99 & $\mathrm{FY} 00$ & FY01 & $\mathrm{FY} 02$ & FY03 & $\mathrm{FY} 04$ & FY05 & FY06 & FY07 & FY08 & FY09 \\
\hline & & & & & & & & & & & & \\
\hline NEPA/Licensing & 5.0 & & 0.5 & 1.3 & 1.3 & 1.3 & 0.5 & & & & & \\
\hline Engineering & 29.1 & & 3.6 & 13.4 & 9.0 & 2.7 & 0.4 & & & & & \\
\hline Construction & 202.2 & 0.2 & 2.0 & 5.4 & 37.2 & 120.7 & 36.7 & & & & & \\
\hline Start-up & 11.8 & & & & & & 11.8 & & & & & \\
\hline Total Investment Loan & $2 \overline{48.2}$ & 0.2 & 6.0 & 20.2 & 47.6 & 124.7 & 49.4 & & & & & \\
\hline Accumulated Debt: & & 0.2 & 6.8 & 29.3 & 83.4 & 225.8 & 298.7 & 278.5 & 256.7 & 233.0 & 207.3 & 179.4 \\
\hline \multicolumn{13}{|l|}{ Operation Expenses: } \\
\hline Debt Payment & 455.2 & & & & & & & 45.5 & 45.5 & 45.5 & 45.5 & 45.5 \\
\hline Operation \& Maintenance & 676.8 & & & & & & 4.5 & 27.1 & 27.1 & 27.1 & 27.1 & 27.1 \\
\hline Decon \&Decommission & 23.1 & & & & & & & & & & & \\
\hline Total Operation Expenses & $11 \overline{55.1}$ & & & & & & 4.5 & 72.6 & 72.6 & 72.6 & 72.6 & 72.6 \\
\hline \multicolumn{13}{|l|}{ Revenues: } \\
\hline Break-even Conversion Revenue & 926.5 & & & & & & 10.7 & 64.1 & 64.1 & 64.1 & 64.1 & 64.1 \\
\hline HF Product Sales & 228.6 & & & & & & 1.5 & 9.1 & 9.1 & 9.1 & 9.1 & 9.1 \\
\hline Total Revenue & $1 \overline{155.1}$ & & & & & & 12.2 & 73.2 & 73.2 & 73.2 & 73.2 & 73.2 \\
\hline Cash Funding Requirements: & 719.5 & 0.2 & 6.0 & 20.2 & 47.6 & 124.7 & 52.4 & 17.9 & 17.9 & 17.9 & 17.9 & 17.9 \\
\hline Break-even Government Payment: & 926.5 & & & & & & 10.7 & 64.1 & 64.1 & 64.1 & 64.1 & 64.1 \\
\hline
\end{tabular}

Notes: Cash funding requirements reflect cash flow required for construction and operating minus revenue from AHF sales. Break-even government payment is the funding from DOE paid to the private plant owner for the conversion service to cover the break-even cost for construction loan payment, operation, and D\&D only; no profits included.

Assumptions:

Loan Interest Rate@ 8.5\% for Construction Loan during construction period

Loan Interest Rate@ 8.5\% for payback in 10 years at start of operation

Chemical Sale Price: $\quad 70 £ / l b$ of HF 
Table 5.5, continued Expenditure Funding Profile

U3O8/AHF/CaF2 25 Years POPO

10-year payback

AHF Production Mode

(in million FY2000 dollars)

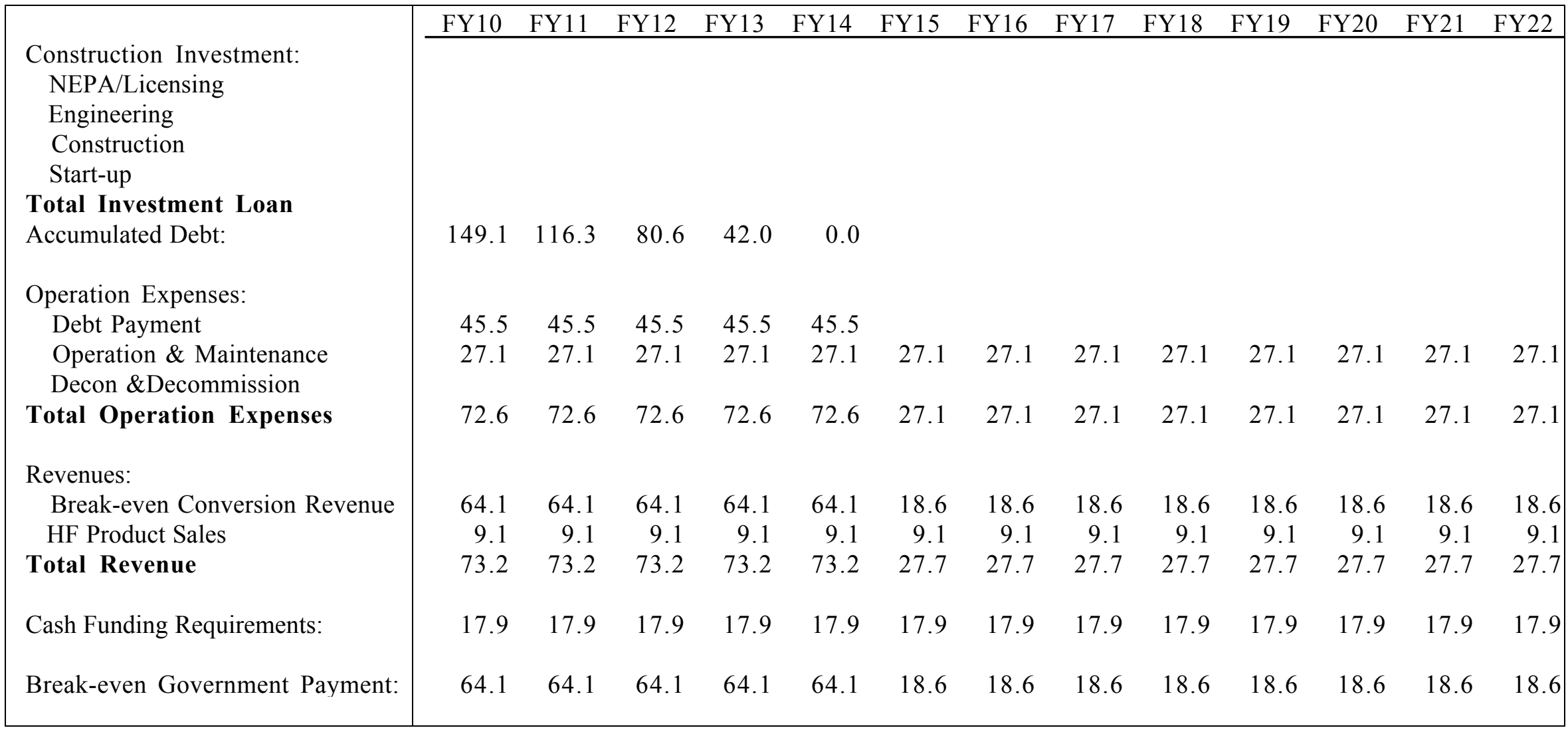


Table 5.5, continued Expenditure Funding Profile

U3O8/AHF/CaF2 25 Years POPO

10-year payback

AHF Production Mode

(in million FY2000 dollars)

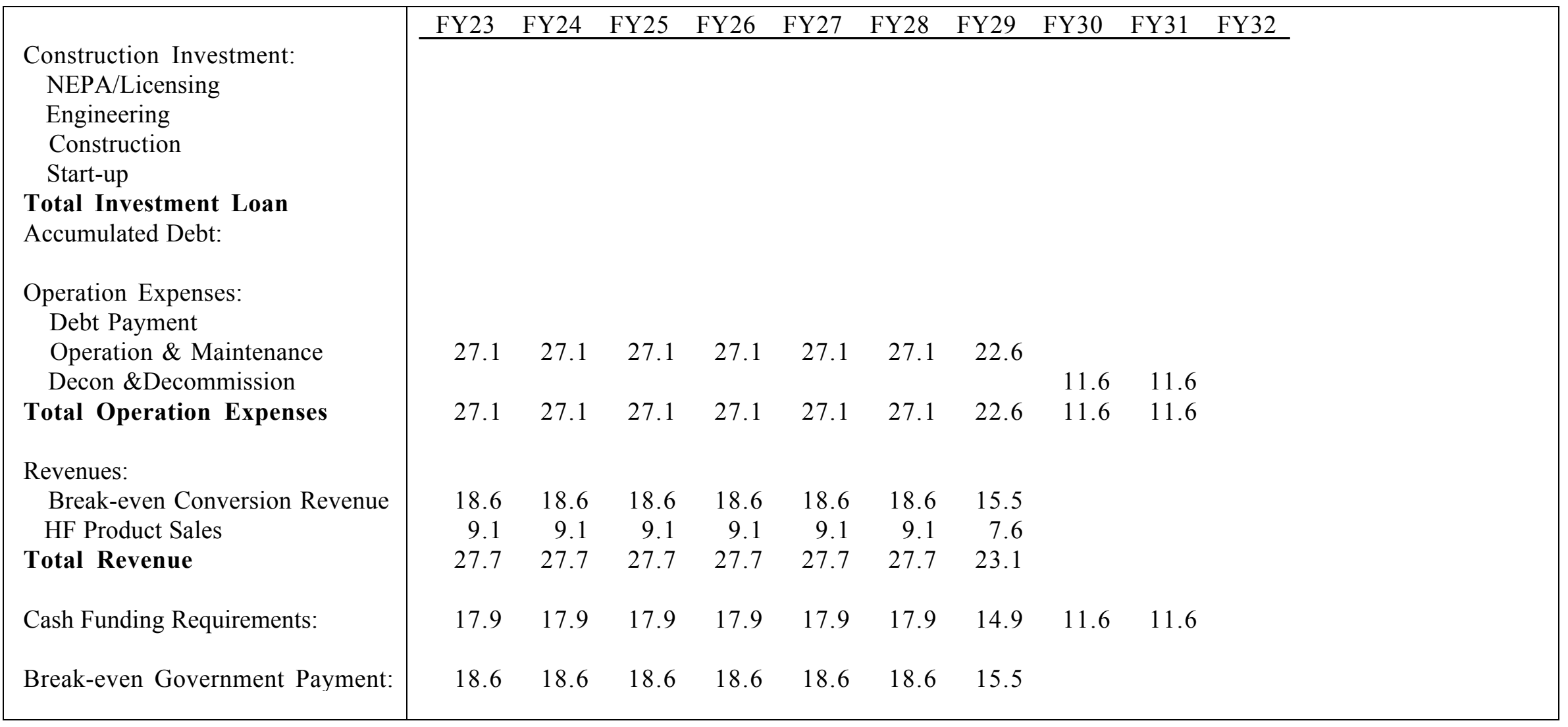


Table 5.6 Expenditure Funding Profile

U3O8/AHF/CaF2 25 Years POPO

10-year payback

CaF2 Production Mode (in million FY2000 dollars)



Notes: Cash funding requirements reflect cash flow required for construction and operating minus revenue from AHF sales. Break-even government payment is the funding from DOE paid to the private plant owner for the conversion service Assumptions: to cover the break-even cost for construction loan payment, operation, and D\&D only; no profits included.

Loan Interest Rate @ 8.5\% for Construction Loan during construction period

Loan Interest Rate $@, 8.5 \%$ for payback in 10 years at start of operation 
Table 5.6, continued Expenditure Funding Profile

U3O8/AHF/CaF2 25 Years POPO

10-year payback

CaF2 Production Mode

(in million FY2000 dollars)

\begin{tabular}{|c|c|c|c|c|c|c|c|c|c|c|c|c|c|}
\hline & FY10 & FY11 & FY12 & FY13 & FY14 & FY15 & FY16 & FY17 & FY18 & FY19 & FY20 & FY21 & FY22 \\
\hline $\begin{array}{l}\text { Construction Investment: } \\
\text { NEPA/Licensing } \\
\text { Engineering } \\
\text { Construction } \\
\text { Start-up }\end{array}$ & & & & & & & & & & & & & \\
\hline $\begin{array}{l}\text { Total Investment Loan } \\
\text { Accumulated Debt: }\end{array}$ & 149.1 & 116.3 & 80.6 & 42.0 & 0.0 & & & & & & & & \\
\hline $\begin{array}{l}\text { Operation Expenses: } \\
\text { Debt Payment }\end{array}$ & 45.5 & 45.5 & 45.5 & 45.5 & 45.5 & & & & & & & & \\
\hline $\begin{array}{l}\text { Operation \& Maintenance } \\
\text { Decon \&Decommission }\end{array}$ & 29.6 & 29.6 & 29.6 & 29.6 & 29.6 & 29.6 & 29.6 & 29.6 & 29.6 & 29.6 & 29.6 & 29.6 & 29.6 \\
\hline Total Operation Expenses & 75.1 & 75.1 & 75.1 & 75.1 & 75.1 & 29.6 & 29.6 & 29.6 & 29.6 & 29.6 & 29.6 & 29.6 & 29.6 \\
\hline Revenues: & & & & & & & & & & & & & \\
\hline $\begin{array}{l}\text { Break-even Conversion Revenue } \\
\text { HF Product Sales }\end{array}$ & 75.8 & 75.8 & 75.8 & 75.8 & 75.8 & 30.2 & 30.2 & 30.2 & 30.2 & 30.2 & 30.2 & 30.2 & 30.2 \\
\hline Total Revenue & 75.8 & 75.8 & 75.8 & 75.8 & 75.8 & 30.2 & 30.2 & 30.2 & 30.2 & 30.2 & 30.2 & 30.2 & 30.2 \\
\hline Cash Funding Requirements: & 29.6 & 29.6 & 29.6 & 29.6 & 29.6 & 29.6 & 29.6 & 29.6 & 29.6 & 29.6 & 29.6 & 29.6 & 29.6 \\
\hline Break-even Government Payment: & 75.8 & 75.8 & 75.8 & 75.8 & 75.8 & 30.2 & 30.2 & 30.2 & 30.2 & 30.2 & 30.2 & 30.2 & 30.2 \\
\hline
\end{tabular}


Table 5.6, continued Expenditure Funding Profile

U3O8/AHF/CaF2 25 Years POPO

10-year payback

CaF2 Production Mode

(in million FY2000 dollars)

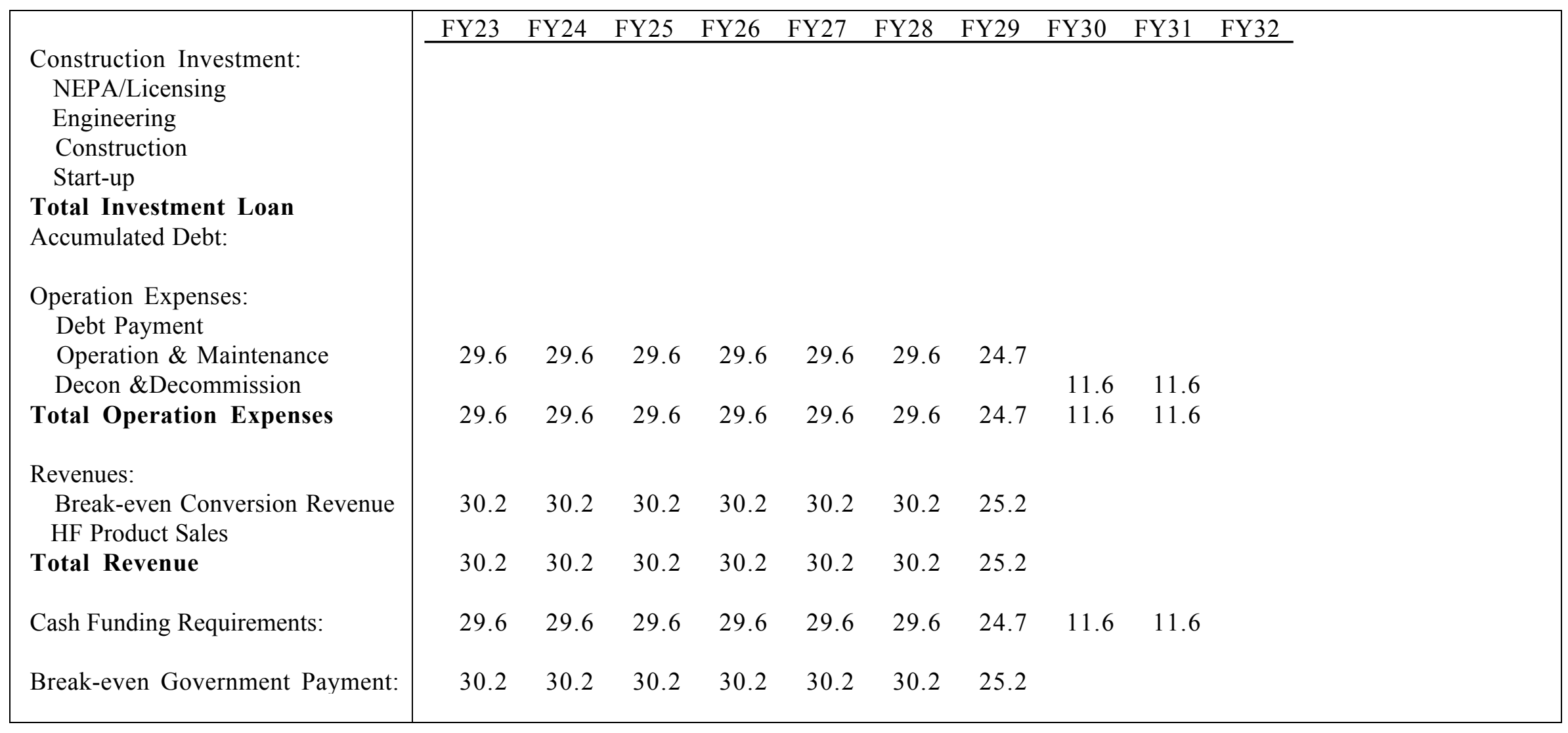





\section{DUF6 Conversion to UO2/AHF}

\subsection{Introduction}

About 700,000 metric tons (MT) of depleted uranium hexafluoride (DUF6) are currently stored at the Paducah, Portsmouth and Oak Ridge sites. Public Law 105-204 requires the DOE to submit to Congress a plan to ensure that all funds accrued on the books of USEC for disposition of DUF6 will be used for the construction and operation of plants to treat and recycle the DUF6. The Department of Energy's Initial Plan calls for construction to begin in the year 2002 time frame.

This report section examines the cost and issues for plant construction based on a conversion plant using a dry process to convert DUF6 to uranium dioxide aggregate and anhydrous hydrogen fluoride (AHF) as final products. The UO2 aggregate can be used to make dense concrete for shielding applications. The construction and operation of the conversion plant is based on private ownership with DOE regulations and operating for 25 years.

A preconceptual plant design, rough cost estimate, and preliminary project schedule were developed. The integrated conversion plant includes capabilities for DUF6 cylinder preparation, conversion of DUF6 to uranium dioxide (UO2) and fluorine byproducts, manufacture of UO2 aggregate, empty cylinder treatment for disposal, and interim storage for UO2 aggregate and byproducts.

Significant design bases for the conversion plant include:

- The plant will convert DUF6 to UO2 by a dry process. Hydrogen fluoride (HF) off-gas will be treated to produce AHF and a minor quantity of calcium fluoride $(\mathrm{CaF} 2)$.

- $\quad$ The UO2 will be mixed with additives, pressed into pellets, and sintered to produce dense UO2 aggregate. The aggregate is assumed to be $93 \% \mathrm{UO} 2$, sintered at $1300^{\circ} \mathrm{C}$, have a final diameter and length of $3 / 4 \mathrm{inch}$, and a particle density of $8 \mathrm{~g} / \mathrm{cc}$.

- The plant capacity will be based on a 25 year operating period to process a DUF6 inventory of 36,910 cylinders (450,000 MT DUF6) over the life of the plant.

- Storage will be provided for one year production of $\mathrm{UO} 2$ aggregate and $\mathrm{CaF} 2$ product and two months production of AHF.

- The AHF product is available for sale by plant owner to commercial users. The UO2 aggregate and $\mathrm{CaF} 2$ products are returned to the $\mathrm{DOE}$.

- To bound costs associated with empty cylinders, assume all empty cylinders will be washed, compacted, and returned to the DOE for disposal.

- The plant will be on a DOE owned site at or near a gaseous diffusion plant and include the support facilities and infrastructures/utilities needed for a greenfield facility.

- The design will consider addition of future process and storage buildings. 


\subsection{Summary of Results}

The plant annually processes 18,000 MT of UF6 contained in 1,476 cylinders to produce 14,846 MT of 93\% UO2 aggregate, 5,944 MT of AHF, $304 \mathrm{MT}$ of CaF2, and 2,000 MT of empty cylinder metal waste. The plant, which includes a one year storage capacity for UO2 aggregate and CaF2 and two months storage capacity for AHF, occupies about 37 acres. Additional storage capacity would require about 4 acres for each year of additional UO2 aggregate storage.

The construction capital cost estimate is \$206 million for the plant facilities. The engineering cost is about $\$ 30$ million. Each year of additional UO2 storage would be \$13 million. These costs are in 1st Quarter FY2000 dollars.

The annual operation and maintenance (O\&M) cost is about $\$ 28$ million. The O\&M cost does not include disposal of empty cylinder metal. Cost for NEPA, regulatory and licensing activities is estimated at \$5 million. Decontamination and decommissioning (D\&D) cost is estimated at \$24 million.

The preliminary schedule assumes selection of a private plant contractor in April 2000. The schedule shows plant engineering design starting in May 2000, construction beginning in November 2001, plant completion in January 2004, and full operation beginning in July 2004. Peak engineering personnel is 80 persons and peak employment during construction is about 450 persons. Plant employment during operations is 191 persons.

The 2002 construction start depends on the key milestone dates for site selection, selection of primary contractor and construction contractor, and construction approval. The schedule includes NEPA activities, as a site-specific EIS is required, and DOE regulatory activities. The amount of UO2 aggregate storage provided affects cost and may need additional study. Process design criteria for UF6 cylinder vaporization, conversion reaction chamber, HF distillation, and empty cylinder treatment are necessary to ensure successful facility design and operation.

\subsection{Conversion Process Description}

Depleted uranium hexafluoride (DUF6) is processed to produce UO2 aggregate and AHF. The average throughput is 5 cylinders per day $(5,670 \mathrm{lb} / \mathrm{hr}$ DUF6) based on $80 \%$ plant availability $(7,000$ hours/yr or 292 days/yr). The process block flow diagram is shown in Figure 6.1.

The DUF6 is shipped by truck from the cylinder yards at the gaseous diffusion plant to an outdoor storage pad at the Conversion Facility. The cylinder is moved into the Process Building for inspection and preparation. The cylinders are loaded into steam-heated autoclaves to vaporize the DUF6 for feeding into the conversion process. Cylinders with questionable integrity are loaded into hot air ovens where the solid UF6 sublimes into a gas under vacuum. This avoids melting the DUF6 and pressurizing the cylinder, which occurs when using an autoclave. Several of the cylinders may be substandard based on the DUF6 Engineering Analysis Report (p. 6.1-4-5).

The UF6 gas is converted to UO2 in a series of two reaction chambers, where it is mixed with an $\mathrm{HF} /$ water vapor mixture in the first reaction chamber and with steam, nitrogen and hydrogen in the second reaction chamber. The chemical reactions are:

$\mathrm{UF} 6+2 \mathrm{H}_{2} \mathrm{O}--->\mathrm{UO}_{2} \mathrm{~F}_{2}+4 \mathrm{HF}$

$\mathrm{UO}_{2} \mathrm{~F}_{2}+\mathrm{H}_{2}--->\mathrm{UO} 2+2 \mathrm{HF}$ 
Four reaction lines are provided to meet the required throughput. The UO2 product is cooled and conveyed to indoor silos for interim storage.

Reaction chamber off-gas containing HF, steam, nitrogen and hydrogen is filtered to remove uranium particulates. The off-gas then flows to an HF distillation system, which concentrates the mixture to produce anhydrous HF in the overhead product. The AHF is collected, sampled, and pumped to large storage tanks in the HF Storage Building, where the AHF is loaded into railcars or tank trucks for delivery to customers. The AHF is expected to contain less than $1 \mathrm{ppm}$ uranium.

The aqueous hydrogen fluoride bottoms stream from HF distillation is collected, vaporized and recycled to the first reaction chamber. To prevent the buildup of impurities in the recycle stream, a small fraction is withdrawn. This purge stream is neutralized with hydrated lime, mixed with cement and water to form a grout, and packaged in drums for disposal.

Off-gas from the distillation column, primarily nitrogen, hydrogen and air inleakage, flows to the scrubber system. Residual HF in the off-gas is removed by scrubbing with a potassium hydroxide (KOH) solution. The off-gas is then HEPA-filtered and discharged to the atmosphere. The spent scrub solution is regenerated with hydrated lime $\left(\mathrm{Ca}(\mathrm{OH})_{2}\right)$, which produces a calcium fluoride $(\mathrm{CaF} 2)$ byproduct. The chemical reactions are:

$\mathrm{HF}+\mathrm{KOH}--->\mathrm{KF}+\mathrm{H}_{2} \mathrm{O}$

$2 \mathrm{KF}+\mathrm{Ca}(\mathrm{OH})_{2}--->\mathrm{CaF} 2+2 \mathrm{KOH}$

The CaF2 is separated by filtering, washed with water, dried and loaded into drums. The drums, containing $700 \mathrm{lb}$ of $\mathrm{CaF} 2$, are transferred to the $\mathrm{CaF} 2$ Storage Building. The $\mathrm{CaF} 2$ is expected to contain less than 1 ppm uranium.

The UO2 powder is converted to pellets suitable for use as aggregate in dense concrete shielding applications. The composition, sintering temperature and dimensions of the aggregate product are being developed and the design parameters mentioned below are nominal values only.

The first step in pelletization is to mix the UO2 powder with additives to produce a 93\% UO2 mixture. The mixture is milled, screened to remove oversize material, and agglomerated into granules to enable reproducible and dust-free feeding to a powder compacting press. The press produces cylindrical pellets that are nominally 1 inch diameter by 1 inch high. The pellets are loaded onto trays, which are moved by conveyor into a sintering furnace. The pellets are sintered at $1300^{\circ} \mathrm{C}$ in a hydrogen atmosphere to form dense, ceramic pellets. The sintered pellets (UO2 aggregate), which are about $3 / 4$ inch diameter by $3 / 4$ inch high, are unloaded from the trays and loaded into metal boxes. The $60 \mathrm{cu} \mathrm{ft}$ box is about $4 \mathrm{x} 4 \mathrm{x} 4 \mathrm{ft}$ tall and hold 8.5 tons $(7.7 \mathrm{MT})$ of UO2 aggregate. The filled boxes are transferred to the UO2 Storage Building.

After vaporization, the empty cylinders are transferred to an outdoor pad and stored for three months. This allows for radioactive decay of non-volatile daughter products in the cylinder. The cylinders are then brought into the Process Building, washed with water, crushed, and loaded into boxes. Each $6 \times 14 \times 3 \mathrm{ft}$ high box contains about 9,000 lb of metal from three crushed cylinders. The filled boxes are stored in the Waste Storage Building and transported to the gaseous diffusion plant for disposition. The cylinder wash effluents are fed into the main conversion processes.

Major process materials and annual quantities are summarized below: 


\begin{tabular}{|c|c|}
\hline Major Input Streams & Major Output Streams \\
\hline $\begin{array}{l}\text { Depleted Uranium Hexafluoride } \\
18,000 \mathrm{MT} / \mathrm{yr} \\
1476 \text { cylinders/yr }\end{array}$ & $\begin{array}{l}\text { Uranium Dioxide Aggregate }(93 \% \mathrm{UO} 2) \\
14,846 \mathrm{MT} / \mathrm{yr} \\
19264 \mathrm{x} 4 \mathrm{x} 4 \mathrm{ft} \text { boxes/yr }(17,000 \mathrm{lb} / \mathrm{box}) \\
\text { or } 29,76030 \text {-gal drums } / \mathrm{yr}(1100 \mathrm{lb} / \mathrm{drum})\end{array}$ \\
\hline $\begin{array}{l}\text { Hydrated Lime } \mathrm{Ca}(\mathrm{OH})_{2} \\
358 \mathrm{MT} / \mathrm{yr} \\
9600 \mathrm{ft} 3 / \mathrm{yr}\end{array}$ & $\begin{array}{l}\text { Anhydrous Hydrogen Fluoride (HF) } \\
5944 \mathrm{MT} / \mathrm{yr} \\
1.64 \mathrm{million} \mathrm{gal} / \mathrm{yr}\end{array}$ \\
\hline $\begin{array}{l}\text { Cement } \\
154 \mathrm{MT} / \mathrm{yr} \\
2890 \mathrm{ft} 3 / \mathrm{yr}\end{array}$ & $\begin{array}{l}\text { Calcium Fluoride }(\mathrm{CaF} 2) \\
304 \mathrm{MT} / \mathrm{yr} \\
958 \text { 55-gal drums/yr }(700 \mathrm{lb} / \mathrm{drum})\end{array}$ \\
\hline $\begin{array}{l}\text { Aggregate Additives } \\
1039 \mathrm{MT} / \mathrm{yr} \\
30,600 \mathrm{ft} 3 / \mathrm{yr}\end{array}$ & $\begin{array}{l}\text { Empty Cylinder Metal Waste } \\
2000 \mathrm{MT} / \mathrm{yr} \\
4926 \times 14 \times 3(\mathrm{H}) \mathrm{ft} \text { boxes/yr }(9000 \mathrm{lb} / \mathrm{box})\end{array}$ \\
\hline $\begin{array}{l}\text { Ammonia }(\mathrm{NH} 3) \\
838 \mathrm{MT} / \mathrm{yr} \\
364,000 \mathrm{gal} / \mathrm{yr}\end{array}$ & $\begin{array}{l}\text { Grouted Waste } \\
367 \mathrm{MT} / \mathrm{yr} \\
101255 \text {-gal drums/yr (800 lb/drum) }\end{array}$ \\
\hline
\end{tabular}

Major process equipment includes four steam autoclaves, six hot air ovens, four reaction chamber lines, UO2 blending system, two lines of powder preparation and compacting equipment, five sintering furnaces, a box loading system, an HF distillation system, off-gas scrubbing system, neutralization/grouting system, two empty cylinder washing machines and one cylinder crusher.

\subsection{Conversion Plant Description}

The Conversion Facility is assumed to be constructed on a DOE site at a greenfield location at or near a gaseous diffusion plant. The Conversion Facility occupies about 37 acres. Additional storage buildings for UO2 aggregate could be built adjacent or at a nearby location. Each additional one year increment of UO2 aggregate storage occupies 4 acres. A conceptual site plan for the Conversion Facility is shown in Figure 6.2.

The Conversion Facility includes full and empty cylinder storage pads, the Process Building, a UO2 aggregate Storage Building, an HF Storage Building, a CaF2 Storage Building, a Waste Storage Building and support facilities. The site plan considers addition of future process facilities such as uranium metal.

The Conversion Facility will be designed and constructed in compliance with DOE Orders and applicable regulations and codes, and will meet the intent of NRC standards. In general, a graded approach as established in DOE Order 420.1 is used for the design of all structures, systems, and components (SSC) in the plant facilities. All SSC's will be assigned a Natural Phenomena Performance Category using the criteria in the DOE Standards DOE-STD-1020-94 and DOE-STD-1021-93 during the design phase.

In the absence of a hazard analysis, it is assumed that the Process Building is performance category PC-3 to control and confine hazardous material. The building structure is reinforced concrete construction in the processing areas. The remainder of the building housing the personnel support area is steel frame, metal siding construction. The Process Building is $30 \mathrm{ft}$ high in the processing areas and $18 \mathrm{ft}$ high in the support areas. HVAC equipment is located on a mezzanine level. The process room air is filtered through 
one stage of HEPA filters prior to discharge to atmosphere. The Process Building general arrangement is shown in Figure 6.3.

The UO2 Storage Building and CaF2 Storage Building have a one year capacity. The UO2 Building holds 2000 boxes stacked two high, and the CaF2 Building holds 958 drums stacked two high. The Waste Building has a one month capacity for staging treated empty cylinders and process waste for transport offsite. The UO2, CaF2, and waste storage buildings are assumed PC-2 to maintain storage function after the occurrence of a natural phenomena hazards event. These buildings are steel frame and concrete clad panel construction and are ventilated and lighted, but no heating, cooling or HEPA filtration is provided. Access aisles allow personnel to inspect the bins during storage. A general storage arrangement in the UO2 Building is shown in Figure 6.4.

The HF Storage Building has a two months capacity with ten 34,000-gallon storage tanks. The HF Storage Building is assumed PC-3 to control and confine hazardous material. The building structure is reinforced concrete construction. The HF storage tanks are housed separately in cell rooms.

Plant operations are assumed to be continuous for 24 hours/day, 7 days/week, 52 weeks/year. Due to seven day per week operation, a fourth shift is necessary to account for normal days off for employees. The number of employees during operation is estimated to be 191 persons, with 68 employees on day shift and 41 each of the other three shifts. The numbers are estimated based on process operation labor and facility support labor requirements needed to operate the plant. A breakdown of the plant operation employees by category and by shift is shown in Table 6.1 .

\subsection{Cost Estimate}

The cost estimates are rough order of magnitude estimates based on a preconceptual level design information. The cost estimate results are summarized below:

\begin{tabular}{|l|c|c|c|}
\cline { 2 - 4 } \multicolumn{1}{c|}{} & \multicolumn{1}{c|}{$\begin{array}{c}\text { Cost } \\
\text { (\$million) }\end{array}$} & $\begin{array}{c}\text { Contingency } \\
\text { (\$million) }\end{array}$ & $\begin{array}{c}\text { Total Cost } \\
\text { (\$million) }\end{array}$ \\
\hline Conversion Facility & -- & -- & 30 \\
\hline Engineering & 153 & 53 & 206 \\
\hline $\begin{array}{l}\text { Plant Facilities } \\
\text { Construction Cost }\end{array}$ & -- & -- & 12 \\
\hline Startup Cost & -- & -- & 28 \\
\hline $\begin{array}{l}\text { Annual Operations and } \\
\text { Maintenance Cost (O\&M) }\end{array}$ & -- & -- & 24 \\
\hline $\begin{array}{l}\text { Decontamination and } \\
\text { Decommissioning (D\&D) }\end{array}$ & -- & -- & 1.1 \\
\hline Additional Storage & 11 & 2 & 13 \\
\hline Engineering & -- & -- & 5 \\
\hline $\begin{array}{l}\text { UO2 Storage (1 yr capacity) } \\
\text { Construction Cost }\end{array}$ & & & \\
\hline NEPA/Licensing & & & \\
\hline
\end{tabular}


The estimates do not include costs for plant design criteria development, cost of land, site qualifications, or extension of local roads and utility lines to the site boundary. The estimates take into account the labor productivity and indirect cost factors for a privately run project. Cost estimate bases are described in the Appendix.

The construction capital costs are based on an engineering, procurement and construction management (EPCM) approach. Capital costs, see Table 6.2, are reported in 1st quarter fiscal year 2000 dollars (October 1999). Labor costs are based on local wage rates at a generic gaseous diffusion plant located in mid-U.S.A. The capital cost estimate utilized historical cost data, estimating manuals, allowances and budgetary quotations. A 35\% contingency was applied to the capital costs for the Conversion Facility and $15 \%$ for the subsequent Storage Facilities. These contingency levels are based on previous risk analysis on projects of similar scope and level of design details. Engineering cost was estimated at $14.4 \%$ of the capital costs for the Conversion Facility and 8\% for the subsequent Storage Facilities. The lower percentages are used for the subsequent Storage Facilities because previous building engineering design can be reused. Product and waste container costs are included in the O\&M costs. The D\&D cost was estimated as $10 \%$ of the capital cost.

The O\&M cost includes costs for materials, utilities, labor, and waste disposal, see Table 6.3. Plant startup cost was assumed to be $65 \%$ of the annual O\&M labor cost. The annual O\&M cost does not include the cost for disposal of empty cylinder metal waste. If the empty cylinder metal is to be disposed as low-level waste (LLW), the estimated disposal cost would range from \$1 million to \$12 million annually, depending on the disposal sites. Revenue from sales of AHF is also not included in the O\&M cost. The O\&M cost includes $\$ 1.8$ million a year for boxes to package the UO2 product. This cost could be saved if the empty boxes are returned from customers and reused.

The annual expenditure required to support the construction and operation of the conversion plant for the initial project years is shown in Table 6.4. The expenditure profile for all years is shown below. The expenditure profiles are derived from loading the estimated capital and operating costs onto the project schedule. A constant FY2000 dollar value is used in the expenditure outlay because of the difficulty in accurately projecting the inflation rate for future years.

\subsection{Project Schedule}

An estimated preliminary project schedule is shown in Figure 6.5. The schedule allows 2.5 years for engineering design and 2 years for construction. The schedule is based on a fast track premise with overlapping engineering phases and early procurement of some key equipment (most equipment is available in 12-18 month lead time) and a two-phase construction plan. The estimated peak engineering personnel is 80 persons and peak employment during construction is 450 persons.

\subsection{Discussion and Issues}

\subsubsection{Process}

Boxes were used to package the UO2 aggregate because of the space savings compared to drums. Using boxes instead of drums significantly reduces the storage building area. If only a limited amount of UO2 aggregate is to be stored, drums may be preferable due to easier handling. Additional study is needed to determine the best storage container to use with the cost considerations on facilities and transport.

In cylinder washing, the empty cylinders are cleaned to remove the reactive fluoride materials inside the cylinder. It was assumed that the metal from washed empty cylinders is returned to the DOE for disposal. The residual uranium contaminated cylinders might require the cylinder metal to be disposed of as LLW. 
Alternate dispositions include recycling and reusing the radioactively-contaminated carbon steel for LLW containers for further use in the nuclear industry or decontaminating the metal sufficiently for disposal as non-hazardous waste or scrap.

\subsubsection{Facility}

Buildings for processing and storage were assumed to be performance category PC-2 or PC-3. A safety and accident analysis was not performed and is needed to determine the hazard classification and performance category. The appropriate structure for buildings housing large quantities of UO2 needs study.

The DUF6 Engineering Analysis Report has identified issues with federal (49CFR173.420) or ANSI N14.1 transportation requirements and overpressured, overfilled or substandard cylinders. The Report suggests that a new overpack be designed and licensed if filled substandard cylinders must be shipped from off-site. The cost of overpacks is not considered in the report. This transportation issue still needs to be resolved.

The preconceptual plant design is essentially a single line plant. Multiple autoclaves, ovens, conversion reaction chambers, and sintering furnaces are provided to obtain the design throughput. The HF distillation system, off-gas scrubber, and impurity neutralization units are single line systems with installed spares on maintenance-prone items such as pumps and filters. A RAM (reliability, availability, maintainability) analysis may help determine if this configuration is satisfactory and whether independent parallel lines might be desirable.

\subsubsection{Cost Estimate}

The cost estimate is based on a privately owned and privately operated plant located on a government facility site. The major contributors to the capital cost are the Process Building including the structure and service systems. The major process equipment costs are the cylinder handling crane, autoclaves, hot air ovens and DUF6 compressors, conversion reaction chambers, sintering furnaces, distillation equipment, and cylinder tilt and roll wash stands. The cost of boxes to package the UO2 aggregate is about \$1.8 million a year. Significant cost could be saved if the boxes are recycled from UO2 aggregate users. The cost to dispose of empty cylinder metal is not included in this report. If it is disposed as LLW, the disposal cost could be significant.

\subsubsection{Schedule}

The schedule shows a construction start early in the year 2002. This appears to be attainable if the site selection, selection of contractor, and early approval for construction dates are met. The Record of Decision is expected to be issued by the end of June.

\subsection{References}

Initial Plan for the Conversion of Depleted Uranium Hexafluoride, as Required by Public Law 105-204, U.S. Department of Energy, 1999

Draft Engineering Analysis Report for the Long-Term Management of Depleted Uranium Hexafluoride, UCRL-AR-124080, Lawrence Livermore National Laboratory, May 1997

Uranium Hexafluoride: A Manual of Good Handling Practices, ORO-651, U.S. Department of Energy, October 1991 


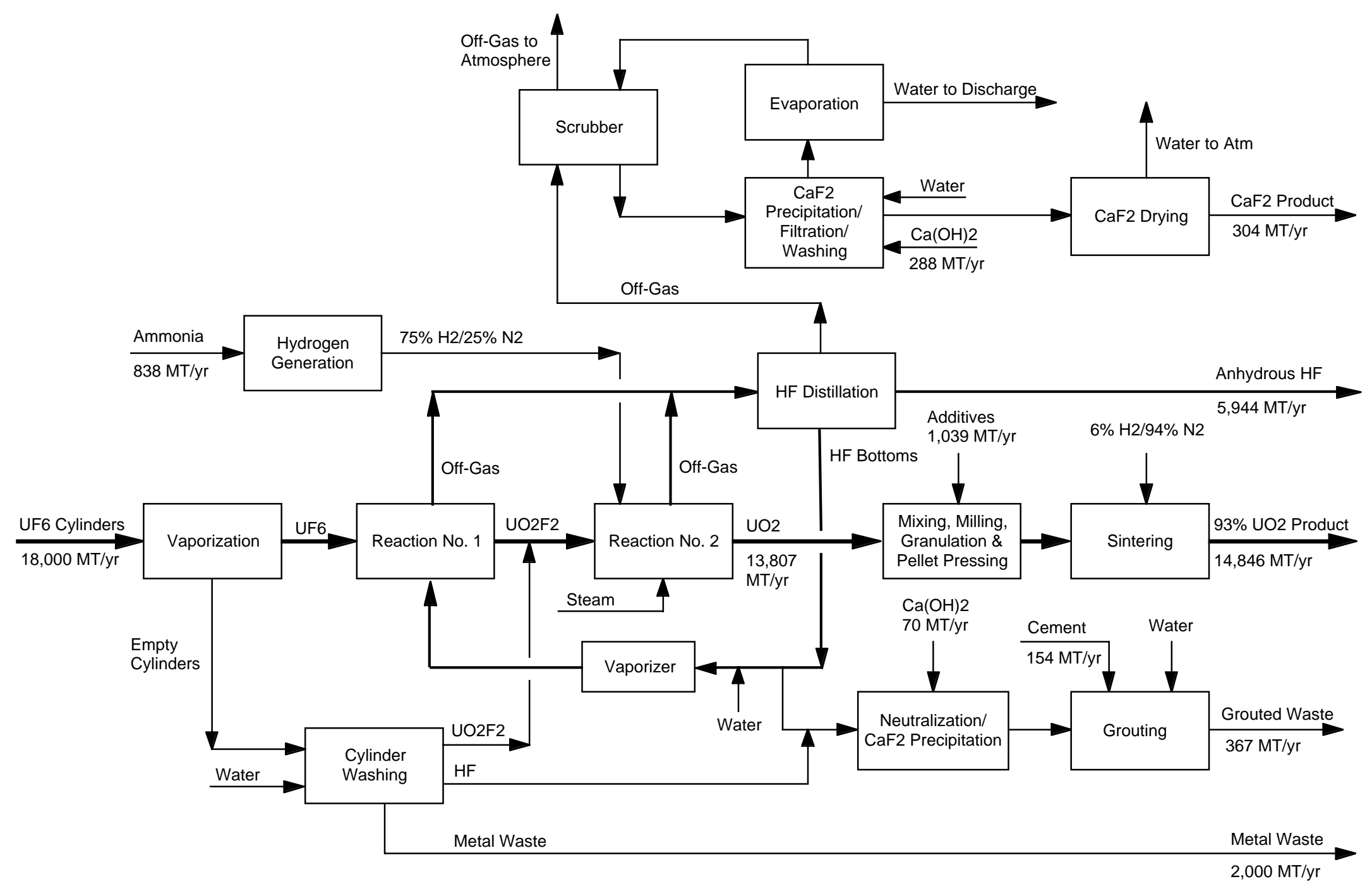

Figure 6.1 Process Block Flow Diagram

Conversion to UO2 and AHF 


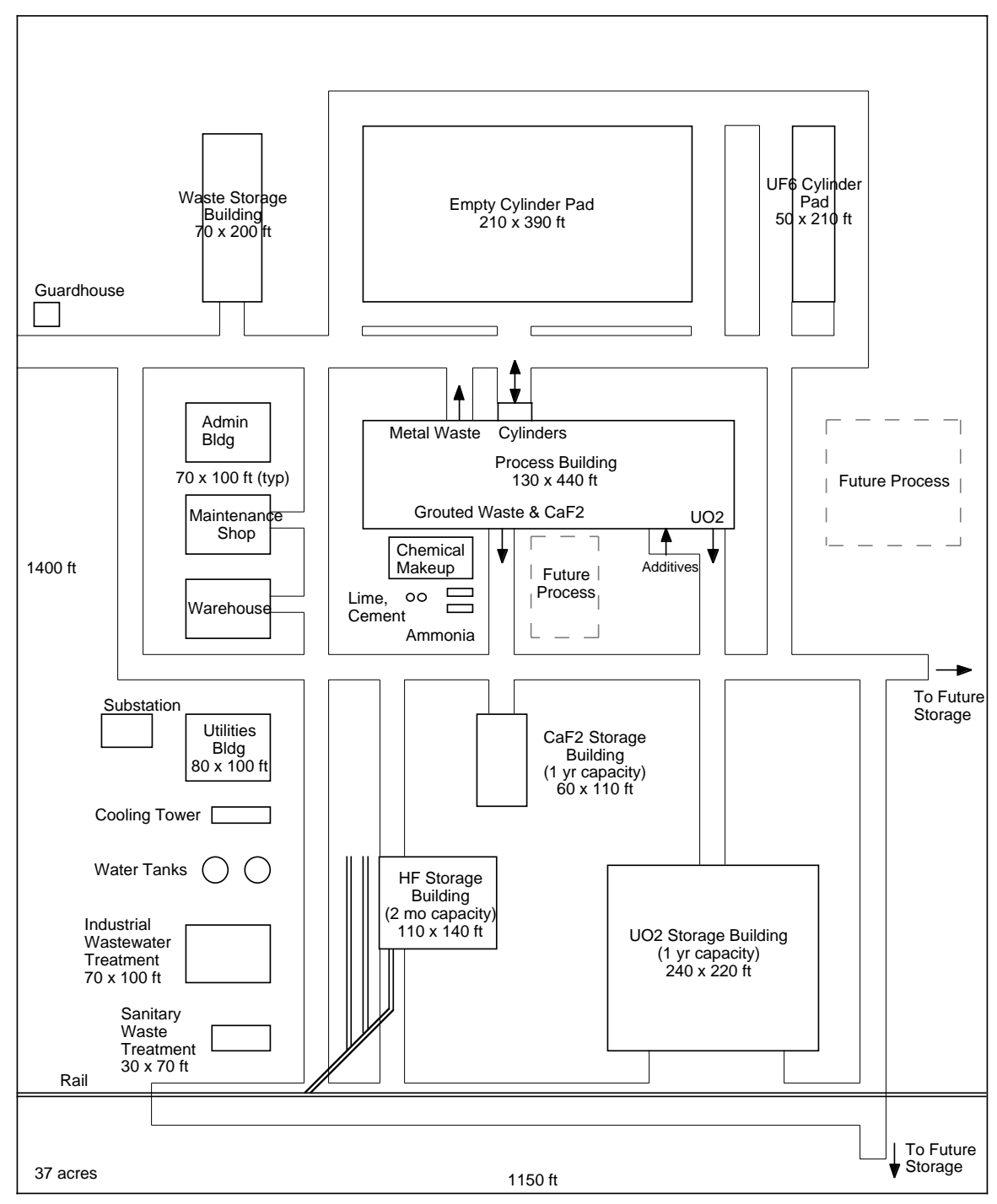

Figure 6.2 Facility Site Plan

Conversion to UO2 and AHF 


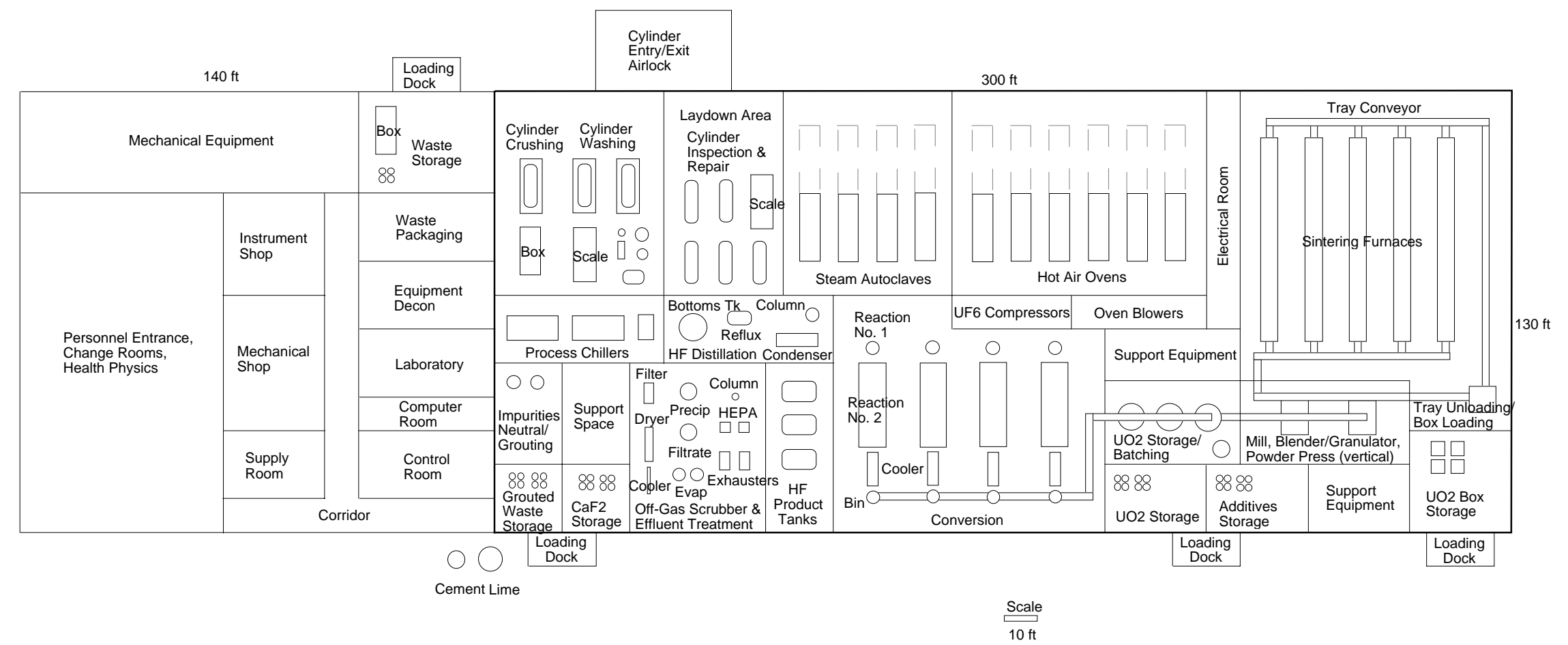

Figure 6.3 Process Building General Arrangement Conversion to UO2 and AHF 
$240 \mathrm{ft}$

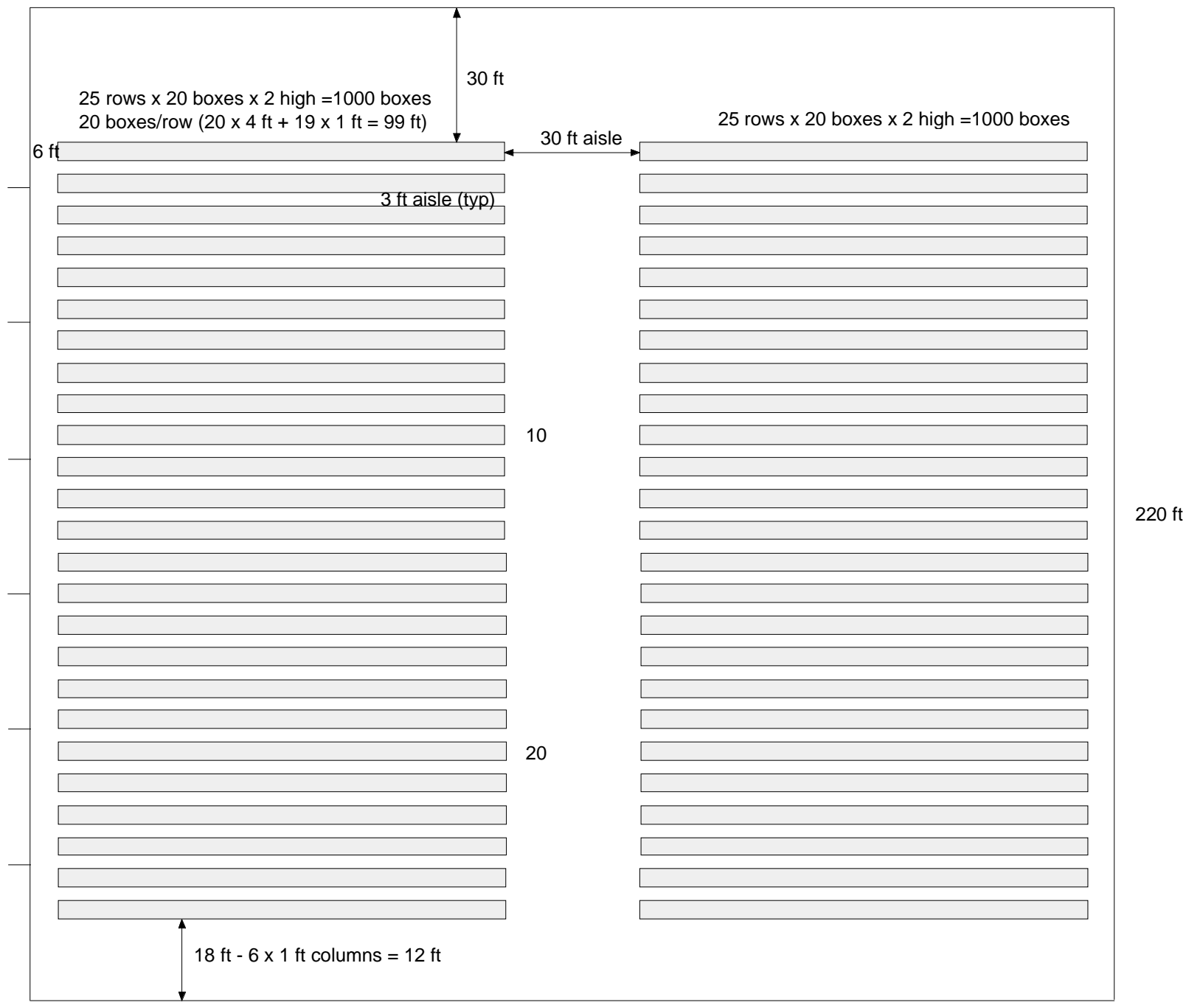

Storage provided $=2000$ boxes Storage required for $1 \mathrm{yr}=1926$ boxes

Figure 6.4 UO2 Storage Building Plan Conversion to $\mathrm{UO2}$ and $\mathrm{AHF}$ 


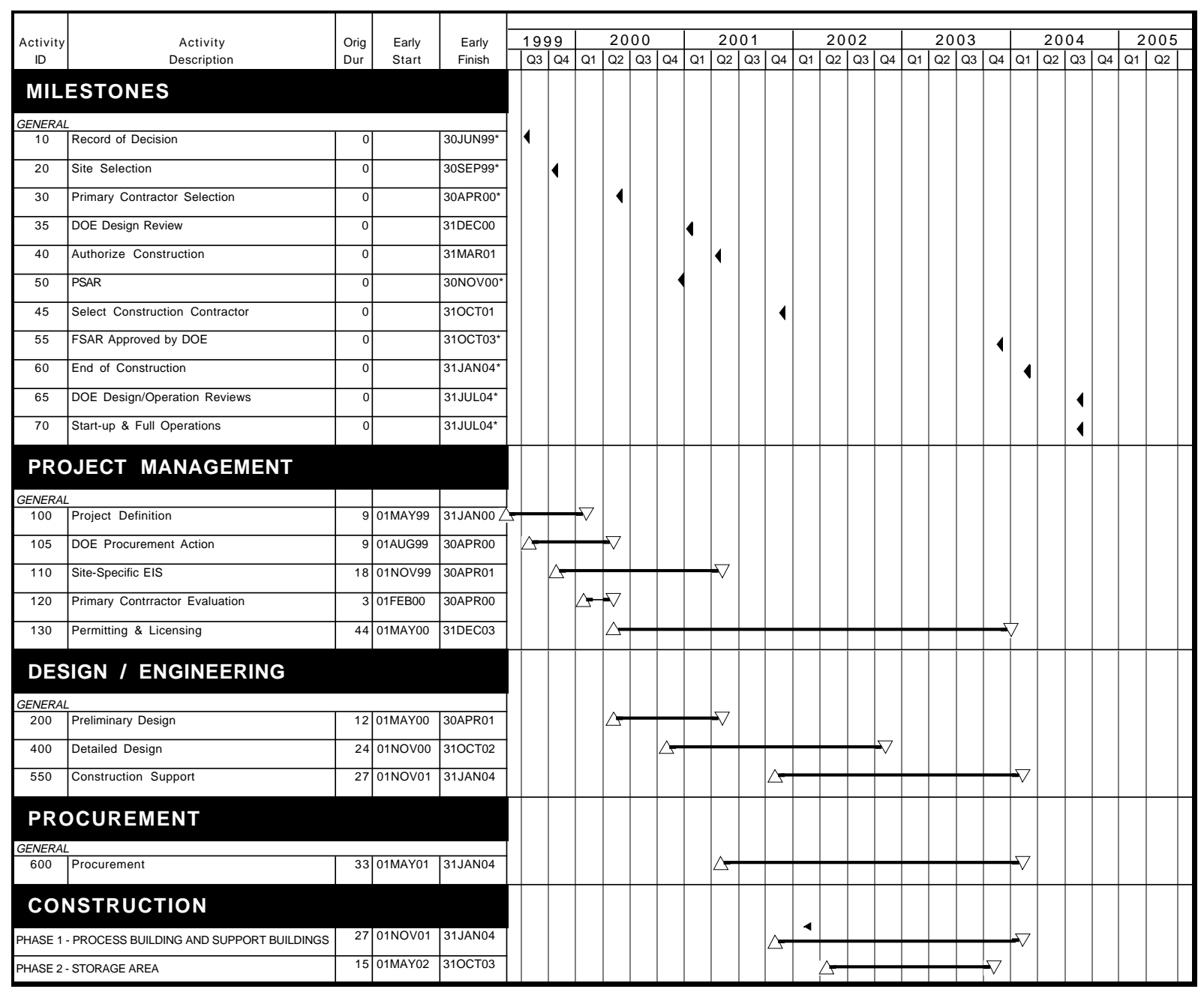

Figure 6.5 UO2/AHF Plant, 25 Year Privately Owned and Operated Preliminary Project Schedule 
Table 6.1 Plant Manpower Estimates for UO2/AHF Conversion Facility 25 Years Privately Owned and Privately Operated

\begin{tabular}{|l|c|}
\hline Labor Category & Total Employees \\
\hline Officials and Managers & 6 \\
\hline Professionals & 10 \\
\hline Technicians & 16 \\
\hline Office and Clericals & 10 \\
\hline Craft Workers (Maint./Production) & 24 \\
\hline Operators & 92 \\
\hline Line Supervision & 17 \\
\hline Security & 16 \\
\hline Total & $\mathbf{1 9 1}$ \\
\hline
\end{tabular}

Table 6.2 UO2/AHF Project Capital Cost Estimate

\begin{tabular}{|l|r|r|r|}
\hline \multicolumn{1}{|c|}{ Facility/Cost Items } & \multicolumn{1}{c|}{ Subtotal } & \multicolumn{1}{c|}{ Contingency } & \multicolumn{1}{c|}{ Total } \\
\hline Process Equipment & $41,874,000$ & $14,656,000$ & $56,530,000$ \\
\hline Process Facilities & $75,488,000$ & $26,421,000$ & $101,909,000$ \\
\hline Balance of Plant & $35,348,000$ & $12,372,000$ & $47,720,000$ \\
\hline Subtotal & $152,710,000$ & $53,449,000$ & $206,159,000$ \\
\hline Engineering \& Design @14.4\% & $21,990,000$ & $7,697,000$ & $29,687,000$ \\
\hline Total & $\mathbf{1 7 4 , 7 0 0 , 0 0 0}$ & $\mathbf{6 1 , 1 4 6 , 0 0 0}$ & $\mathbf{2 3 5 , 8 4 6 , 0 0 0}$ \\
\hline
\end{tabular}


Table 6.3 UO2 and AHF Operation and Maintenance Cost Estimate

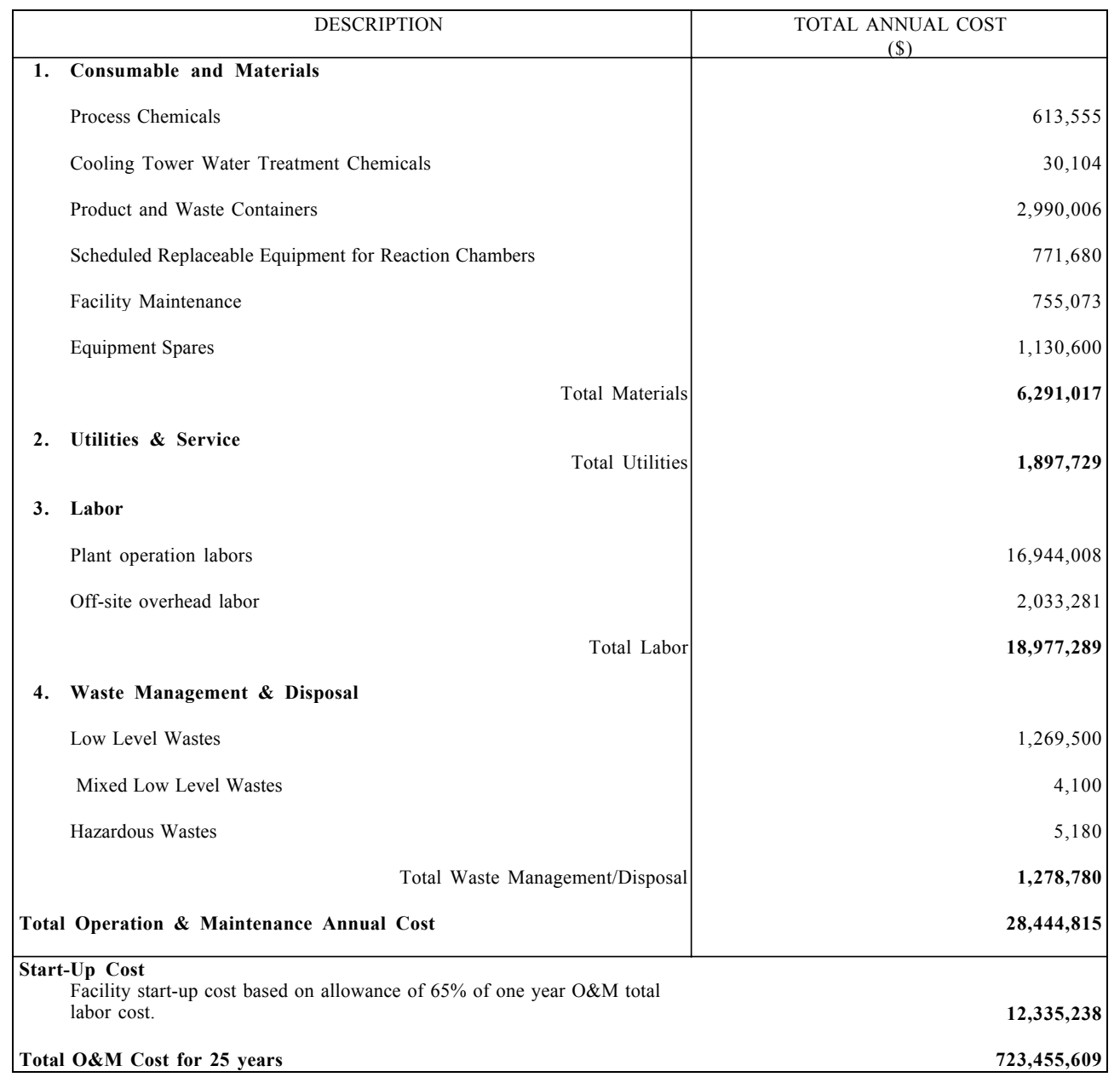


Table 6.4 Expenditure Funding Profile

UO2/AHF 25 Years POPO

10-year payback

(in million FY2000 dollars)



Notes: Cash funding requirements reflect cash flow required for construction and operating minus revenue from AHF sales. Break-even government payment is the funding from DOE paid to the private plant owner for the conversion service

Assumptions: to cover the break-even cost for construction loan payment, operation, and D\&D only; no profits included.

Loan Interest Rate @ 8.5\% for Construction Loan during construction period

Loan Interest Rate @ 8.5\% for payback in 10 years at start of operation

Chemical Sale Price: $\quad 70 \notin / \mathrm{lb}$ of $\mathrm{HF}$ 
Table 6.4, continued Expenditure Funding Profile

UO2/AHF 25 Years POPO

10-year payback

(in million FY2000 dollars)

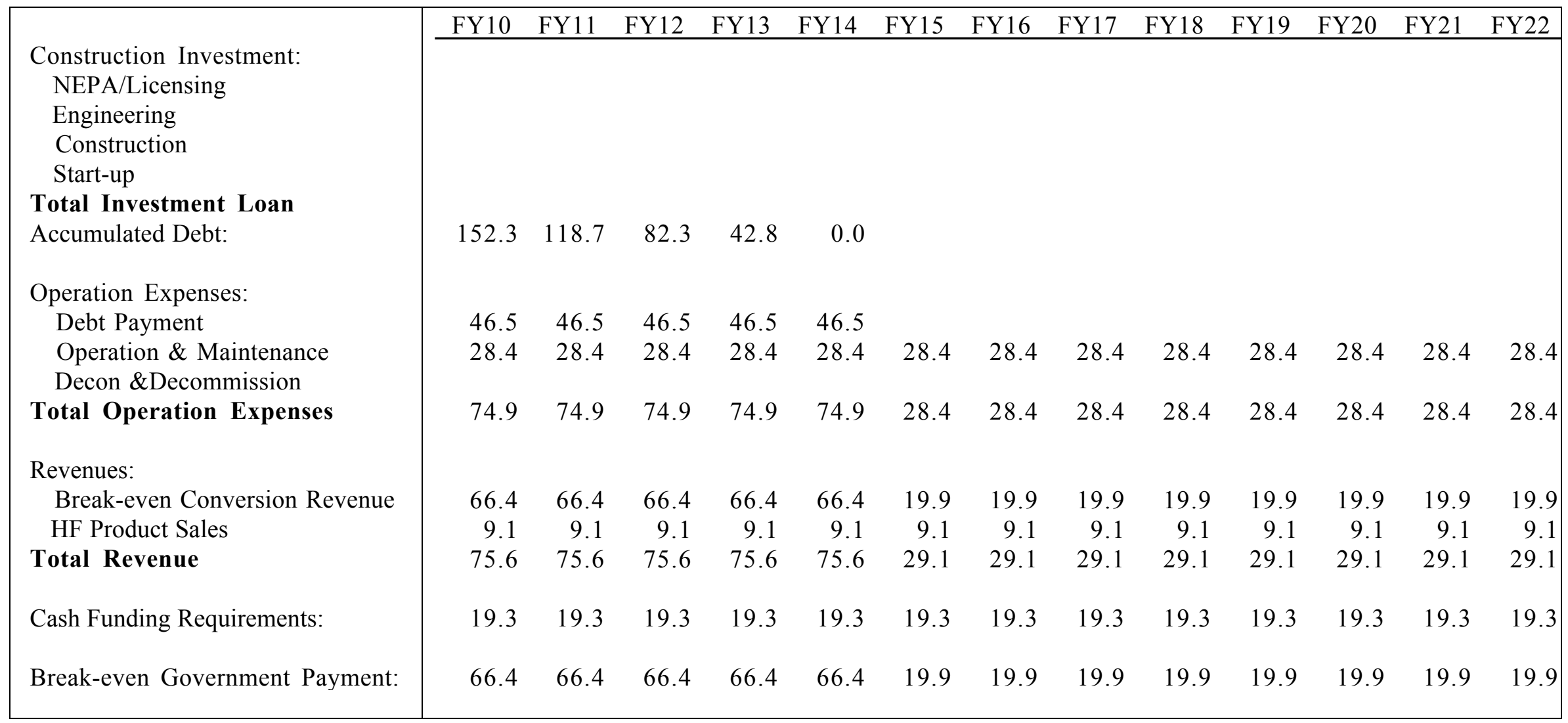


Table 6.4, continued Expenditure Funding Profile

UO2/AHF 25 Years POPO

10-year payback

(in million FY2000 dollars)







\section{Preliminary Case Study: DUF6 Conversion to U3O8/CaF2}

\subsection{Introduction}

About 700,000 metric tons (MT) of depleted uranium hexafluoride (DUF6) are currently stored at the Paducah, Portsmouth and Oak Ridge sites. Public Law 105-204 requires the DOE to submit to Congress a plan to ensure that all funds accrued on the books of USEC for disposition of DUF6 will be used for the construction and operation of plants to treat and recycle the DUF6. The Department of Energy's Initial Plan calls for construction to begin in the year 2002 time frame.

For this preconceptual design project, the preliminary case study, to examine the cost and issues involved in a 2002 time frame for construction start was based on a conversion plant using a dry process to convert DUF6 to uranium oxide (U3O8) and calcium fluoride (CaF2) as final products. The process selected to study involves least process equipment and byproduct streams. The construction and operation of the conversion plant is based on a government owned and contractor operated facility in conformance with DOE standards and operating for 25 years.

A preconceptual plant design, rough cost estimate, and preliminary project schedule were developed. The integrated conversion plant includes capabilities for DUF6 cylinder preparation, conversion of DUF6 to uranium oxide and fluorine byproducts, empty cylinder treatment for disposal, and interim storage for oxide and byproducts.

Significant design bases for the conversion plant include:

- The plant will convert DUF6 to U3O8 by a dry process. Hydrogen fluoride (HF) off-gas will be treated to produce solid $\mathrm{CaF} 2$.

- The plant capacity will be based on a 25 year operating period to process DUF6 inventory of 36,910 cylinders (450,000 MT DUF6).

- $\quad$ Storage will be provided for one year production of $\mathrm{U} 3 \mathrm{O} 8$ and $\mathrm{CaF} 2$ product.

- The $\mathrm{U} 3 \mathrm{O} 8$ and $\mathrm{CaF} 2$ products are retained by the DOE for other uses or disposal.

- To bound costs associated with empty cylinders, assume all empty cylinders will be washed, compacted, and returned to the DOE for disposal.

- The plant will be on a DOE owned site at or near a gaseous diffusion plant and include the support facilities and infrastructures/utilities needed for a greenfield facility.

- The design will consider addition of future process and storage buildings.

\subsection{Summary of Results}

The plant annually processes 18,000 MT of UF6 contained in 1,476 cylinders to produce 14,352 MT of U3O8, 11,966 MT of CaF2, and 2,000 MT of empty cylinder metal waste. The plant, which includes a one year storage capacity for $\mathrm{U} 3 \mathrm{O} 8$ and $\mathrm{CaF} 2$, occupies about 36 acres. Additional storage capacity would require about 5 acres for each year of additional $\mathrm{U} 3 \mathrm{O} 8$ storage or $\mathrm{CaF} 2$ storage. 
The construction capital cost estimate is $\$ 187$ million for the plant facilities. The engineering cost is about \$34 million. Each year of additional storage would be \$22 million for U3O8 and \$18 million for CaF2. These costs are in 1st Quarter FY2000 dollars.

The annual operation and maintenance (O\&M) cost is about $\$ 31$ million. The O\&M cost does not include disposal of empty cylinder metal. Cost for NEPA, regulatory and licensing activities is estimated at $\$ 5$ million. Decontamination and decommissioning (D\&D) cost is estimated at \$22 million.

The preliminary schedule assumes selection of an A/E contractor by June 2000 . The schedule shows plant engineering design starting in July 2000, construction beginning in April 2002, plant completion in June 2004, and full operation beginning in December 2004. Peak engineering personnel is 80 persons and peak employment during construction is about 430 persons. Plant employment during operations is 193 persons.

The 2002 construction start depends on the key milestone dates for site selection, selection of primary contractor and construction contractor, and construction approval. The schedule includes NEPA activities, as a site-specific EIS is required, and DOE regulatory activities. The amount of U3O8 and CaF2 storage provided affects cost and may need additional study. Process design criteria for UF6 cylinder vaporization, conversion reaction chamber, HF distillation, and empty cylinder treatment are necessary to ensure successful facility design and operation.

\subsection{Conversion Process Description}

Depleted uranium hexafluoride (DUF6) is processed to produce uranium oxide (U3O8) and calcium fluoride $(\mathrm{CaF} 2)$. The average throughput is 5 cylinders per day

$(5,670 \mathrm{lb} / \mathrm{hr}$ DUF6) based on $80 \%$ plant availability (7,000 hours/yr or 292 days/yr). The process block flow diagram is shown in Figure 7.1.

The DUF6 is shipped by truck from the cylinder yards at the gaseous diffusion plant (GDP) to an outdoor storage pad at the Conversion Facility. The cylinder is moved into the Process Building for inspection and preparation. The cylinders are loaded into steam-heated autoclaves to vaporize the DUF6 for feeding into the conversion process. Cylinders with questionable integrity are loaded into hot air ovens where the solid DUF6 sublimes into a gas under vacuum. This avoids melting the DUF6 and pressurizing the cylinder, which occurs when using an autoclave. Several of the cylinders may be substandard based on the DUF6 Engineering Analysis Report (p. 6.1-4-5).

The DUF6 gas is mixed with steam, nitrogen and hydrogen and converted to U3O8 in a series of two reaction chambers. The chemical reactions are:

$$
\begin{aligned}
& \mathrm{UF} 6+2 \mathrm{H}_{2} \mathrm{O}--->\mathrm{UO}_{2} \mathrm{~F}_{2}+4 \mathrm{HF} \\
& 3 \mathrm{UO}_{2} \mathrm{~F}_{2}+3 \mathrm{H}_{2} \mathrm{O}--->\mathrm{U} 3 \mathrm{O} 8+6 \mathrm{HF}+0.5 \mathrm{O}_{2} \\
& \mathrm{H} 2+0.5 \mathrm{O}_{2}--->\mathrm{H}_{2} \mathrm{O}
\end{aligned}
$$

Four reaction lines are provided to meet the required throughput. The U3O8 product is cooled, compacted with a rotary compactor to increase its bulk density, and packaged in metal bins. The $100 \mathrm{cu} \mathrm{ft}$ bins are about $4 \times 4 \times 7$ (height) $\mathrm{ft}$ and hold 9 tons $(8.16 \mathrm{MT})$ of U3O8. The filled bins are transferred to the U3O8 Storage Building. 
Reaction chamber off-gas containing HF, excess steam, and nitrogen is filtered to remove uranium particulates. The off-gas flows to the HF absorption columns, where the HF and steam are condensed and an aqueous HF solution is produced. The HF solution is neutralized with slaked lime according to the reaction:

$2 \mathrm{HF}+\mathrm{Ca}(\mathrm{OH})_{2}--->\mathrm{CaF} 2+2 \mathrm{H}_{2} \mathrm{O}$

The resulting $\mathrm{CaF} 2$ precipitate is separated by filtering, washed with water, dried and loaded into bins. The $4 \times 4 \times 7 \mathrm{ft}, 100 \mathrm{cu} \mathrm{ft}$ bins, which hold 5 tons (4.54 MT) of CaF2, are transferred to the CaF2 Storage Building. The $\mathrm{CaF} 2$ is expected to contain less than $1 \mathrm{ppm}$ uranium.

Off-gas from the absorption columns flows to the scrubber system. Residual HF in the off-gas is removed by scrubbing with a potassium hydroxide solution. The off-gas is then HEPA filtered and discharged to the atmosphere.

After vaporization, the empty cylinders are transferred to an outdoor pad and stored for three months. This allows for radioactive decay of non-volatile daughter products in the cylinder. The cylinders are then brought into the Process Building, washed with water, crushed, and loaded into boxes for disposal as LLW. Each $6 \times 14 \times 3$ (height) $\mathrm{ft}$ box contains about 9,000 lb of metal from three crushed cylinders. A special cylinder handling fixture is provided for cylinders with questionable wall strength. The cylinder wash effluents are fed into the main conversion processes.

The process materials and annual quantities are summarized below:

\begin{tabular}{|c|c|}
\hline Major Input Streams & Major Output Streams \\
\hline $\begin{array}{l}\text { Depleted Uranium Hexafluoride } \\
18,000 \mathrm{MT} / \mathrm{yr} \\
1476 \text { cylinders/yr }\end{array}$ & $\begin{array}{l}\text { Uranium Oxide (U3O8) } \\
14,352 \mathrm{MT} / \mathrm{yr} \\
17584 \times 4 \times 7 \text { (H) ft bins/yr } \\
(18,000 \mathrm{lb} / \mathrm{bin}) \\
\text { or } 24,34455 \text {-gal drums/yr } \\
(1300 \mathrm{lb} / \text { drum })\end{array}$ \\
\hline $\begin{array}{l}\text { Lime }(\mathrm{CaO}) \\
8505 \mathrm{MT} / \mathrm{yr} \\
312,600 \mathrm{ft} 3 / \mathrm{yr}\end{array}$ & $\begin{array}{l}\text { Calcium Fluoride }(\mathrm{CaF} 2) \\
11,966 \mathrm{MT} / \mathrm{yr} \\
26394 \mathrm{x} 4 \mathrm{x} 7 \mathrm{~h}) \mathrm{ft} \text { boxes/yr } \\
(10,000 \mathrm{lb} / \text { drum })\end{array}$ \\
\hline $\begin{array}{l}\text { Hydrated Lime } \mathrm{Ca}(\mathrm{OH}) 2 \\
113 \mathrm{MT} / \mathrm{yr} \\
4100 \mathrm{ft} 3 / \mathrm{yr}\end{array}$ & $\begin{array}{l}\text { Empty Cylinder Metal Waste } \\
2000 \mathrm{MT} / \mathrm{yr} \\
4926 \mathrm{x} 14 \mathrm{x} 3(\mathrm{~h}) \mathrm{ft} \text { boxes/yr } \\
(9000 \mathrm{lb} / \mathrm{box})\end{array}$ \\
\hline $\begin{array}{l}\text { Ammonia (NH3) } \\
193 \mathrm{MT} / \mathrm{yr} \\
84,000 \mathrm{gal} / \mathrm{yr}\end{array}$ & \\
\hline
\end{tabular}

Major process equipment includes four steam autoclaves, six hot air ovens, four reaction chamber lines, U3O8 compaction and bin loading system, off-gas scrubbing system, HF absorption and neutralization, CAF2 drying and bin loading, two empty cylinder washing machines, and one cylinder crusher. 


\subsection{Conversion Plant Description}

The Conversion Facility is assumed to be constructed on a DOE site at a greenfield location at or near the gaseous diffusion plants. The Conversion Facility occupies about 36 acres. Additional storage buildings for $\mathrm{U} 3 \mathrm{O} 8$ and $\mathrm{CaF} 2$ could be built adjacent or at a nearby location. Each additional one year increment of $\mathrm{U} 3 \mathrm{O} 8$ or $\mathrm{CaF} 2$ storage occupies about 5 acres. A conceptual site plan for the Conversion Facility is shown in Figure 7.2.

The Conversion Facility includes full and empty cylinder storage pads, the Process Building, a U3O8 Storage Building, a CaF2 Storage Building, a Waste Storage Building, and support facilities. The site plan considers addition of future process facilities such as uranium metal, sintered uranium pellets, or anhydrous HF production.

The Conversion Facility will be designed and constructed in compliance with DOE Orders and applicable regulations and codes, and will meet the intent of NRC standards. In general, a graded approach as established in DOE Order 420.1 is used for the design of all structures, systems, and components (SSC) in the plant facilities. All SSC's will be assigned a Natural Phenomena Performance Category using the criteria in the DOE Standards DOE-STD-1020-94 and DOE-STD-1021-93 during the design phase.

In the absence of a hazard analysis, it is assumed that the Process Building is performance category PC-3 to control and confine hazardous material. The building structure is reinforced concrete construction in the processing areas. The remainder of the building housing the personnel support area is steel frame, metal siding construction. The Process Building is $30 \mathrm{ft}$ high in the processing areas and $18 \mathrm{ft}$ high in the support areas. HVAC equipment is located on a mezzanine level. The process room air is filtered through one stage of HEPA filters prior to discharge to atmosphere. The Process Building general arrangement is shown in Figure 7.3.

The U3O8 Storage Building and CaF2 Storage Building have a one year capacity. The U3O8 Building holds 1,760 bins stacked one high, and the CaF2 Building holds 2,640 bins stacked two high. The Waste Building has a one month capacity for staging treated empty cylinders and process waste for transport offsite. The U3O8, CaF2, and waste storage buildings are assumed PC-2 to maintain storage function after the occurrence of a natural phenomena hazards event. These buildings are steel frame and concrete clad panel construction and are ventilated and lighted, but no heating, cooling or HEPA filtration is provided. Access aisles allow personnel to inspect the bins during storage. A general storage arrangement in the U3O8 Building is shown in Figure 7.4. A storage arrangement for the CaF2 Building is shown in Figure 7.5.

Plant operations are assumed to be continuous for 24 hours/day, 7 days/week, 52 weeks/year. Due to seven day per week operation, a fourth shift is necessary to account for normal days off for employees. The number of employees during operation is estimated to be 193 persons, with 70 employees on day shift and 41 each of the other three shifts. The numbers are estimated based on process operation labor and facility support labor requirements needed to operate the plant. No allowance is included for plant medical or fire fighting personnel. A breakdown of the plant operation employees by category and by shift is shown in Table 7.1. 


\subsection{Cost Estimate}

The cost estimates are rough order of magnitude estimates based on a preconceptual level design information. The cost estimate results are summarized below:

\begin{tabular}{|l|c|c|c|}
\cline { 2 - 4 } \multicolumn{1}{c|}{} & \multicolumn{1}{c|}{$\begin{array}{c}\text { Cost } \\
\text { (\$million) }\end{array}$} & $\begin{array}{c}\text { Contingency } \\
\text { (\$million) }\end{array}$ & $\begin{array}{c}\text { Total Cost } \\
\text { (\$million) }\end{array}$ \\
\hline Conversion Facilities & & & 34 \\
\hline Engineering & -- & -- & 187 \\
\hline $\begin{array}{l}\text { Plant Facilities } \\
\text { Construction Cost }\end{array}$ & 138 & -- & 13 \\
\hline Startup Cost & -- & -- & 31 \\
\hline $\begin{array}{l}\text { Annual Operations and } \\
\text { Maintenance Cost (O\&M) }\end{array}$ & -- & -- & 22 \\
\hline $\begin{array}{l}\text { Decontamination and } \\
\text { Decommissioning (D\&D) }\end{array}$ & -- & -- & 3.2 \\
\hline Additional Storage & -- & 3 & 22 \\
\hline Engineering & 19 & 2 & 18 \\
\hline $\begin{array}{l}\text { U3O8 Storage (1 yr capacity) } \\
\text { Capital Cost }\end{array}$ & 16 & -- & 5 \\
\hline $\begin{array}{l}\text { CaF2 Storage (1 yr capacity) } \\
\text { Capital Cost }\end{array}$ & -- & & \\
\hline NEPA/Licensing & & & \\
\hline
\end{tabular}

The estimates do not include costs for plant design criteria development, cost of land, site qualifications, or extension of local roads and utility lines to the site boundary. The estimates take into account the procurement pricing, labor productivity, and indirect cost factors for a government project. Cost estimate bases are described in the Appendix.

The construction capital costs are based on an engineering, procurement and construction management (EPCM) approach. Capital costs, see Table 7.2, are reported in 1st quarter fiscal year 2000 dollars (October 1999). Labor costs are based on local wage rates at a generic gaseous diffusion plant located in mid-U.S.A. The capital cost estimate utilized historical cost data, estimating manuals, allowances and budgetary quotations. A 35\% contingency was applied to the capital costs for the Conversion Facility and $15 \%$ for the subsequent Storage Facilities. These contingency levels are based on previous risk analysis on projects of similar scope and level of design details. Engineering cost was estimated at $18 \%$ of the capital costs for the Conversion Facility and 8\% for the subsequent Storage Facilities. The lower percentages are used for the subsequent Storage Facilities because previous building engineering design can be reused. Product and wastes container costs are included in the O\&M costs. The D\&D cost was estimated as $10 \%$ of the capital cost.

The O\&M cost includes costs for materials, utilities, labor, waste disposal, and management and operation (M\&O) contractor fees, see Table 7.3. Plant startup cost was assumed to be $65 \%$ of the annual O\&M labor cost. The annual O\&M cost does not include the cost for disposal of empty cylinder metal waste. If the empty cylinder metal is to be disposed as low-level waste (LLW), the estimated disposal cost would range from $\$ 1$ million to $\$ 12$ million annually, depending on the disposal sites. Revenue from sales 
of $\mathrm{CaF} 2$ is also not included in the $\mathrm{O} \& \mathrm{M}$ cost. If the $\mathrm{CaF} 2$ is sold, the estimated annual savings could be based on CAF2 revenue and reuse of bins.

The annual expenditure required to support the construction and operation of the conversion plant in the initial project years is shown in Table 7.4 The expenditure profile for all years is shown below. The expenditure profiles are derived from loading the estimated capital and operating costs onto the project schedule. A constant FY2000 dollar value is used in the expenditure outlay because of the difficulty in accurately projecting the inflation rate for future years.

\subsection{Project Schedule}

An estimated preliminary project schedule is shown in Figure 7.6. The schedule allows 3 years for Title I and II design and 2 years for construction. The schedule is based on a fast track premise with overlapping engineering phases and early procurement of some equipment (most equipment is available in 12-18 month lead time) and a two-phase construction plan. The estimated peak engineering personnel is 80 persons and peak employment during construction is 430 persons.

\subsection{Discussion and Issues}

\subsubsection{Process}

Bins were used to package the $\mathrm{U} 3 \mathrm{O} 8$ because of the space savings compared to 55-gallon drums. Using bins instead of drums reduces the storage building area by about $35 \%$. Additional study is needed to determine the best storage container to use with the cost considerations on facilities and transport.

The $\mathrm{CaF} 2$ product is not a hazardous waste, but $\mathrm{CaF} 2$ powder is a health hazard and containment is required during handling. Packaging the $\mathrm{CaF} 2$ in sealed bins is appropriate for both long-term storage or transport to customers. Other methods of handling the $\mathrm{CaF} 2$ include bulk storage in vaults or silos and shipment in rail hopper cars or tank trucks.

In cylinder washing, the empty cylinders are cleaned to remove the reactive fluoride materials inside the cylinder. It was assumed that the metal from washed empty cylinders is returned to the DOE for disposal. The residual uranium contaminated cylinders might require the cylinder metal to be disposed of as LLW. Alternate dispositions include recycling and reusing the radioactively-contaminated carbon steel for LLW containers for further use in the nuclear industry, or decontaminating the metal sufficiently for disposal as non-hazardous waste or scrap.

The purity of the calcium oxide ( $\mathrm{CaO}$, quicklime) fed to lime slaking and used to neutralize the $\mathrm{HF}$ affects the purity of the $\mathrm{CaF} 2$ product. Typical high calcium quicklime contains up to $5 \%$ impurities (mainly $\mathrm{MgO}$ and $\mathrm{CaCO}_{3}$ ), which could end up in the $\mathrm{CaF} 2$ product. If this impurity is objectionable, high purity calcium oxide could be used.

\subsubsection{Facility}

Buildings for processing and storage were assumed to be performance category PC-2 or PC-3. A safety and accident analysis was not performed and is needed to determine the hazard classification and performance category. The appropriate structure, confinement and ventilation for buildings housing large quantities of U3O8 needs study.

The DUF6 Engineering Analysis Report has identified issues with federal (49CFR173.420) or ANSI N14.1 transportation requirements and overpressured, overfilled or substandard cylinders. The Report 
suggests that a new overpack be designed and licensed if filled substandard cylinders must be shipped from off-site. The cost of overpacks is not considered in the report. This transportation issue still needs to be resolved.

The preconceptual plant design is essentially a single line plant. Multiple autoclaves, ovens, and conversion reaction chambers are provided to obtain the design throughput. The reaction chamber off-gas and $\mathrm{CaF} 2$ systems are single line systems with installed spares on maintenance-prone items such as pumps and filters. A RAM (reliability, availability, maintainability) analysis would determine if this configuration is satisfactory and whether independent parallel lines might be desirable.

\subsubsection{Cost Estimate}

The cost estimate is based on a government owned and contractor operated plant located on a government facility site. The major contributors to the capital cost are the Process Building including the structure and service systems. The major process equipment costs are the cylinder handling crane, autoclaves, hot air ovens and DUF6 compressors, conversion reaction chambers, and cylinder tilt and roll wash stands. The cost to dispose of empty cylinder metal is not included in this report. If it is disposed as LLW, the disposal cost could be significant.

\subsubsection{Schedule}

The schedule shows a construction start early in the second quarter of year 2002. This appears to be attainable if the site selection, selection of contractor, and early approval for construction dates are met. The Record of Decision is expected to be issued by the end of June.

\subsubsection{Production Criteria}

This case study assumes the government develops its own processes, rather than using pre-existing processes owned by private companies.

Production criteria for conversion facility are required for plant design. Major areas of the conversion process requiring criteria verification include:

The DUF6 to U3O8 conversion requires data on reaction chamber size and details, operating conditions, and off-gas particulate removal.

The calcium fluoride process requires selection and sizing the filtration and drying equipment.

Empty cylinder treatment entails characterizing the wash effluents and confirming they can be fed into the main conversion process.

The DUF6 vaporization rate from a large cylinder in a hot air oven needs to be determined.

Methods to determine whether a cylinder is in good condition and suitable for autoclave vaporization.

Depending on the availability of process data, establishment of design criteria might require literature survey, laboratory studies, or pilot plant demonstration. 


\subsection{References}

Initial Plan for the Conversion of Depleted Uranium Hexafluoride, as Required by Public Law 105-204, U.S. Department of Energy, 1999

Draft Engineering Analysis Report for the Long-Term Management of Depleted Uranium Hexafluoride, UCRL-AR-124080, Lawrence Livermore National Laboratory, May 1997

Uranium Hexafluoride: A Manual of Good Handling Practices, ORO-651, U.S. Department of Energy, October 1991 


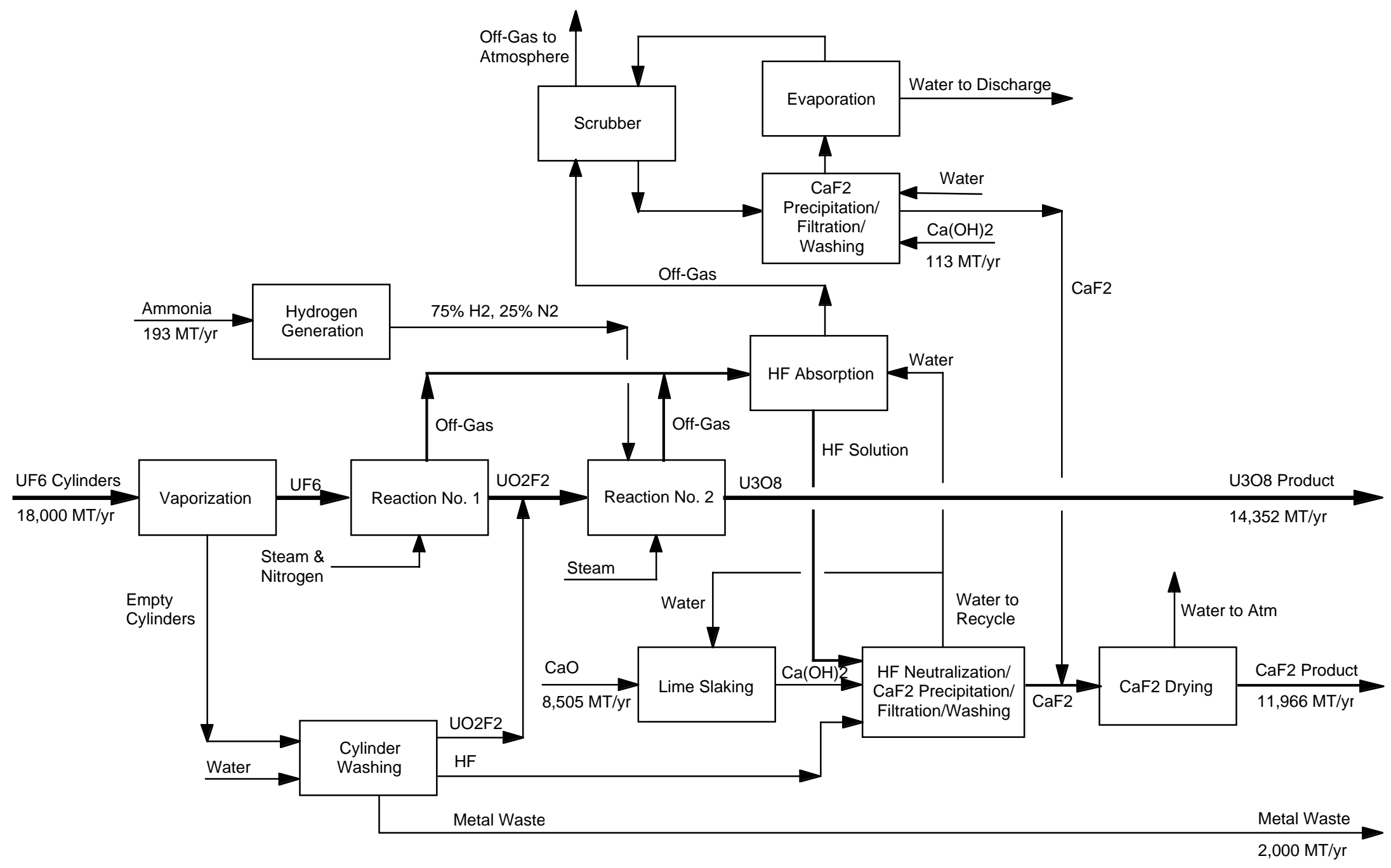

Figure 7.1 Process Block Flow Diagram

Conversion to U3O8 and CaF2 


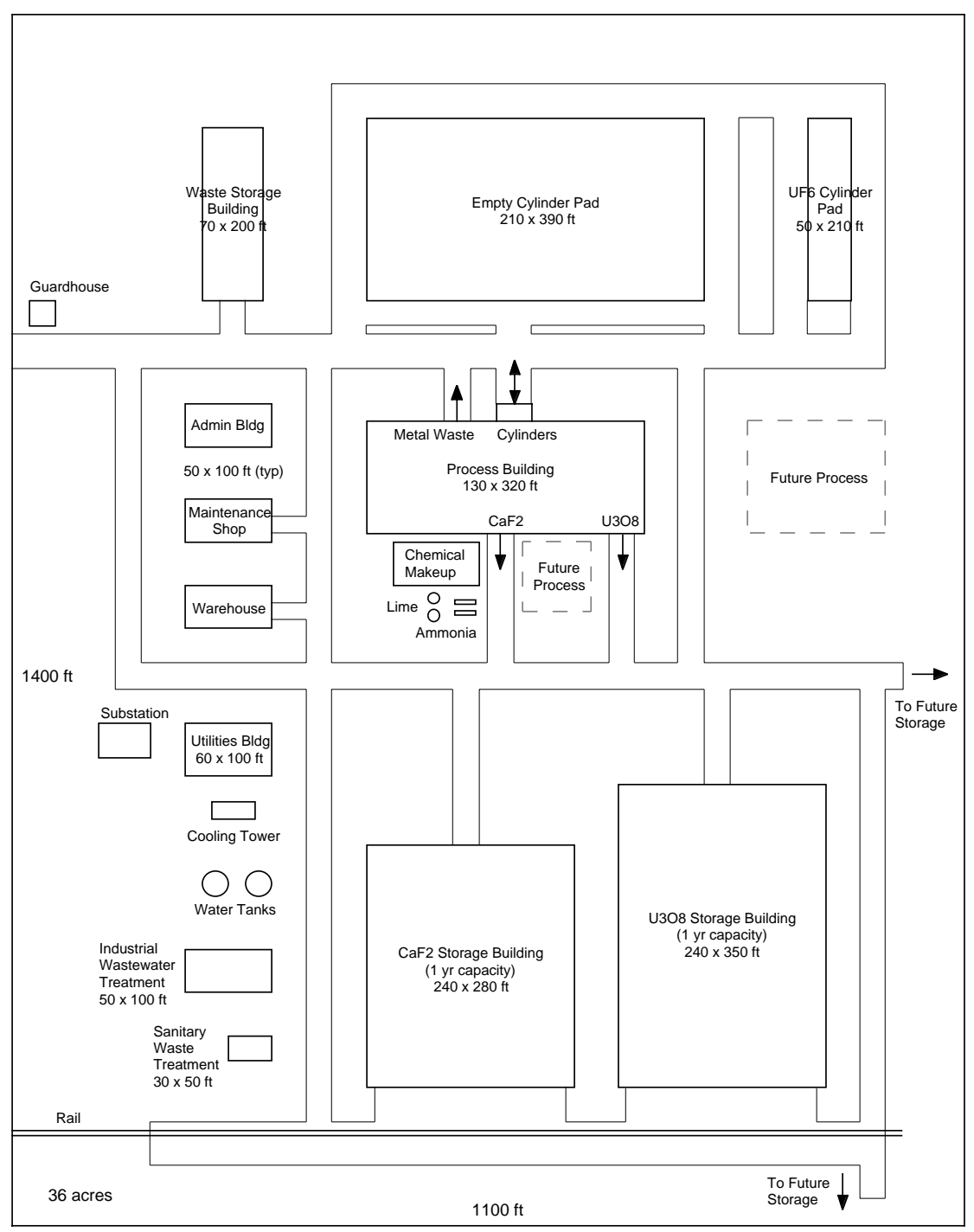

Figure 7.2 Site Plan

Conversion to $\mathrm{U} 308$ and $\mathrm{CaF2}$ 


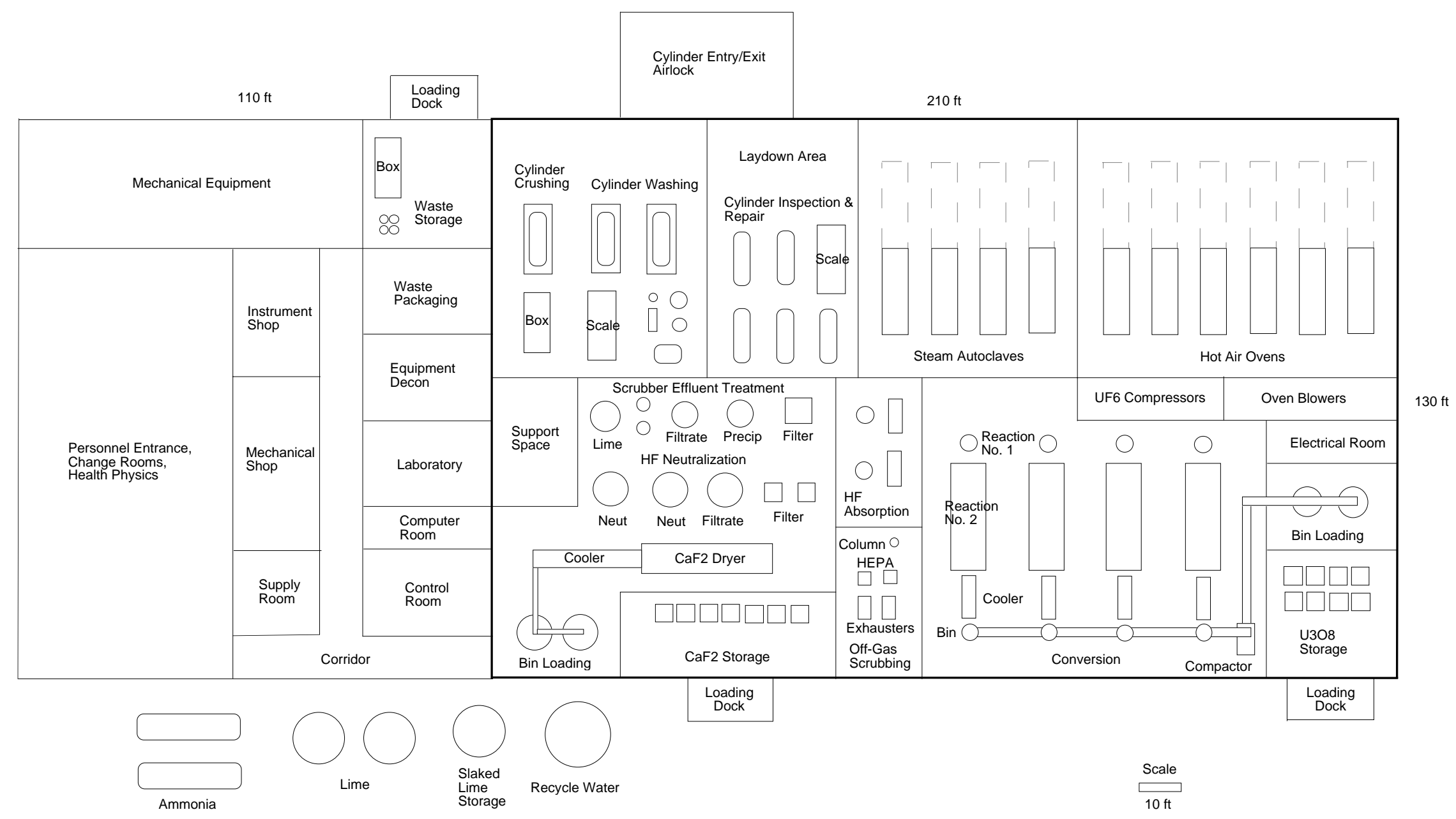

Figure 7.3 Process Building General Arrangement

Conversion to $\mathrm{U3O8}$ and $\mathrm{CaF2}$ 
$240 \mathrm{ft}$

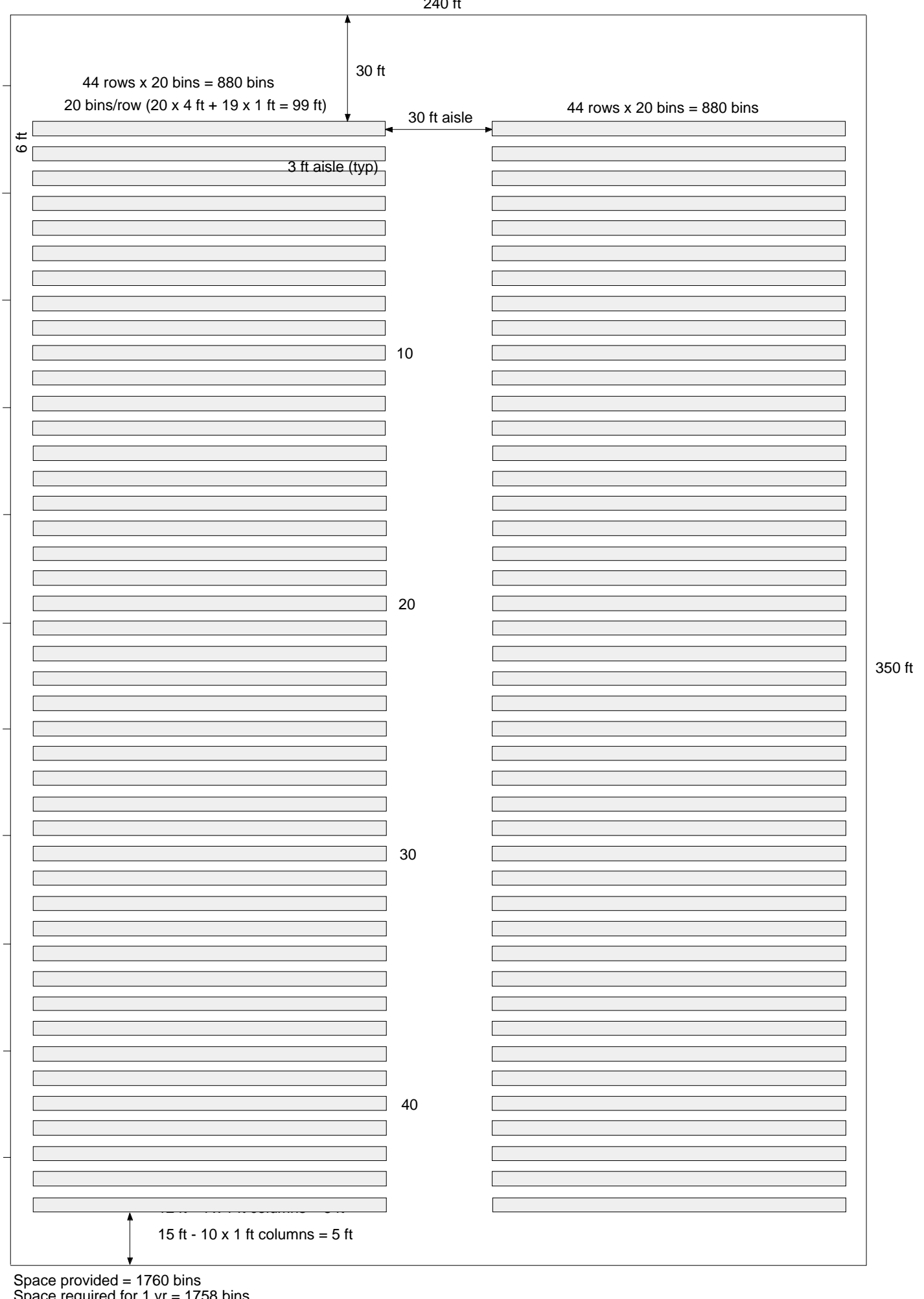

Figure 7.4 U308 Storage Building Plan

Conversion to U3O8 and CaF2 
$240 \mathrm{ft}$

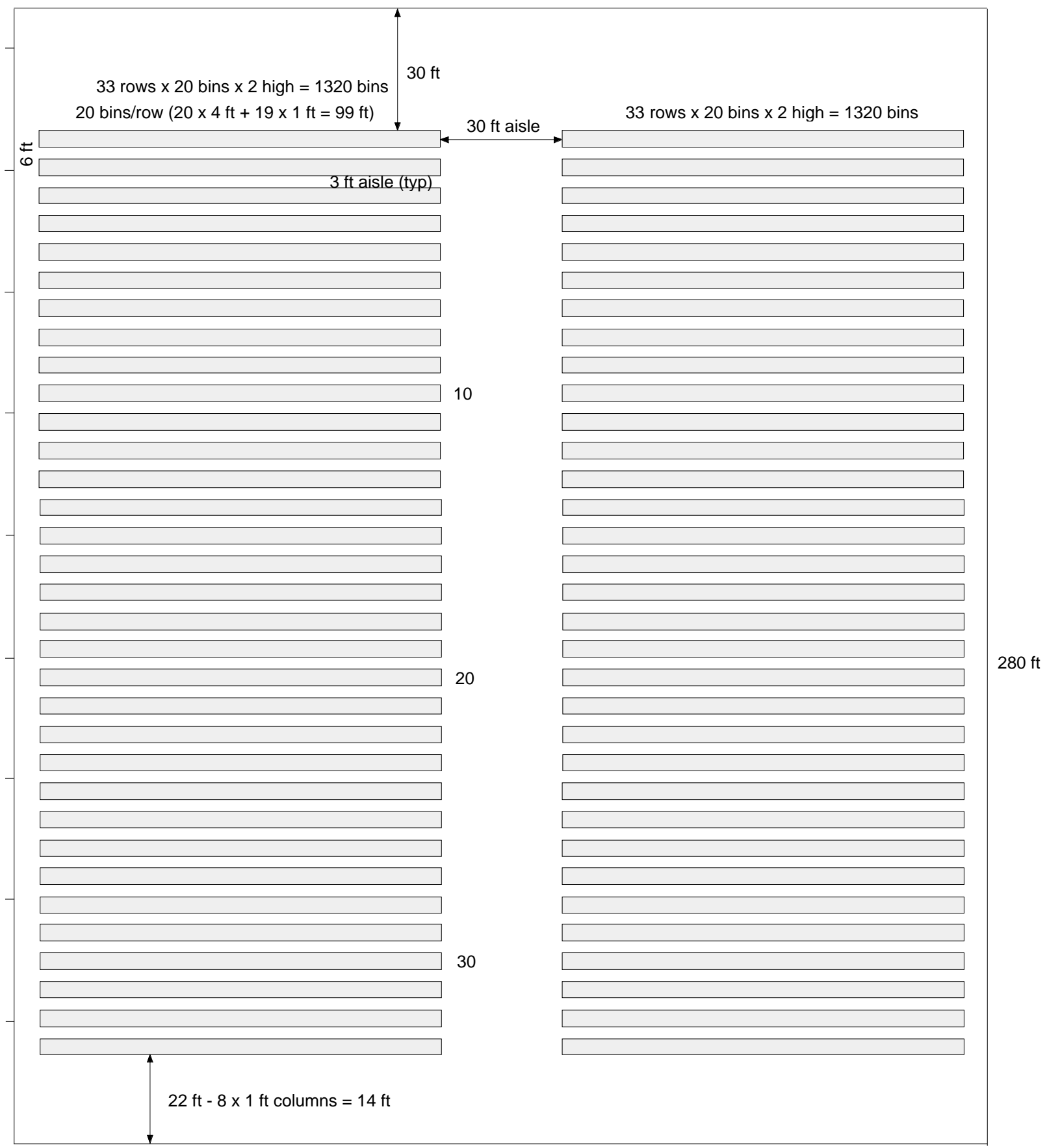

Space provided $=2640$ bins

Space required for $1 \mathrm{yr}=2639$ bins

Figure 7.5 CaF2 Storage Building Plan

Conversion to $\mathrm{U} 308$ and $\mathrm{CaF} 2$ 


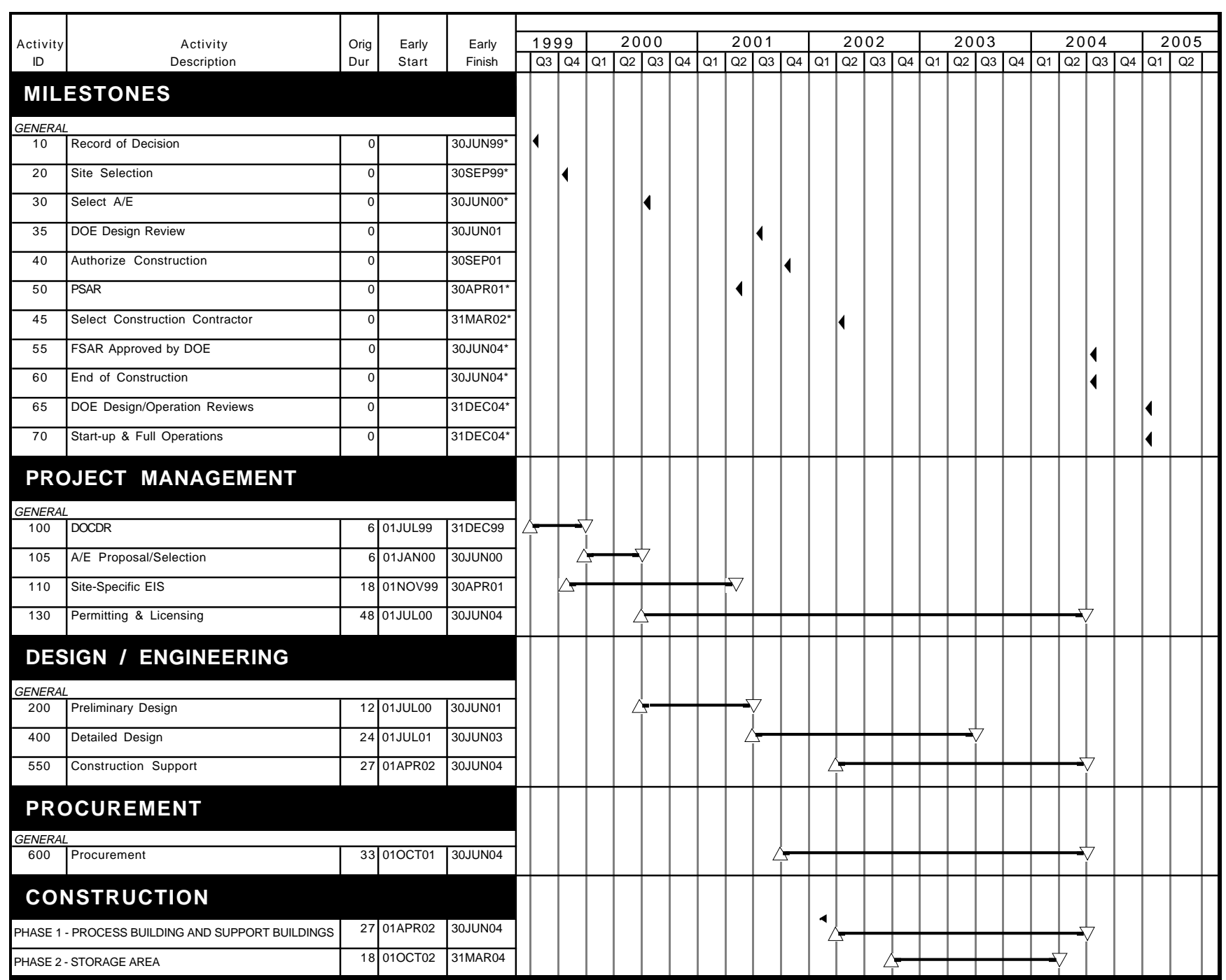

Figure 7.6 U3O8/CaF2 Plant, 25 Year Government Owned and Contractor Operated Preliminary Project Schedule 
Table 7.1 Plant Operation Manpower Estimates for U3O8/CaF2 Conversion Facility 25 Years Government Owned and Contractor Operated

\begin{tabular}{|l|c|}
\hline Labor Category & Total Employees \\
\hline Officials and Managers & 6 \\
\hline Professionals & 10 \\
\hline Technicians & 16 \\
\hline Office and Clericals & 12 \\
\hline Craft Workers (Maint./Production) & 24 \\
\hline Operators & 84 \\
\hline Line Supervision & 17 \\
\hline Security & 24 \\
\hline Total & $\mathbf{1 9 3}$ \\
\hline
\end{tabular}

Table 7.2 U3O8/CaF2 Project Capital Cost Estimate

\begin{tabular}{|l|r|r|r|}
\hline \multicolumn{1}{|c|}{ Facility/Cost Items } & \multicolumn{1}{c|}{ Subtotal } & \multicolumn{1}{c|}{ Contingency } & \multicolumn{1}{c|}{ Total } \\
\hline Process Equipment & $33,283,000$ & $11,649,000$ & $44,932,000$ \\
\hline Process Facilities & $71,070,000$ & $24,875,000$ & $95,945,000$ \\
\hline Balance of Plant & $33,996,000$ & $11,898,000$ & $45,894,000$ \\
\hline Subtotal & $138,349,000$ & $48,422,000$ & $186,771,000$ \\
\hline Engineering \& Design @14.4\% & $24,903,000$ & $8,716,000$ & $33,619,000$ \\
\hline Total & $\mathbf{1 6 3 , 2 5 2 , 0 0 0}$ & $\mathbf{5 7 , 1 3 8 , 0 0 0}$ & $\mathbf{2 2 0 , 3 9 0 , 0 0 0}$ \\
\hline
\end{tabular}




\section{Table 7.3 U308/CaF2 Operation and Maintenance Cost Estimate}

\begin{tabular}{|c|c|c|}
\hline \multicolumn{2}{|r|}{ DESCRIPTION } & $\begin{array}{c}\text { TOTAL ANNUAL COST } \\
(\$) \\
\end{array}$ \\
\hline 1. & Consumable and Materials & \\
\hline & Process Chemicals & 667,604 \\
\hline & Cooling Tower Water Treatment Chemicals & 33,655 \\
\hline & Product and Waste Containers & $6,058,285$ \\
\hline & Scheduled Replaceable Equipment for Reaction Chambers & 771,680 \\
\hline & Facility Maintenance & 641,915 \\
\hline & Equipment Spares & 898,640 \\
\hline & Total Materials & $9,071,779$ \\
\hline 2. & Utilities \& Service & $1,925,953$ \\
\hline 3. & Labor & \\
\hline & Plant operation labors & $17,196,012$ \\
\hline & Off-site overhead labor & $2,063,521$ \\
\hline & Total Labor & $19,259,533$ \\
\hline 4. & Waste Management \& Disposal & \\
\hline & Low Level Wastes & 424,500 \\
\hline & Mixed Low Level Wastes & 4,100 \\
\hline & Hazardous Wastes & 5,180 \\
\hline & Total Waste Management/Disposal & 433,780 \\
\hline Subto & otal Operation \& Maintenance Annual Cost & $30,691,046$ \\
\hline & M\&O Contractor Fees $(2 \%)$ & 613,821 \\
\hline Total & Operation \& Maintenance Annual Cost & $31,304,867$ \\
\hline Start- & $\begin{array}{l}\text {-Up Cost } \\
\text { Facility start-up cost based on allowance of } 65 \% \text { of one year O\&M total } \\
\text { labor cost. }\end{array}$ & $12,518,697$ \\
\hline Total & O\&M Cost for 25 years & $795,140,365$ \\
\hline
\end{tabular}


Table 7.4 Expenditure Funding Profile

U3O8/CaF2 25 Years GOCO

(in million FY2000 dollars)

\begin{tabular}{|c|c|c|c|c|c|c|c|c|c|c|c|c|}
\hline & TOTAL & FY99 & FY00 & FY01 & FY02 & FY03 & FY04 & FY05 & FY06 & FY07 & FY08 & FY09 \\
\hline NEPA/Licensing & 5.0 & & 0.5 & 1.3 & 1.3 & 1.3 & $\overline{0.6}$ & & & & & \\
\hline Engineering & 33.6 & & 4.1 & 15.5 & 10.4 & 3.1 & 0.5 & & & & & \\
\hline Construction & $\underline{186.8}$ & 0.2 & 2.0 & 6.0 & 33.5 & 84.5 & 60.6 & & & & & \\
\hline Total Capital Cost: & 225.4 & 0.2 & 6.6 & 22.8 & 45.2 & 88.9 & 61.7 & & & & & \\
\hline Startup & 12.5 & & & & & & 12.5 & & & & & \\
\hline Operations & 782.6 & & & & & & & 23.5 & 31.3 & 31.3 & 31.3 & 31.3 \\
\hline Decon \&Decommission & $\underline{22.0}$ & & & & & & & & & & & \\
\hline Total Operation Cost: & $8 \overline{17.2}$ & & & & & & 12.5 & 23.5 & 31.3 & 31.3 & 31.3 & 31.3 \\
\hline Revenue from Chemical Sale: & & & & & & & & & & & & \\
\hline Total Budget Outlay: & 1042.6 & 0.2 & 6.6 & 22.8 & 45.2 & 88.9 & 74.2 & 23.5 & 31.3 & 31.3 & 31.3 & 31.3 \\
\hline
\end{tabular}


Table 7.4, continued Expenditure Funding Profile

U3O8/CaF2 25 Years GOCO

(in million FY2000 dollars)

\begin{tabular}{|c|c|c|c|c|c|c|c|c|c|c|c|c|c|}
\hline & FY10 & FY11 & FY12 & FY13 & FY14 & FY15 & FY16 & FY17 & FY18 & FY19 & FY20 & FY21 & FY22 \\
\hline $\begin{array}{l}\text { NEPA/Licensing } \\
\text { Engineering } \\
\text { Construction }\end{array}$ & & & & & & & & & & & & & \\
\hline $\begin{array}{l}\text { Startup } \\
\text { Operations } \\
\text { Decon \&Decommission }\end{array}$ & 31.3 & 31.3 & 31.3 & 31.3 & 31.3 & 31.3 & 31.3 & 31.3 & 31.3 & 31.3 & 31.3 & 31.3 & 31.3 \\
\hline $\begin{array}{r}\text { Total Operation Cost: } \\
\text { Revenue from Chemical Sale: }\end{array}$ & 31.3 & 31.3 & 31.3 & 31.3 & 31.3 & 31.3 & 31.3 & 31.3 & 31.3 & 31.3 & 31.3 & 31.3 & 31.3 \\
\hline Total Budget Outlay: & 31.3 & 31.3 & 31.3 & 31.3 & 31.3 & 31.3 & 31.3 & 31.3 & 31.3 & 31.3 & 31.3 & 31.3 & 31.3 \\
\hline
\end{tabular}


Table 7.4, continued Expenditure Funding Profile

U3O8/CaF2 25 Years GOCO

(in million FY2000 dollars)





Appendix: Preconceptual Cost Estimate Bases and Details 


\section{Capital Cost Estimate Basis}

\section{Process equipment}

The process equipment estimate is based on the equipment list in the preconceptual design. They are priced using previous estimates for similar equipment as a guide, current estimating manuals, and inhouse data bases.

\section{Process Facilities}

The Process Facilities include the Process Building and the Product Storage Buildings. Building quantities are quantified take-offs from the conceptual sketches.

\section{Process Building}

The Process Building consists of both reinforced concrete and structural steel structure. Most of the process building is "special construction" with "standard construction" support areas as shown on the sketches in the scope figures.

U3O8, UO2, and CaF2 Storage Buildings

The applicable U3O8, UO2, and CaF2 Storage Buildings are steel frame structures with concrete clad panel wall and metal deck/concrete roofing.

\section{AHF Storage Building}

The applicable AHF Storage Building is a reinforced concrete building.

\section{Site and Balance of Plant}

Balance of plant includes the site improvements and utilities, and the support buildings.

The site is assumed level site with ground characteristics suitable for facility construction and easy access for construction activities. Site includes DUF6 cylinder concrete storage pad and empty cylinder concrete storage pad with steel saddles.

The yard mechanical includes cooling towers, domestic water, service water and fire water tanks, and exhaust stack; and yard equipment and cranes are included.

Yard piping systems are based on the rough takeoff from the site sketch and average estimated sizes. It is assumed $75 \%$ of these pipes are on pipe rack and $25 \%$ are buried.

An electrical substation and duct bank, yard lighting, and ambient air monitors are included.

Support buildings include a waste storage building, administration building, utility building, warehouse building, maintenance shop, industrial waste treatment building, sanitary waste treatment, and entry control building, and others. 


\section{U3O8, UO2, and CaF2 Future Storage Facilities (Additional Storage)}

Cost estimates for applicable additional storage facilities are similar to above and include standard site preparation, roads, and services. Contingency is assumed at 15\% and Engineering Costs are assumed at $8 \%$ of Capital Costs.

\section{Quantity development and pricing}

Quantities were factored based on building sizing from the estimates for similar facilities, and priced on current pricing levels.

\section{Manual labor}

Davis-Bacon manual labor rates for a generic GDP in the Midwest area were used. The Workers' Compensation Insurance rates and SUI rates are included in the wage rates. A standard 40 hour work week was used and an allowance for casual overtime was included by craft.

\section{Initial Spares}

$100 \%$ spares are included for the critical engineered process equipment. Initial spares are included at 5\% of the support system mechanical equipment cost.

\section{State Sales Tax}

A sales tax of $6 \%$ is included for materials and equipment

\section{Distributable (General Conditions), Overhead and Profit costs}

Distributable costs include temporary construction facilities, construction equipment, tools, materials, and other distributable support and non-manual labor costs, and field office costs. The distributable costs are factored from direct labor costs at rates based on recent evaluation of private nuclear/industrial rates. POPO cases, or government nuclear projects for GOCO cases.

Contractor's bond is calculated at $2 \%$ of total construction cost for POPO cases and $1 \%$ for GOCO cases.

Construction contractor's overhead and profit was factored at $5 \%$ of the material and subcontractors' cost and $15 \%$ of the labor costs.

\section{Construction management}

Construction management costs, including the construction manager's overhead and profit, was included at $8 \%$ of the construction contractor's costs for POPO cases and $10 \%$ for GOCO cases.

\section{Architect-engineering, and procurement}

Architect-Engineer's design and construction support costs include all functions such as engineering management, project control, all discipline engineering, documentation, quality control, procurement, and support services. The costs were factored at $14.4 \%$ of the field and management costs for POPO cases and $18 \%$ for GOCO cases. 


\section{Program management}

Program management costs are factored at $5.4 \%$ of the field costs for POPO cases and $6 \%$ for GOCO cases.

\section{Escalation}

Costs are at $1^{\text {st }}$ Quarter of FY 2000 level. Escalation beyond $1^{\text {st }} Q / F Y 00$ is excluded.

\section{Contingency}

Contingencies are allowed at $35 \%$ for construction and project management.

\section{Exclusions}

1. Cost of land.

2. Roads/rail and utilities outside the project fence line.

3. Research and development costs.

4. Site qualifications.

5. DOE Oversight.

6. Transportation.

\section{Operation and Maintenance Cost Estimate Basis}

The operations cost in this estimate is defined as the operation and maintenance costs of the facility over its expected operating life. The operation and maintenance cost for the DUF6 Conversion Plant includes operating personnel wages, utilities, consumables, operation material and maintenance expenditures, and waste management and disposal. M\&O contractor fees are also applied to GOCO cases.

\section{Consumable Material Costs}

Consumable material costs from process operations such as chemicals and additives are based on quoted costs in Chemical Marketing Prices Report magazines. Cooling tower water system chemical treatment costs are based on a preliminary quote from NALCO Chemical Company for treating the required gallons of make-up water. Product bins are based on quoted costs from Container Products Corporation. Other material costs include supply of waste containers and drums. The costs for the facilities equipment maintenance is based on an allowance of $1 \%$ of total equipment capital cost plus $1 \%$ of total direct operation and maintenance labor costs. The cost for major capital replacement is based on an allowance of $2 \%$ of total facility equipment costs.

\section{Utilities Cost}

The operating cost for utilities and services to operate the facilities is estimated using an allowance of $10 \%$ of the total labor cost. 


\section{Labor Cost}

Operation labor costs are based on the plant operating manpower estimate. The rates for the non-manual labor employees including fringe benefits are based on wage rates for a generic Gas Diffusion Plant site. Offsite labor is estimated using an allowance of $12 \%$ of the total labor cost.

\section{Waste Management and Disposal Cost}

Waste management and disposal costs are estimated based on costs given in the DUF6 Analysis Guidelines (in the Engineering Analysis Report) for unit volumes for treatment and disposal of hazardous, mixed and low level radwaste to a shallow burial site. These costs are for conversion process waste only and not for conversion products.

\section{M\&O Contractor Fees}

The management and operation $(\mathrm{M} \& \mathrm{O})$ contractor fees paid to the operating contractor are assumed to be $2 \%$ of the annual operating costs for the GOCO cases.

\section{Exclusions}

The transportation of waste out of the facility is excluded from the O\&M cost estimate. Cost for disposal of empty cylinder metal is excluded. Also in GOCO cases, costs for DOE oversight of the facility operation and payments in-lieu-of-taxes to local communities are not included.

\section{Annual Expenditure Funding Profile Estimate Basis}

The estimated annual expenditures required to support the construction and operation of the DUF6 conversion plant are derived on the basis of the project schedule, and capital and O\&M costs estimated in this report. The funding profiles provided are based on a rough macro cost analysis with assumed factors, such as chemical pricing, and, in POPO cases, conversion service payment, interest rates, and loan payment terms. Assumptions and qualifications for the funding profile estimate are as follows:

The conversion plant is assumed operating under either the privately owned and privately operated or government owned and contractor operated scenario.

The conversion plant is designed, constructed, and operated based on the preliminary project schedule developed in this report.

Construction capital cost, start-up and O\&M costs, and costs for NEPA/licensing and D\&D estimated in this report are used.

The expenditure funding profiles are expressed in fiscal year annually with constant dollar value at first quarter of FY 2000.

For POPO cases, private finance is used to raise the construction capital. The private finance is based on a construction loan with an assumed commercial interest rate to cover the design, construction, and startup expenditures. The loan is paid back during an assumed period after production start with operation revenues from conversion service payment and HF chemical sales. The private operator will receive payment from the government for the conversion service. The payment is based on amount of DUF6 
processed after production start at assumed rates such that the private operator's income is near breakeven.

HF product is sold to commercial users by the DOE or plant owner at $70 \notin$ per pound based on market quoted price. Revenue from sales is received after production start. CaF2 product is retained by DOE and no revenue is assumed from the product.

Plant amortization deduction, asset depreciation deduction, tax on incomes, and asset salvage after completion of operation and D\&D are not considered. 